\title{
Supplemental Information for Significant temperature dependence of the isosteric heats of adsorption of gases in zeolites demonstrated by experiments and molecular simulations
}

\author{
Alexander S. Hyla, ${ }^{1 \dagger}$ Hanjun Fang, ${ }^{1}$ Salah Eddine Boulfelfel, ${ }^{1}$ Giovanni Muraro, ${ }^{2}$ \\ Charanjit Paur, ${ }^{2}$ Karl Strohmaier, ${ }^{2}$ Peter I. Ravikovitch, ${ }^{2}{ }^{*}$ David S. Sholl ${ }^{1 *}$ \\ ${ }^{1}$ School of Chemical \& Biomolecular Engineering, Georgia Institute of Technology, \\ Atlanta, GA 30332-0100, USA. \\ ${ }^{2}$ Corporate Strategic Research, ExxonMobil Research and Engineering, \\ 1545 Route 22 East, Annandale, NJ 08801, USA \\ † Current Address: Department of Chemical \& Petroleum Engineering, University of Calgary, \\ 2500 University Dr. NW, Calgary, AB T2N 1N4, Canada \\ * Corresponding authors e-mails: \\ peter.ravikovitch@exxonmobil.com,david.sholl@chbe.gatech.edu
}

\section{Choice of force field for study:}

11 different force fields in the literature were found to have parameters that describe the adsorption of $\mathrm{CO}_{2}$ in siliceous zeolites. ${ }^{1-11}$ For each of the force fields, if an adsorbate-adsorbate model was given (EPM2 ${ }^{12}$ or TraPPE ${ }^{13}$ ), that was used for the GCMC simulations describing the adsorption of $\mathrm{CO}_{2}$ in ITQ-29 at $195 \mathrm{~K}$, as described in the main paper. The simulated adsorption isotherms are presented below in Figure S1, along with 2 experimental isotherms obtained from calorimetric measurements from this work. The CCFF results are by far the closest to the experimental results. All but 3 of the force fields examined predict the same general shape of the isotherm as the isotherms obtained from the calorimetric measurements, but deviate from the experimental isotherms in the region around $1,000 \mathrm{~Pa}$. The CCFF results show almost quantitative agreement with the experiments. This region of the isotherm is where the loadings start to increase towards saturation loading. Since the simulations are performed at the same pressures, a direct comparison of the force fields to CCFF results can be performed and the results are shown below in Figure S2. The parameters of all 11 force fields used in this study can be found in Table S2. 


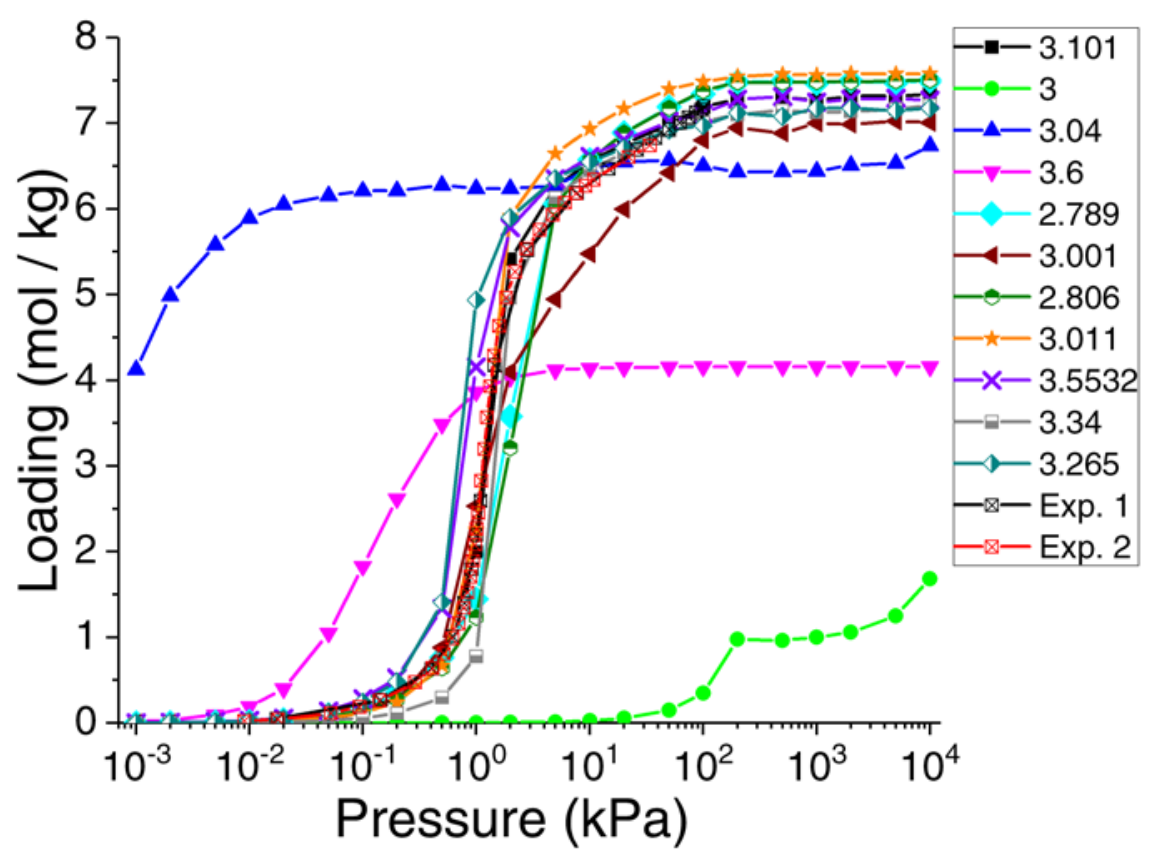

Figure S1: Comparison of adsorption isotherms calculated by 11 different force fields for $\mathrm{CO}_{2}$ in ITQ-29 at $195 \mathrm{~K}$ to two experimental calorimetric measurements from this work. The results are labeled by the $\sigma$ parameter from the force field for the oxygen atoms in the zeolite framework. The data labeled 3.101 is our CCFF results.

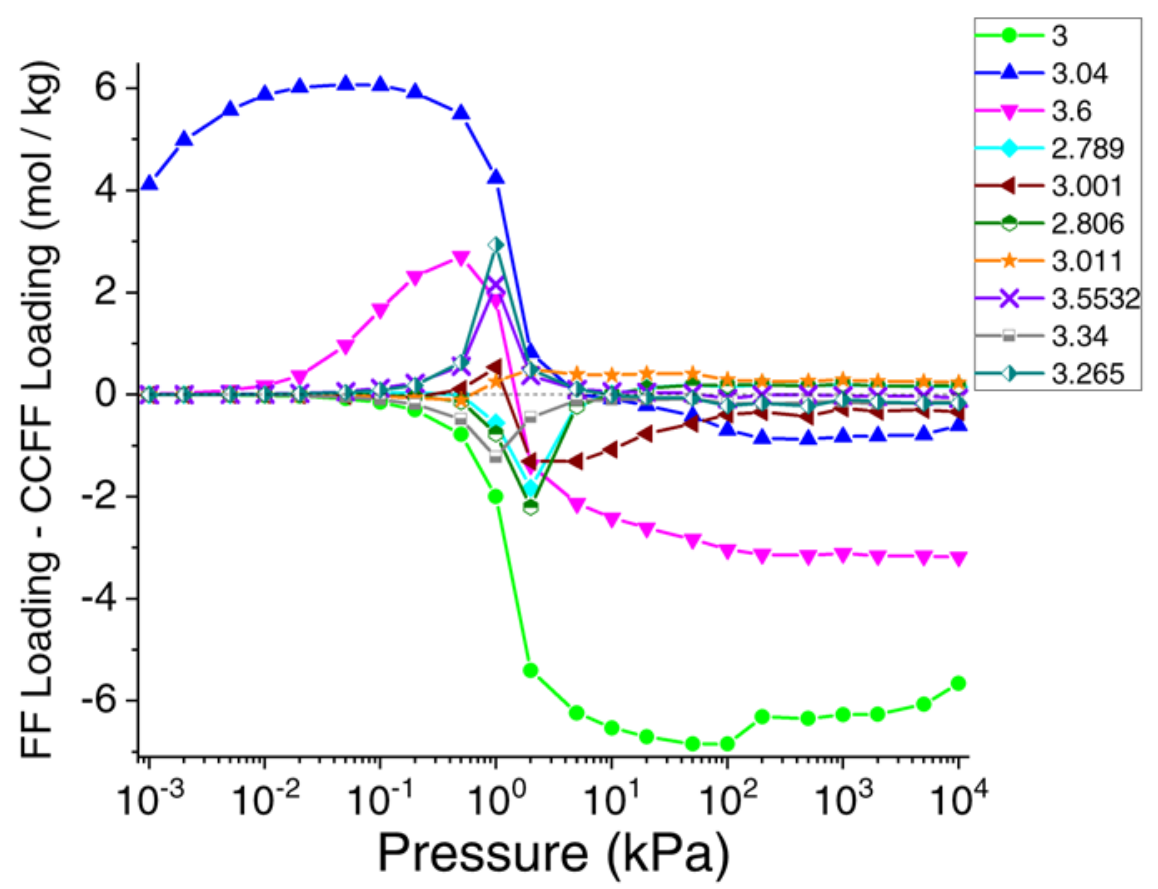

Figure S2: Comparison of the loadings calculated by the literature force fields versus the CCFF results. The results are labeled by the $\sigma$ parameter from the force field for the oxygen atoms in the zeolite framework. The dotted line is the CCFF results. The region around 1,000 $\mathrm{Pa}$ corresponds to the region of the isotherm where the loading starts to rapidly increase towards the saturation loading. 


\section{Force Field Development for $\mathrm{CH}_{4}$ in Na-exchanged Zeolites}

Recently, we implemented an approach to developing first-principles-based force fields for $\mathrm{CH}_{4}$ in siliceous zeolites. ${ }^{14}$ This approach uses the fully periodic framework to represent the adsorbent structure and relies on electronic structure calculations for hundreds or thousands of adsorption configurations scattered throughout the framework. Both united-atom (UA) and allatom (AA) models were tested for $\mathrm{CH}_{4}$ in siliceous zeolites, and they performed similarly well in predicting adsorption and diffusion properties. Here we extend our approach to Na-exchanged zeolites, where Na-LTA with $\mathrm{Si} / \mathrm{Al}=3\left(\mathrm{Na}_{6} \mathrm{Al}_{6} \mathrm{Si}_{18} \mathrm{O}_{48}\right)$ is used as the zeolite model and the AA $\mathrm{CH}_{4}$ model is chosen considering the stronger Coulomb interactions for $\mathrm{CH}_{4}$ in cationic zeolites than in siliceous zeolites. The details about the force field potential can be found in our previous work. $^{14}$

Similar to siliceous zeolites, DFT/CC (density functional theory/coupled cluster) method is used to get reliable interaction energies of $\mathrm{CH}_{4}$ in the Na-exchanged zeolite model. ${ }^{14,15}$ The $\mathrm{CC}$ correction functions for $\mathrm{Si}$, and $\mathrm{O}$ are taken from our previous calculations for siliceous zeolites, ${ }^{14}$ and for Al they are treated the same as Si. The CC correction functions for Na cations are not considered as discussed by Otero Arean et al. ${ }^{16}$ The configurations in force field fitting data sets are from conventional NVT $(\mathrm{N}=1, \mathrm{~T}=300 \mathrm{~K})$ Monte Carlo simulations, where the force field parameters for $\mathrm{AA} \mathrm{CH}_{4}$ interacting with $\mathrm{Si}$ and $\mathrm{O}$ are retained for Na-exchanged zeolites. In the first iteration, the ClayFF parameters ${ }^{9}$ are used for $\mathrm{Al}$ and $\mathrm{Na}$, TraPPE parameters $^{17}$ for the $\mathrm{C}$ atom of $\mathrm{CH}_{4}$, and DDEC3 charges ${ }^{18-20}$ for the atoms of $\mathrm{CH}_{4}$. LorentzBerthelot mixing rules are applied for the Lennard-Jones for cross interacting species. A total of 1000 configurations are chosen from the NVT MC snapshots and used in force field fitting. The fitted FF parameters are then used in the next iteration following the same procedure. We perform this procedure for several iterations until the vdW (van der Waals) force field parameters for the atoms of $\mathrm{CH}_{4}$ and zeolite ( $\mathrm{Al}$ and $\mathrm{Na}$ ) are converged (the changes of the parameters are within $\pm 3 \%$ ). The resulting force field (denoted CCFF) parameters for $\mathrm{CH}_{4}$ in Na-containing zeolites are summarized in Table S1.

A detailed comparison of the interaction energies predicted with CCFF and the corresponding energies at the DFT/CC level is shown in Figure S3. The DFT/CC calculations of the last iteration span a range of adsorption energies, from -21 to $-1 \mathrm{~kJ} / \mathrm{mol}$. As expected from their derivation, the CCFF interaction energies are reasonably consistent with the DFT/CC results. The residual standard deviation (RSD) and mean deviation (MD) between the force field and the DFT/CC results are 1.4 and $0.1 \mathrm{~kJ} / \mathrm{mol}$, respectively.

We validated CCFF by comparing the simulated adsorption isotherms and isosteric heats of adsorption for $\mathrm{CH}_{4}$ in LTA-4A and Na-LTA ( $\mathrm{Si} / \mathrm{Al}=2$ and 5) with available experimental data. In these simulations, the force field parameters for cation-framework interactions are from our previous work of $\mathrm{CO}_{2}$ adsorption in Na- exchanged zeolites. ${ }^{1}$ The validation results are shown in Figure S4. CCFF performs reasonably well for $\mathrm{CH}_{4}$ adsorption in these three Naexchanged zeolites. The parameters of the force fields used in this study can be found in Tables S2 and S3. 
Table S1: Force field parameters for all-atom (AA) $\mathrm{CH}_{4}$ in Na-exchanged zeolites, derived from DFT/CC calculations in this work. This force field is defined as CCFF.

\begin{tabular}{|c|c|c|c|}
\hline \multirow{2}{*}{ Cross species } & \multicolumn{3}{|c|}{ CCFF } \\
\hline & $\varepsilon / \mathrm{k}_{\mathrm{B}}(\mathrm{K})$ & $\sigma(\AA)$ & Atomic charge (e) \\
\hline \multicolumn{4}{|c|}{$\mathrm{AA} \mathrm{CH}_{4}\left(\mathrm{C} \_\mathrm{CH}_{4}\right.$ and $\left.\mathrm{H} \_\mathrm{CH}_{4}\right)$} \\
\hline $\mathrm{Si}_{\mathrm{zeo}}-\mathrm{C} \_\mathrm{CH}_{4}$ & $33.98^{\mathrm{a}}$ & $3.845^{\mathrm{a}}$ & $\mathrm{Si}_{\text {zeo }}(2.2124)^{\mathrm{a}}$ \\
\hline $\mathrm{Si}_{\text {zeo }}-\overline{\mathrm{H}} \_\mathrm{CH}_{4}$ & $24.15^{\mathrm{a}}$ & $3.298^{\mathrm{a}}$ & $\mathrm{O}_{\text {zeo }}^{\mathrm{Si}}(-1.1062)^{\mathrm{a}}$ \\
\hline $\mathrm{O}_{\text {zeo }}-\mathrm{C} \_\mathrm{CH}_{4}$ & $19.88^{\mathrm{a}}$ & $3.391^{\mathrm{a}}$ & $\mathrm{O}_{\text {zeo }}{ }^{\mathrm{Al}}(-1.3211)$ \\
\hline $\mathrm{O}_{\text {zeo }}-\mathrm{H} \_\mathrm{CH}_{4}$ & $16.17^{\mathrm{a}}$ & $2.844^{\mathrm{a}}$ & $\mathrm{Al}_{\text {zeo }}(2.0833)$ \\
\hline $\mathrm{Al}_{\text {zeo }}-\mathrm{C}_{-} \mathrm{CH}_{4}$ & 42.83 & 3.460 & $\mathrm{Na}_{\text {zeo }}(0.9887)$ \\
\hline $\mathrm{Al}_{\text {zeo }}-\mathrm{H} \_\mathrm{CH}_{4}$ & 31.21 & 2.956 & C_CH $\mathrm{CH}_{4}(-0.516)^{\mathrm{a}}$ \\
\hline $\mathrm{Na}_{\mathrm{zeo}}-\mathrm{C} \_\mathrm{CH}_{4}$ & 88.79 & 2.906 & $\mathrm{H} \_\mathrm{CH}_{4}(0.129)^{\mathrm{a}}$ \\
\hline $\mathrm{Na}_{\mathrm{zeo}}-\mathrm{H} \_\mathrm{CH}_{4}$ & 78.92 & 2.401 & \\
\hline
\end{tabular}

a The parameters from our previous work of $\mathrm{AA} \mathrm{CH}_{4}$ in siliceous zeolites are retained for Na-exchanged zeolites. ${ }^{14}$ 
(a)

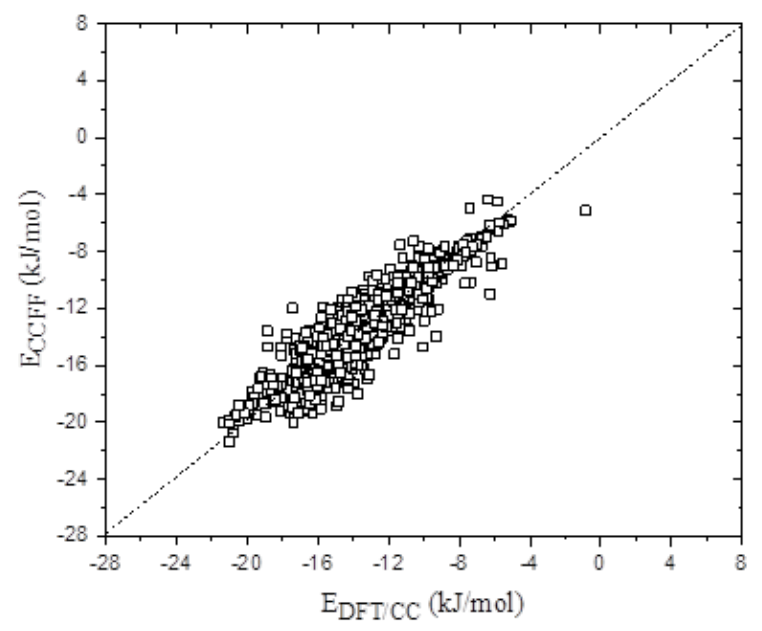

(b)

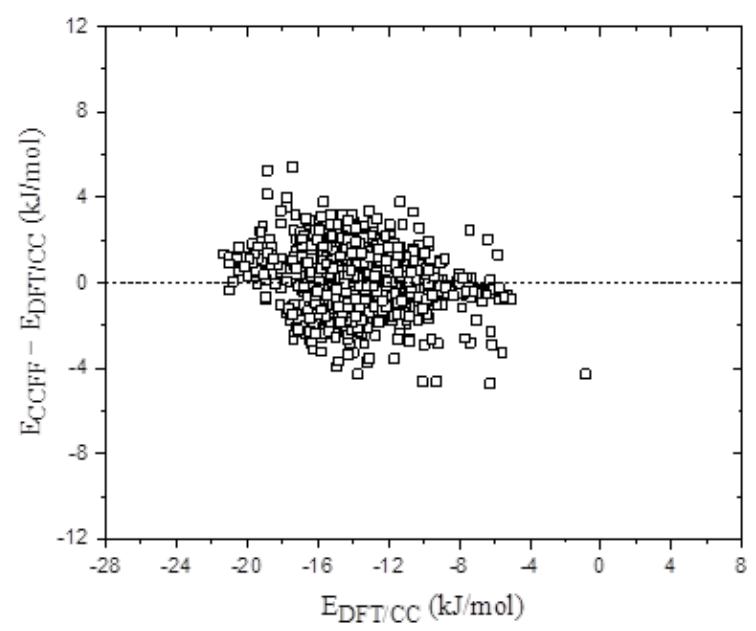

(c)

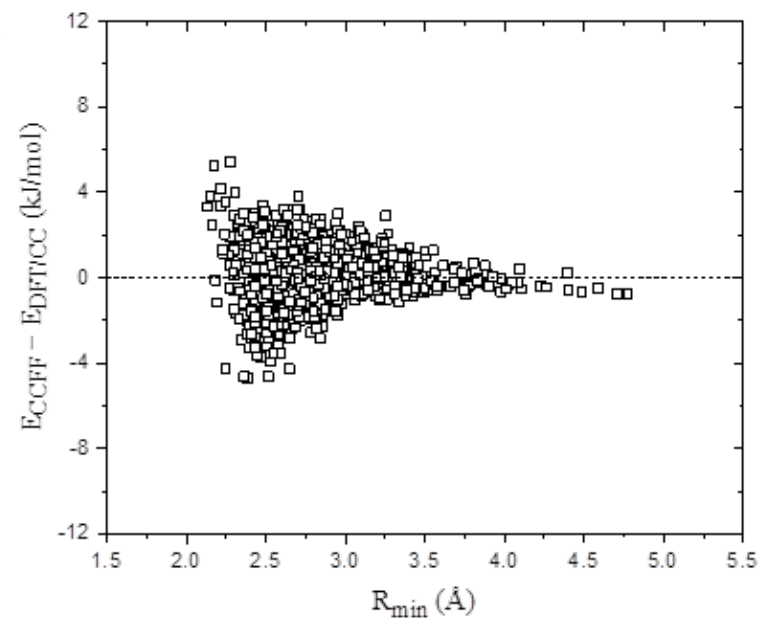

Figure S3: Force field fitting results of the last iteration for $\mathrm{CH}_{4}$ in $\mathrm{Na}-\mathrm{LTA}(\mathrm{Si} / \mathrm{Al}=3)$ : (a) comparison of the interaction energies of $\mathrm{CH}_{4}$ in zeolite for CCFF and DFT/CC, (b) the difference in interaction energies, $\mathrm{E}_{\mathrm{CCFF}}-\mathrm{E}_{\mathrm{DFT} / \mathrm{CC}}$, as a function of $\mathrm{E}_{\mathrm{DFT} / \mathrm{CC}}$, and (c) $\mathrm{E}_{\mathrm{CCFF}}-\mathrm{E}_{\mathrm{DFT} / \mathrm{CC}}$ as a function of the minimum atomic distance between $\mathrm{CH}_{4}$ and zeolite. A total of $1000 \mathrm{CH}_{4}$ configurations are included. 
(a)

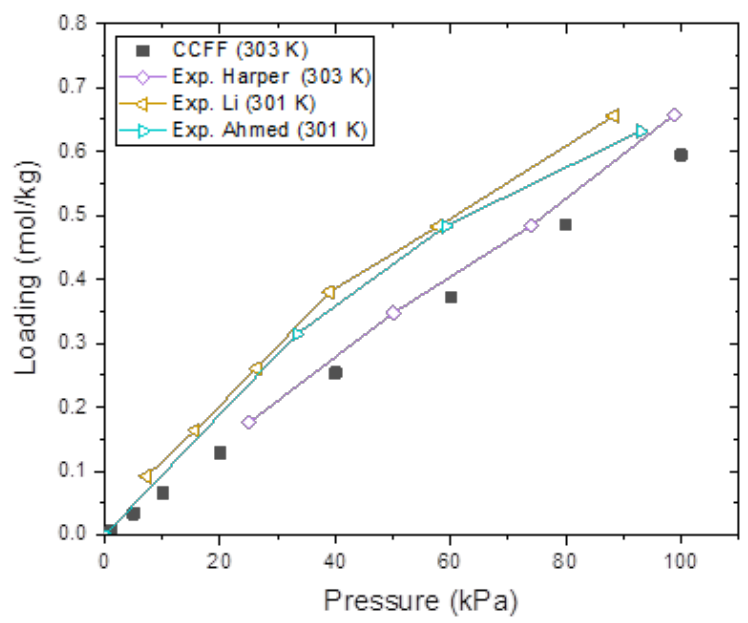

(c)

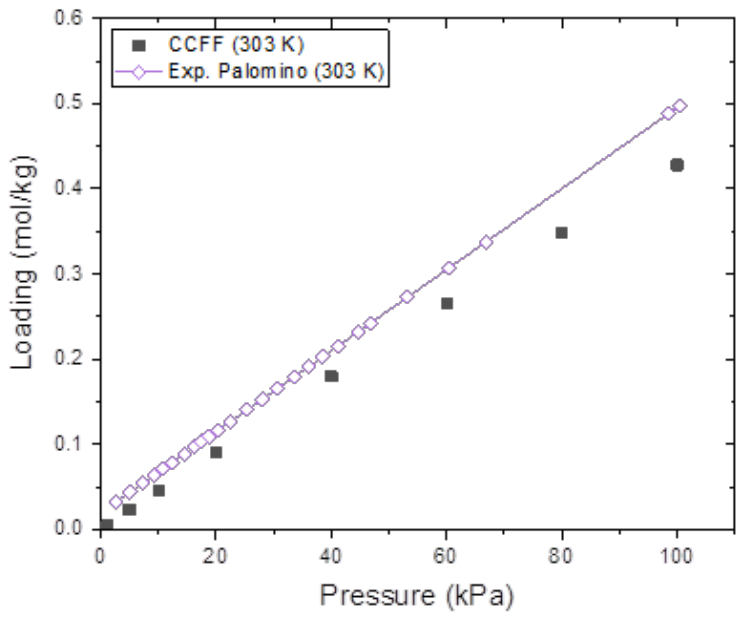

(e)

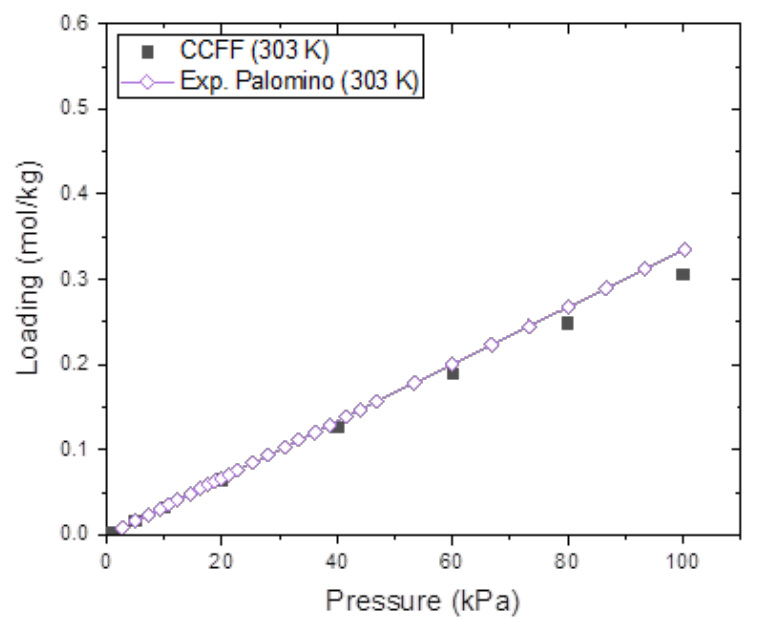

(b)

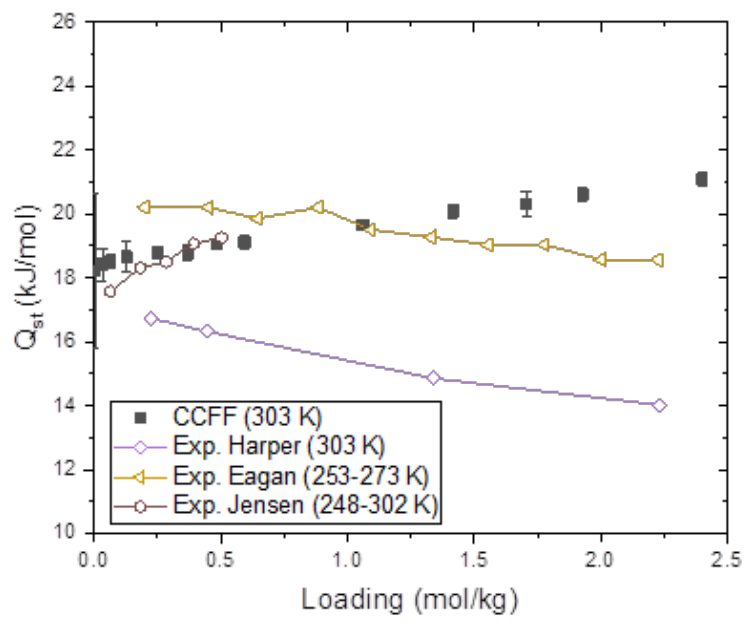

(d)

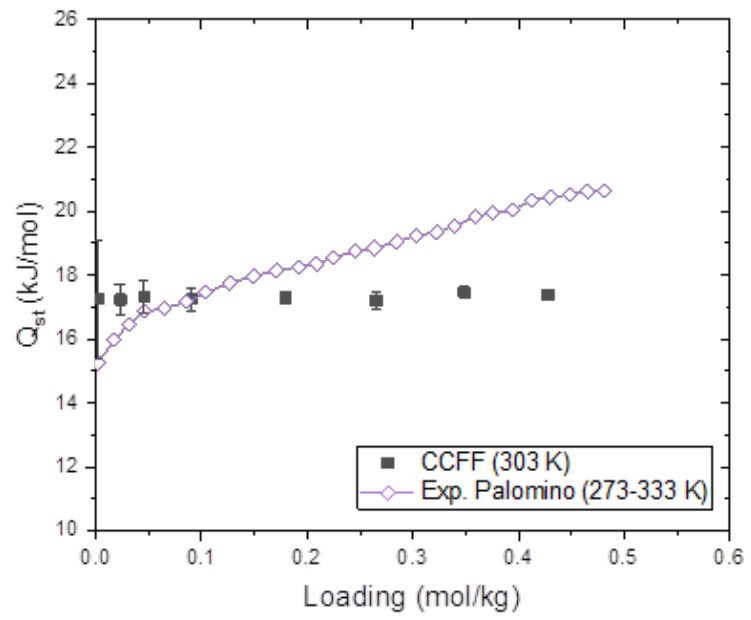

(f)

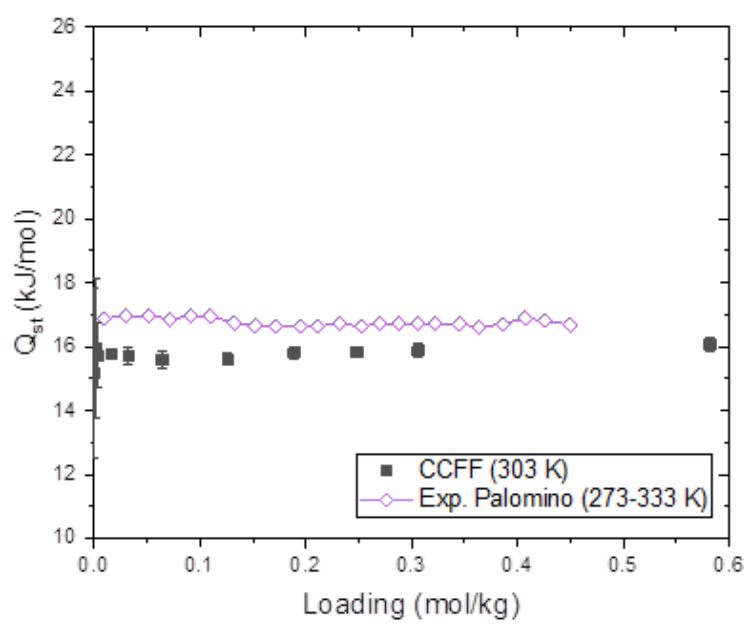

Figure S4: Comparison of simulated (CCFF) and experimental adsorption isotherms and heats of adsorption of $\mathrm{CH}_{4}$ in (a and b) LTA-4A, (c and d) Na-LTA with Si/Al = 2, and (e and f) NaLTA with $\mathrm{Si} / \mathrm{Al}=5$. The experimental data are from Harper et al., ${ }^{21} \mathrm{Li}$ et al., ${ }^{22}$ Ahmed et al., ${ }^{23}$ Eagan et al., ${ }^{24}$ Jensen et al., ${ }^{25}$ and Palomino et al. ${ }^{26}$ 
Table S2: Force field parameters for siliceous zeolites used in this study. $\varepsilon / \mathrm{k}_{\mathrm{B}}$ has units of K, $\sigma$ has units of $\AA$, masses are given in atomic mass units (amu), and charges are given in amu.

\begin{tabular}{|c|c|c|c|c|c|c|c|c|c|c|c|}
\hline $\begin{array}{l}\text { Force } \\
\text { Field }\end{array}$ & $\begin{array}{c}\mathbf{C C F F}^{\mathbf{a}} \\
\sigma=3.101\end{array}$ & $\sigma=3$ & $\sigma=3.04$ & $\sigma=3.6$ & $\sigma=2.789$ & $\sigma=3.001$ & $\sigma=2.806$ & $\sigma=3.011$ & $\sigma=3.5532$ & $\sigma=3.34$ & $\sigma=3.265$ \\
\hline \multicolumn{12}{|c|}{$\mathrm{CO}_{2}$} \\
\hline $\mathrm{CO}_{2}$ model & EPM2 & EPM2 & TraPPE & EPM2 & TraPPE & EPM2 & EPM2 & EPM2 & EPM2 & TraPPE & TraPPE \\
\hline Interaction & Lennard- & Lennard- & Lennard- & Lennard- & Lennard- & Lennard- & Lennard- & Lennard- & Lennard- & Lennard- & Lennard- \\
\hline $\begin{array}{l}\text { Model } \\
\text { Mixing }\end{array}$ & Jones & Jones & Jones & $\begin{array}{l}\text { Jones } \\
\text { Lorentz- }\end{array}$ & $\begin{array}{l}\text { Jones } \\
\text { Lorentz- }\end{array}$ & $\begin{array}{l}\text { Jones } \\
\text { Lorentz- }\end{array}$ & $\begin{array}{l}\text { Jones } \\
\text { Lorentz- }\end{array}$ & Jones & Jones & Jones & Jones \\
\hline $\begin{array}{l}\text { rules } \\
\text { ruxing }\end{array}$ & Berthelot & Berthelot & Berthelot & Berthelot & Berthelot & Berthelot & Berthelot & Berthelot & Berthelot & Berthelot & Berthelot \\
\hline $\mathrm{C}_{\mathrm{CO} 2}-\mathrm{O}_{\mathrm{zeo}}$ & $\begin{array}{l}\varepsilon=29.116 \\
\sigma=3.193\end{array}$ & $\begin{array}{l}\varepsilon=24.372 \\
\sigma=2.9\end{array}$ & $\begin{array}{l}\varepsilon=61.41 \\
\sigma=2.897\end{array}$ & $\begin{array}{l}\varepsilon=42.125 \\
\sigma=3.9\end{array}$ & $\begin{array}{l}\varepsilon=50.20 \\
\sigma=2.7815\end{array}$ & $\begin{array}{l}\varepsilon=37.595 \\
\sigma=3.511\end{array}$ & $\begin{array}{l}\varepsilon=29.116 \\
\sigma=3.193\end{array}$ & $\begin{array}{l}\varepsilon=38.24537 \\
\sigma=2.884\end{array}$ & $\begin{array}{l}\varepsilon=46.90 \\
\sigma=2.96\end{array}$ & $\begin{array}{l}\varepsilon=37.82856 \\
\sigma=3.050\end{array}$ & $\begin{array}{l}\varepsilon=44.15201 \\
\sigma=3.050\end{array}$ \\
\hline $\begin{array}{l}\mathrm{C}_{\mathrm{CO} 2}- \\
\mathrm{Si}_{\text {zeo }}\end{array}$ & $\begin{array}{l}\varepsilon=49.754 \\
\sigma=3.620\end{array}$ & None & None & None & None & None & $\begin{array}{l}\varepsilon=49.754 \\
\sigma=3.620\end{array}$ & $\begin{array}{l}\varepsilon=29.99276 \\
\sigma=2.8635\end{array}$ & $\begin{array}{l}\varepsilon=0.16 \\
\sigma=3.03\end{array}$ & $\begin{array}{l}\varepsilon=24.37212 \\
\sigma=2.550\end{array}$ & None \\
\hline $\mathrm{O}_{\mathrm{CO} 2}-\mathrm{O}_{\mathrm{zeo}}$ & $\begin{array}{l}\varepsilon=23.433 \\
\sigma=3.067\end{array}$ & $\begin{array}{l}\varepsilon=41.689 \\
\sigma=3.025\end{array}$ & $\begin{array}{l}\varepsilon=118.793 \\
\sigma=3.255\end{array}$ & $\begin{array}{l}\varepsilon=69.743 \\
\sigma=3.48\end{array}$ & $\begin{array}{l}\varepsilon=84.93 \\
\sigma=2.9195\end{array}$ & $\begin{array}{l}\varepsilon=78.98 \\
\sigma=3.237\end{array}$ & $\begin{array}{l}\varepsilon=23.433 \\
\sigma=3.067\end{array}$ & $\begin{array}{l}\varepsilon=64.70212 \\
\sigma=3.022\end{array}$ & $\begin{array}{l}\varepsilon=79.35 \\
\sigma=3.10\end{array}$ & $\begin{array}{l}\varepsilon=64.70703 \\
\sigma=3.175\end{array}$ & $\begin{array}{l}\varepsilon=75.52351 \\
\sigma=3.1575\end{array}$ \\
\hline $\begin{array}{l}\mathrm{O}_{\mathrm{CO} 2}- \\
\mathrm{Si}_{\text {zeo }}\end{array}$ & $\begin{array}{l}\varepsilon=38.900 \\
\sigma=3.494\end{array}$ & None & None & None & None & None & $\begin{array}{l}\varepsilon=38.900 \\
\sigma=3.494\end{array}$ & $\begin{array}{l}\varepsilon=50.74065 \\
\sigma=3.0015\end{array}$ & $\begin{array}{l}\varepsilon=0.27 \\
\sigma=3.17\end{array}$ & $\begin{array}{l}\varepsilon=41.68933 \\
\sigma=2.675\end{array}$ & None \\
\hline $\mathrm{C}_{\mathrm{CO} 2}-$ & $\varepsilon=28.129$ & $\varepsilon=27.000$ & $\varepsilon=29.125$ & $\varepsilon=46.650$ & $\varepsilon=28.129$ & $\varepsilon=29.933$ & $\varepsilon=28.129$ & $\varepsilon=28.129$ & $\varepsilon=28.129$ & $\varepsilon=27.000$ & $\varepsilon=27.000$ \\
\hline $\mathrm{C}_{\mathrm{CO} 2}$ & $\sigma=2.757$ & $\sigma=2.8$ & $\sigma=2.753$ & $\sigma=3.83$ & $\sigma=2.76$ & $\sigma=2.745$ & $\sigma=2.757$ & $\sigma=2.757$ & $\sigma=2.757$ & $\sigma=2.8$ & $\sigma=2.8$ \\
\hline $\mathrm{O}_{\mathrm{CO} 2}-$ & $\varepsilon=80.507$ & $\varepsilon=79.000$ & $\varepsilon=110.236$ & $\varepsilon=76.474$ & $\varepsilon=80.507$ & $\varepsilon=85.671$ & $\varepsilon=80.507$ & $\varepsilon=80.507$ & $\varepsilon=80.507$ & $\varepsilon=79.000$ & $\varepsilon=79.000$ \\
\hline $\mathrm{O}_{\mathrm{CO} 2}$ & $\sigma=3.033$ & $\sigma=3.05$ & $\sigma=3.47$ & $\sigma=3.36$ & $\sigma=3.033$ & $\sigma=3.017$ & $\sigma=3.033$ & $\sigma=3.033$ & $\sigma=3.033$ & $\sigma=3.05$ & $\sigma=3.05$ \\
\hline $\begin{array}{l}\mathrm{C}_{\mathrm{CO} 2}- \\
\mathrm{O}_{\mathrm{CO} 2}\end{array}$ & None & $\begin{array}{l}\varepsilon=46.184 \\
\sigma=2.925\end{array}$ & $\begin{array}{l}\varepsilon=56.88 \\
\sigma=3.112\end{array}$ & $\begin{array}{l}\varepsilon=18.335 \\
\sigma=3.31\end{array}$ & $\begin{array}{l}\varepsilon=47.59 \\
\sigma=2.89\end{array}$ & $\begin{array}{l}\varepsilon=50.64 \\
\sigma=2.88\end{array}$ & None & $\begin{array}{l}\varepsilon=47.58762 \\
\sigma=2.895\end{array}$ & $\begin{array}{l}\varepsilon=47.58762 \\
\sigma=2.895\end{array}$ & $\begin{array}{l}\varepsilon=46.18441 \\
\sigma=2.925\end{array}$ & $\begin{array}{l}\varepsilon=46.18441 \\
\sigma=2.925\end{array}$ \\
\hline \multicolumn{12}{|c|}{ Atom properties } \\
\hline $\begin{array}{l}\mathrm{C}_{\mathrm{CO} 2} \text { mass } \\
\text { (charge) }\end{array}$ & $\begin{array}{l}12.0 \\
(0.6512)\end{array}$ & $\begin{array}{l}12.0 \\
(0.7000)\end{array}$ & $\begin{array}{l}12.0 \\
(0.8000)\end{array}$ & $\begin{array}{l}12.0 \\
(0.7200)\end{array}$ & $\begin{array}{l}12.0 \\
(0.6512)\end{array}$ & $\begin{array}{l}12.0 \\
(0.65)\end{array}$ & $\begin{array}{l}12.0 \\
(0.6512)\end{array}$ & $\begin{array}{l}12.0 \\
(0.6512)\end{array}$ & $\begin{array}{l}12.0 \\
(0.6512)\end{array}$ & $\begin{array}{l}12.0 \\
(0.7000)\end{array}$ & $\begin{array}{l}12.0 \\
(0.7000)\end{array}$ \\
\hline $\mathrm{O}_{\mathrm{CO} 2}$ mass & 15.9994 & 15.9994 & 15.9994 & 15.9994 & 15.9994 & 15.9994 & 15.9994 & 15.9994 & 15.9994 & 15.9994 & 15.9994 \\
\hline (charge) & $(-0.3256)$ & $(-0.3500)$ & $(-0.4000)$ & $(-0.3600)$ & $(-0.3256)$ & $(-0.325)$ & $(-0.3256)$ & $(-0.3256)$ & $(-0.3256)$ & $(-0.3500)$ & $(-0.3500)$ \\
\hline $\mathrm{O}_{\mathrm{zeo}}$ mass & 15.9994 & 15.9994 & 15.9994 & 15.9994 & 15.9994 & 15.9994 & 15.9994 & 15.9994 & 15.9994 & 15.9994 & 15.9994 \\
\hline (charge) & $(-1.1062)$ & $(-0.4000)$ & $(-1.8500)$ & $(-1.2000)$ & $(-1.0250)$ & $(-0.393)$ & $(-1.0000)$ & $(-0.7065)$ & $(-1.0500)$ & $(-0.7500)$ & $(-1.0000)$ \\
\hline $\mathrm{Si}_{\text {zeo }}$ mass & 28.0855 & 28.0855 & 28.0855 & 28.0855 & 28.0855 & 28.0855 & 28.0855 & 28.0855 & 28.0855 & 28.0855 & 28.0855 \\
\hline (charge) & $(2.2124)$ & $(0.8000)$ & $(3.7000)$ & $(2.4000)$ & $(2.0500)$ & $(0.786)$ & $(2.0000)$ & $(1.4130)$ & $(2.1000)$ & $(1.5000)$ & $(2.0000)$ \\
\hline \multicolumn{12}{|c|}{$\mathrm{CH}_{4}(\mathrm{CCFF} \text { only })^{\mathrm{b}}$} \\
\hline $\mathrm{CH}_{4}$ model & TraPPE & & & & & & & & & & \\
\hline Mixing & Lorentz- & & & & & & & & & & \\
\hline rules & Berthelot & & & & & & & & & & \\
\hline Interaction & Lennard- & & & & & & & & & & \\
\hline Model & Jones & & & & & & & & & & \\
\hline $\begin{array}{l}\mathrm{CH}_{4 \_} \text {sp3 }- \\
\mathrm{O}_{\text {zeo }}\end{array}$ & $\varepsilon=109.759$ & $\sigma=3.416$ & & & & & & & & & \\
\hline $\mathrm{CH}_{4} \_\mathrm{sp} 3-$ & $\varepsilon=148.0$ & $\sigma=3.73$ & & & & & & & & & \\
\hline \multicolumn{12}{|c|}{ Atom Properties } \\
\hline & Mass & Charge & & & & & & & & & \\
\hline $\mathrm{CH}_{4}$ & 16.03176 & 0.0 & & & & & & & & & \\
\hline $\mathrm{O}_{\text {zeo }}$ & 15.9994 & -1.1062 & & & & & & & & & \\
\hline $\mathrm{Si}_{\mathrm{zeo}}$ & 28.0855 & 2.2124 & & & & & & & & & \\
\hline \multicolumn{12}{|c|}{$\mathrm{N}_{2}$ (CCFF only) $^{\mathrm{C}}$} \\
\hline $\mathrm{N}_{2}$ model & 2LJ3CB.MS & M potential & & & & & & & & & \\
\hline Mixing & Lorentz- & & & & & & & & & & \\
\hline rules & Berthelot & & & & & & & & & & \\
\hline Interaction & Lennard- & & & & & & & & & & \\
\hline Model & Jones & & & & & & & & & & \\
\hline $\mathrm{N}_{2}-\mathrm{O}_{\text {zeo }}$ & $\varepsilon=27.31$ & $\sigma=3.14$ & & & & & & & & & \\
\hline $\mathrm{N}_{2}-\mathrm{Si}_{\text {zeo }}$ & $\varepsilon=46.00$ & $\sigma=3.57$ & & & & & & & & & \\
\hline \multirow[t]{2}{*}{$\mathrm{N}_{2}-\mathrm{N}_{2}$} & $\varepsilon=36.4$ & $\sigma=3.32$ & & & & & & & & & \\
\hline & Mass & Charge & & & & & & & & & \\
\hline $\mathrm{N}_{2}$ & 14.0067 & -0.40484 & & & & & & & & & \\
\hline $\mathrm{N}_{2}$ C.O.M. & 0 & 0.80968 & & & & & & & & & \\
\hline $\mathrm{O}_{\text {zeo }}$ & 15.9994 & -1.1062 & & & & & & & & & \\
\hline $\mathrm{Si}_{\text {zeo }}$ & 28.0855 & 2.2124 & & & & & & & & & \\
\hline
\end{tabular}

${ }^{\mathrm{a}}$ Ref. 1; ${ }^{\mathrm{b}}$ Ref. 14; ${ }^{\mathrm{c}}$ Ref. 30; 
Table S3: Force field parameters for cationic zeolites used in this study.

\begin{tabular}{|c|c|c|c|c|}
\hline \multicolumn{5}{|c|}{ CCFF Force Field } \\
\hline \multicolumn{5}{|c|}{$\mathrm{CO}_{2}{ }^{\mathrm{a}}$} \\
\hline $\mathrm{CO}_{2}$ model & EPM2 & & & \\
\hline Mixing rules & Lorentz- Berthelot & & & \\
\hline Force Field Parameters & Interaction Model & $\varepsilon / \mathbf{k}_{\mathrm{B}}(\mathbf{K})$ & $\sigma(\AA)$ & \\
\hline $\mathrm{C}_{\mathrm{CO} 2}-\mathrm{O}_{\text {zeo }}$ & Lennard-Jones & 29.116 & 3.193 & \\
\hline $\mathrm{C}_{\mathrm{CO} 2}-\mathrm{Si}_{\mathrm{zeo}}$ & Lennard-Jones & 49.754 & 3.620 & \\
\hline $\mathrm{O}_{\mathrm{CO} 2}-\mathrm{O}_{\mathrm{zeo}}$ & Lennard-Jones & 23.433 & 3.067 & \\
\hline $\mathrm{O}_{\mathrm{CO} 2}-\mathrm{Si}_{\mathrm{zeo}}$ & Lennard-Jones & 38.900 & 3.494 & \\
\hline $\mathrm{C}_{\mathrm{CO} 2}-\mathrm{Al}_{\mathrm{zeo}}$ & Lennard-Jones & 32.215 & 3.366 & \\
\hline $\mathrm{O}_{\mathrm{CO} 2}-\mathrm{Al}_{\text {zeo }}$ & Lennard-Jones & 25.323 & 3.246 & \\
\hline $\mathrm{C}_{\mathrm{CO} 2}-\mathrm{Na}_{\mathrm{zeo}}$ & Lennard-Jones & 66.778 & 2.827 & \\
\hline $\mathrm{O}_{\mathrm{CO} 2}-\mathrm{Na}_{\text {zeo }}$ & Lennard-Jones & 54.762 & 2.707 & \\
\hline $\mathrm{C}_{\mathrm{CO} 2}-\mathrm{C}_{\mathrm{CO} 2}$ & Lennard-Jones & 28.129 & 2.757 & \\
\hline $\mathrm{O}_{\mathrm{CO} 2}-\mathrm{O}_{\mathrm{CO} 2}$ & Lennard-Jones & 80.507 & 3.033 & \\
\hline & & $A(K)$ & $\mathbf{B}\left(\AA^{-1}\right)$ & $\mathrm{C}(\mathrm{K})$ \\
\hline $\mathrm{Na}_{\mathrm{zeo}}-\mathrm{O}_{\mathrm{zeo}}$ & Buckingham & 37850656.24 & 3.8506 & 526402.05 \\
\hline \multicolumn{5}{|c|}{ Atom Properties } \\
\hline & Mass (amu) & Charge (amu) & & \\
\hline $\mathrm{C}_{\mathrm{CO} 2}$ & 12.0 & 0.6512 & & \\
\hline $\mathrm{O}_{\mathrm{CO} 2}$ & 15.9994 & -0.3256 & & \\
\hline $\mathrm{O}_{\text {zeo }}{ }^{\overline{s i}}$ & 15.9994 & -1.1062 & & \\
\hline $\mathrm{O}_{\text {zeo }}^{\mathrm{Al}}$ & 15.9994 & -1.3211 & & \\
\hline $\mathrm{Si}_{\text {zeo }}$ & 28.0855 & 2.2124 & & \\
\hline $\mathrm{Al}_{\text {zeo }}$ & 26.981539 & 2.0833 & & \\
\hline $\mathrm{Na}_{\text {zeo }}$ & 22.98977 & 0.9887 & & \\
\hline \multicolumn{5}{|c|}{$\mathrm{CH}_{4}{ }^{\mathrm{b}}$} \\
\hline $\mathrm{CH}_{4}$ model & TraPPE & & & \\
\hline Mixing rules & Lorentz- Berthelot & & & \\
\hline Force Field Parameters & Interaction Model & $\varepsilon / \mathbf{k}_{\mathrm{B}}(\mathbf{K})$ & $\sigma(\AA)$ & \\
\hline C__ $\mathrm{CH}_{4}-\mathrm{Si}_{\text {zeo }}$ & Lennard-Jones & 33.979 & 3.845 & \\
\hline H_ $\mathrm{CH}_{4}-\mathrm{Si}_{\text {zeo }}$ & Lennard-Jones & 24.151 & 3.298 & \\
\hline C__ $\mathrm{CH}_{4}-\mathrm{O}_{\mathrm{zeo}}$ & Lennard-Jones & 19.884 & 3.391 & \\
\hline H_ $\mathrm{CH}_{4}-\mathrm{O}_{\text {zeo }}$ & Lennard-Jones & 16.173 & 2.844 & \\
\hline C_ $\mathrm{CH}_{4}-\mathrm{Al}_{\text {zeo }}$ & Lennard-Jones & 42.834 & 3.460 & \\
\hline $\mathrm{H} \_\mathrm{CH}_{4}-\mathrm{Al}_{\text {zeo }}$ & Lennard-Jones & 31.210 & 2.956 & \\
\hline $\mathrm{C} \_\mathrm{CH}_{4}-\mathrm{Na}_{\mathrm{zeo}}$ & Lennard-Jones & 88.789 & 2.906 & \\
\hline $\mathrm{H} \_\mathrm{CH}_{4}-\mathrm{Na}_{\text {zeo }}$ & Lennard-Jones & 78.916 & 2.401 & \\
\hline \multirow[t]{2}{*}{$\mathrm{C} \_\mathrm{CH}_{4}-\mathrm{C} \_\mathrm{CH}_{4}$} & Lennard-Jones & 148.00 & 3.730 & \\
\hline & & A (K) & $\mathbf{B}\left(\AA^{-1}\right)$ & $\mathrm{C}(\mathrm{K})$ \\
\hline $\mathrm{Na}_{\mathrm{zeo}}-\mathrm{O}_{\mathrm{zeo}}$ & Buckingham2 & 37850656.24 & 3.8506 & 526402.05 \\
\hline \multicolumn{5}{|c|}{ Atom Properties } \\
\hline & Mass (amu) & Charge (amu) & & \\
\hline C_ $\mathrm{CH}_{4}$ & 12.0 & -0.516 & & \\
\hline $\mathrm{H}_{-} \mathrm{CH}_{4}$ & 1.00794 & 0.129 & & \\
\hline $\mathrm{O}_{\text {zeo }} \mathrm{Si}$ & 15.9994 & -1.1062 & & \\
\hline $\mathrm{O}_{\text {zeo }} \mathrm{Al}$ & 15.9994 & -1.3211 & & \\
\hline $\mathrm{Si}_{\mathrm{zeo}}$ & 28.0855 & 2.2124 & & \\
\hline $\mathrm{Al}_{\text {zeo }}$ & 26.981539 & 2.0833 & & \\
\hline $\mathrm{Na}_{\text {zeo }}$ & 22.98977 & 0.9887 & & \\
\hline \multicolumn{5}{|c|}{$\mathbf{N}_{2}{ }^{\mathrm{c}}$} \\
\hline $\mathrm{N}_{2}$ model & $\begin{array}{l}\text { 2LJ3CB.MSKM } \\
\text { potential }\end{array}$ & & & \\
\hline Mixing rules & Lorentz- Berthelot & & & \\
\hline
\end{tabular}




\begin{tabular}{|c|c|c|c|c|}
\hline Force Field Parameters & Interaction Model & $\mathbf{\varepsilon} / \mathbf{k}_{\mathrm{B}}(\mathbf{K})$ & $\sigma(\AA)$ & \\
\hline $\mathrm{N}_{2}-\mathrm{O}_{\text {zeo }}$ & Lennard-Jones & 27.31 & 3.14 & \\
\hline $\mathrm{N}_{2}-\mathrm{Si}_{\text {zeo }}$ & Lennard-Jones & 46.00 & 3.57 & \\
\hline $\mathrm{N}_{2}-\mathrm{Al}_{\text {zeo }}$ & Lennard-Jones & 39.51 & 3.71 & \\
\hline $\mathrm{N}_{2}-\mathrm{Na}_{\text {zeo }}$ & Lennard-Jones & 82.64 & 2.659 & \\
\hline \multirow[t]{2}{*}{$\mathrm{N}_{2}-\mathrm{N}_{2}$} & Lennard-Jones & 36.4 & 3.32 & \\
\hline & & $A(K)$ & B $\left(\AA^{-1}\right)$ & C (K) \\
\hline $\mathrm{Na}-\mathrm{O}_{\text {zеo }}$ & Buckingham2 & 37850656.24 & 3.8506 & 526402.05 \\
\hline \multicolumn{5}{|c|}{ Atom Properties } \\
\hline & Mass (amu) & Charge (amu) & & \\
\hline $\mathrm{N}_{2}$ & 14.0067 & -0.40484 & & \\
\hline $\mathrm{N}_{2}$ C.O.M. & 0 & 0.80968 & & \\
\hline $\mathrm{O}_{\text {zeo }} \mathrm{Si}$ & 15.9994 & -1.1062 & & \\
\hline $\mathrm{O}_{\text {zeo }} \mathrm{Al}^{2}$ & 15.9994 & -1.3211 & & \\
\hline $\mathrm{Si}_{\text {zеo }}$ & 28.0855 & 2.2124 & & \\
\hline $\mathrm{Al}_{\text {zeo }}$ & 26.981539 & 2.0833 & & \\
\hline $\mathrm{Na}_{\text {zeo }}$ & 22.98977 & 0.9887 & & \\
\hline
\end{tabular}

\section{Comparison of the ITQ-29 unit cell structure:}

We performed simulations with the crystal structure from Corma, ${ }^{31}$ as well as taking the average structure from molecular dynamics performed in the NPT ensemble, to allow for the volume and shape of the ITQ-29 structure to relax at the chosen temperature of $195 \mathrm{~K}$. The same CCFF force field was used in the simulations for each structure. Comparison with experimental adsorption measurements from calorimetric measurements of ITQ-29 at $195 \mathrm{~K}$ from this work (Figure S5) confirms that both the crystal structure and the temperature dependent structure behave in similar manner, matching well with the experimental data. Since there is quantitative agreement with experimental data and both of the structures, the crystal structure was used for each of the structures investigated further in this study. 


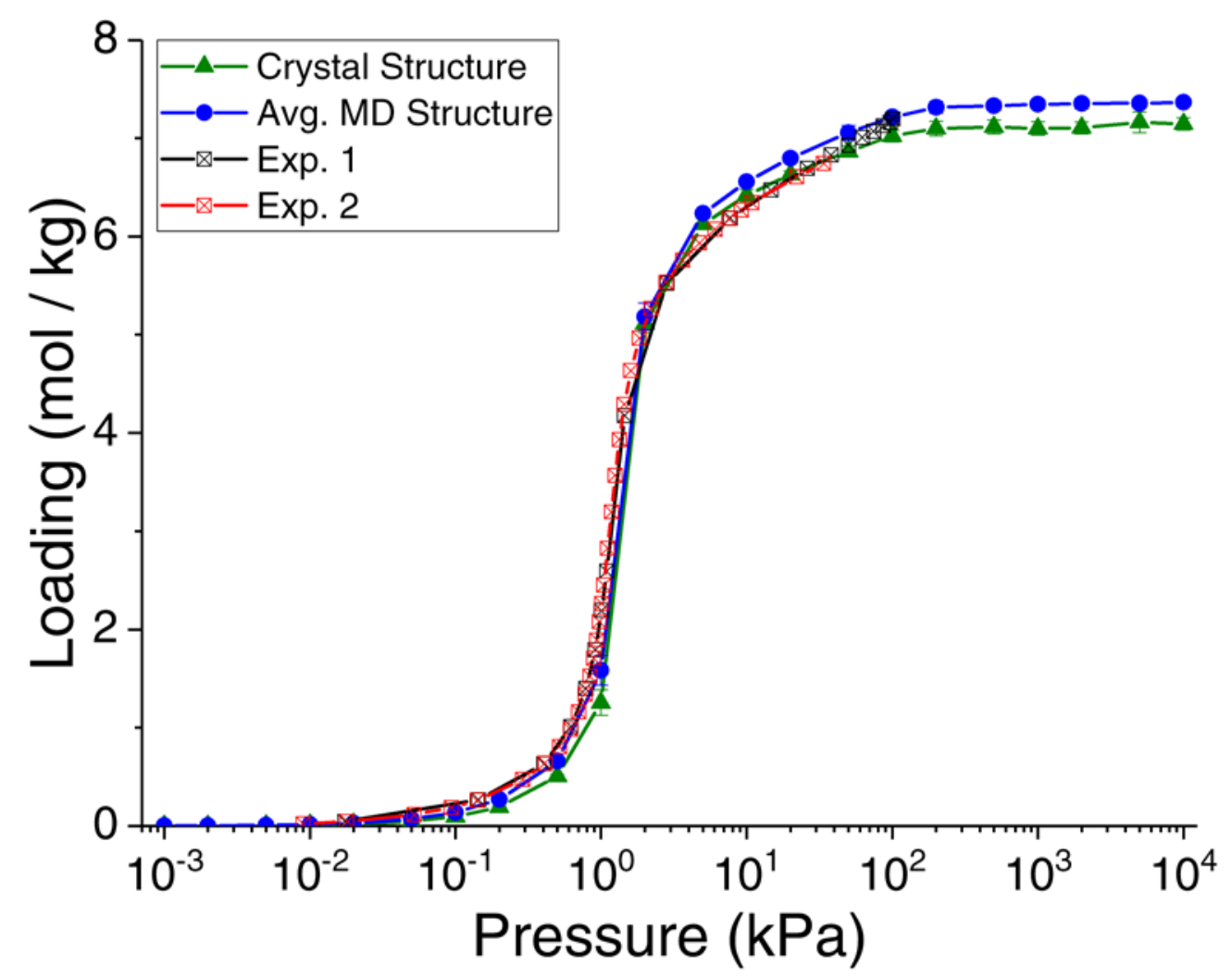

Figure S5: Comparison of experimental isotherms from this work of $\mathrm{CO}_{2}$ in ITQ-29 at $195 \mathrm{~K}$ with the simulated adsorption isotherms using both the crystal structure of ITQ-29 and the average structure obtained from NPT MD simulations to account for temperature effects on the unit cell volume and framework window size.

\section{Comparison of force field with experimental cation positions in 4A structure:}

As a way to further check the CCFF force field, we performed parallel tempering of the cation positions, to compare the distributions of cations in the simulated results to the distribution given in the experimental crystal structure. ${ }^{27}$ The final $10 \%$ of snapshots from GCMC simulations were analyzed to determine the distribution of cations relative to framework ring sizes. The results can be found in Table S4. The CCFF cation distributions and the crystal structure cation distributions are similar, showing the validity of using the CCFF force field in our study. 
Table S4: Distributions of cations within the LTA-4A structure at different temperatures from $300 \mathrm{~K}$ to $600 \mathrm{~K}$, with respect to the six-member ring windows (6MR), eight-member ring windows (8MR), four-member ring windows (4MR), and other positions in the framework. The experimental data is from Pluth and Smith ${ }^{27}$ taken at room temperature.

\begin{tabular}{llllll}
\hline $\begin{array}{l}\text { LTA-4A } \\
\text { Temp. }\end{array}$ & $\mathbf{6 M R}$ & $\mathbf{8 M R}$ & 4MR & Other & Total \\
\hline $300 \mathrm{~K}$ & 64 & 32 & 0 & 0 & 96 \\
$330 \mathrm{~K}$ & 64 & $31.98 \pm 0.14$ & 0 & $0.02 \pm 0.14$ & $96 \pm 0.28$ \\
$360 \mathrm{~K}$ & 64 & 32 & 0 & 0 & 96 \\
$390 \mathrm{~K}$ & 64 & $31.96 \pm 0.20$ & 0 & $0.04 \pm 0.20$ & $96 \pm 0.40$ \\
$420 \mathrm{~K}$ & 64 & $31.88 \pm 0.33$ & $0.06 \pm 0.24$ & $0.06 \pm 0.24$ & $96 \pm 0.81$ \\
$450 \mathrm{~K}$ & 64 & $31.88 \pm 0.33$ & $0.04 \pm 0.20$ & $0.08 \pm 0.27$ & $96 \pm 0.80$ \\
$480 \mathrm{~K}$ & 64 & $31.80 \pm 0.40$ & $0.10 \pm 0.30$ & $0.10 \pm 0.30$ & $96 \pm 1.00$ \\
$510 \mathrm{~K}$ & 64 & $31.90 \pm 0.30$ & $0.02 \pm 0.14$ & $0.08 \pm 0.27$ & $96 \pm 0.71$ \\
$540 \mathrm{~K}$ & 64 & $31.80 \pm 0.45$ & $0.02 \pm 0.14$ & $0.18 \pm 0.18$ & $96 \pm 0.77$ \\
$570 \mathrm{~K}$ & 64 & $31.80 \pm 0.45$ & 0 & $0.20 \pm 0.45$ & $96 \pm 0.90$ \\
$600 \mathrm{~K}$ & 64 & $31.53 \pm 0.61$ & $0.10 \pm 0.30$ & $0.37 \pm 0.56$ & $96 \pm 1.47$ \\
\hline Experiment & 62 & 23 & 6 & 0 & $91.7 \pm 1.0$ \\
\hline
\end{tabular}

\section{Extending the temperature range of study for siliceous zeolites:}

The small increase of the isosteric heat at zero loading near $300 \mathrm{~K}$ for ITQ-29 led us to examine the system at lower temperatures. ITQ-29 results for temperatures down to $10 \mathrm{~K}$ showed an increase of almost $12 \mathrm{~kJ} / \mathrm{mol}$, from $\sim 18 \mathrm{~kJ} / \mathrm{mol}$ at $600 \mathrm{~K}$ to $\sim 30 \mathrm{~kJ} / \mathrm{mol}$ at $10 \mathrm{~K}$. The same temperature range was examined with Si-CHA and Si-MFI to see if this change in heats of adsorption was specific to ITQ-29 or more general for siliceous zeolites or siliceous zeolites with 8MR windows. The Si-CHA does also show a large increase of around $8 \mathrm{~kJ} / \mathrm{mol}$ over the $10 \mathrm{~K}-$ $600 \mathrm{~K}$ range. Si-MFI has a slight temperature dependence, with a change of around $6 \mathrm{~kJ} / \mathrm{mol}$ over the same temperature range, compared to the difference in thermal energy of around 5 $\mathrm{kJ} / \mathrm{mol}$. The results for the three siliceous zeolites from $10-600 \mathrm{~K}$ range are presented in Figure 4. Further study of the ITQ-29 and Si-CHA systems concluded that the $30 \mathrm{~kJ} / \mathrm{mol}$ heat of adsorption is due to $\mathrm{CO}_{2}$ molecules located in the center of the $8 \mathrm{MR}$ window of these zeolites. The difference in thermal energy between 10 and $600 \mathrm{~K}$ is $-4.9 \mathrm{~kJ} / \mathrm{mol}$, because the temperature contribution is subtracted from the values of the heats of adsorption (both at zero and non-zero loading) calculated by the RASPA program. If the values of the heat of adsorption were calculated to be the same at 10 and $600 \mathrm{~K}$, the reported value would be smaller by $4.9 \mathrm{~kJ} / \mathrm{mol}$ at $600 \mathrm{~K}$ compared to the value reported at $10 \mathrm{~K}$. 


\section{Comparison between isosteric heats of adsorption calculated from fluctuation formula and Clausius-Clapeyron equation:}

In order to make sure that the isosteric heats of adsorption obtained from the fluctuation method at different temperatures presented in Figure 1 of the main paper are reliable, the isosteric heats of adsorption were calculated using the Clausius-Clapeyron equation. Heats of adsorption were calculated using the formula:

$$
-q=\left(\langle U \times N\rangle_{\mu}-\langle U\rangle_{\mu}\langle N\rangle_{\mu}\right) /\left(\left\langle N^{2}\right\rangle_{\mu}-\langle N\rangle_{\mu}\langle N\rangle_{\mu}\right)-\left\langle U_{g}\right\rangle-1 / \beta
$$

where $q$ is the heat of adsorption, $\langle\cdots\rangle_{\mu}$ denotes an average in the grand-canonical ensemble, $U$ denotes the energy of a host, $N$ is the number of guest molecules, $\mu$ is the chemical potential of the guest molecules, $\left\langle U_{g}\right\rangle$ is the average energy of an isolated guest molecule, and $\beta=1 /\left(\mathrm{k}_{\mathrm{B}} \mathrm{T}\right) .{ }^{28}$ For the LTA-4A systems, the temperatures of $300 \mathrm{~K}, 450 \mathrm{~K}$, and $600 \mathrm{~K}$ were examined. In order to have isotherms that were not significantly influenced by numerical noise from the simulations, the temperature range used for Clausius-Clapeyron analysis with higher temperatures $(450 \mathrm{~K}$ and $600 \mathrm{~K}$ ) needed to be increased. For $300 \mathrm{~K}$, a range of $\pm 5 \mathrm{~K}$ was enough to see different isotherms for the three temperatures. For $450 \mathrm{~K}$, the range was extended to $\pm 10 \mathrm{~K}$, and for 600 $\mathrm{K}$, the range was extended to $\pm 30 \mathrm{~K}$. The isosteric heats of adsorption from Clausius-Clapeyron analysis are shown below for $450 \mathrm{~K}$ and $600 \mathrm{~K}$ in Figures S6 and S7, respectively. An example of a siliceous system and the comparison between isosteric heats of adsorption from the fluctuation method and Clausius-Clapeyron analysis can be found below in Figure $\mathrm{S} 8$ for $\mathrm{CO}_{2}$ in ITQ-29 at $195 \mathrm{~K}$. In order to test the generality of the agreement of isosteric heats calculated by different methods, the isosteric heats of adsorption were calculated for $\mathrm{CH}_{4}$ in ITQ-29 and the results are shown in Figure S9.

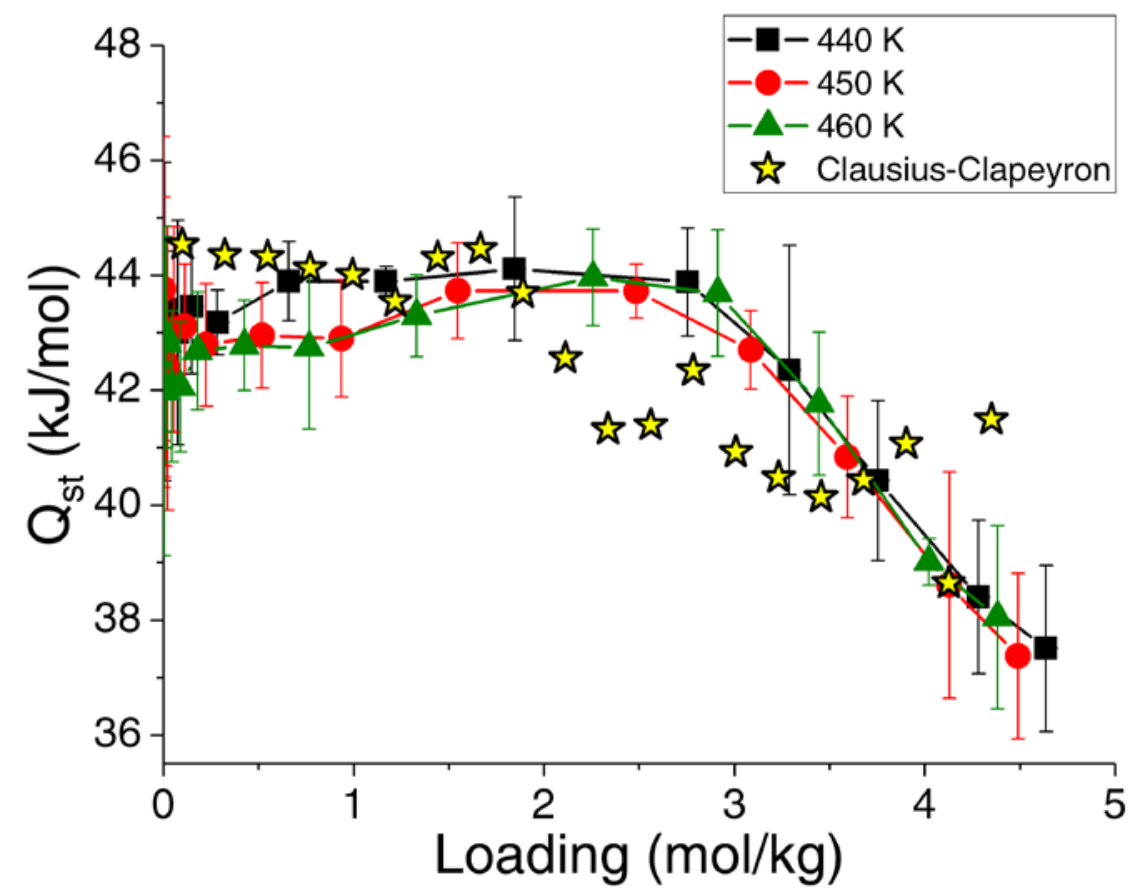

Figure S6: Isosteric heats of adsorption for $\mathrm{CO}_{2}$ interacting with LTA-4A calculated by the fluctuation formula for $440 \mathrm{~K}, 450 \mathrm{~K}$, and $460 \mathrm{~K}$ vs loading, along with the isosteric heat of adsorption obtained using the Clausius-Clapeyron equation (yellow and black stars) for the three temperatures presented in the graph. 


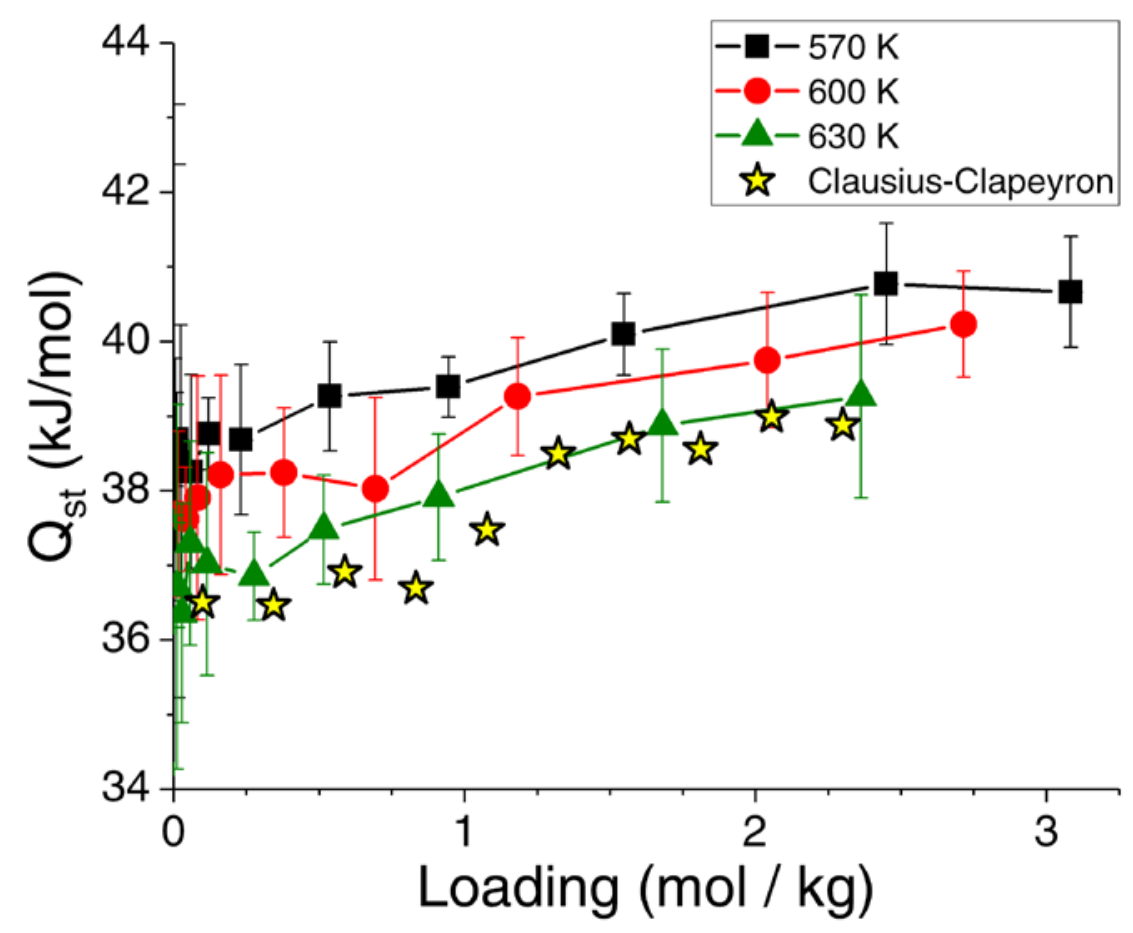

Figure S7: Isosteric heats of adsorption for $\mathrm{CO}_{2}$ interacting with LTA-4A calculated by the fluctuation formula for $570 \mathrm{~K}, 600 \mathrm{~K}$, and $630 \mathrm{~K}$ vs loading, along with the isosteric heat of adsorption obtained using the Clausius-Clapeyron equation (yellow and black stars) for the three temperatures presented in the graph.

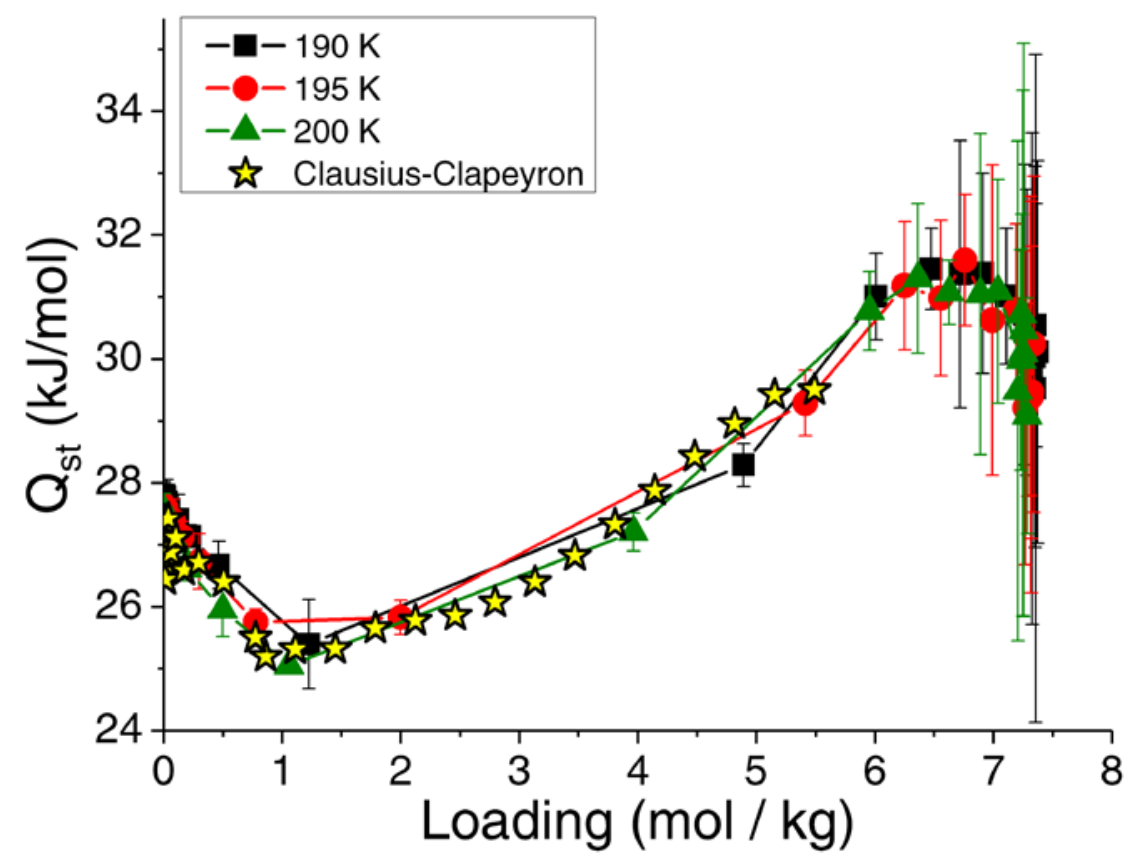

Figure S8: Isosteric heats of adsorption for $\mathrm{CO}_{2}$ interacting with ITQ-29 calculated by the fluctuation formula for $190 \mathrm{~K}, 195 \mathrm{~K}$, and $200 \mathrm{~K}$ vs loading, along with the isosteric heat of adsorption obtained using the Clausius-Clapeyron equation (yellow and black stars) for the three temperatures presented in the graph. 


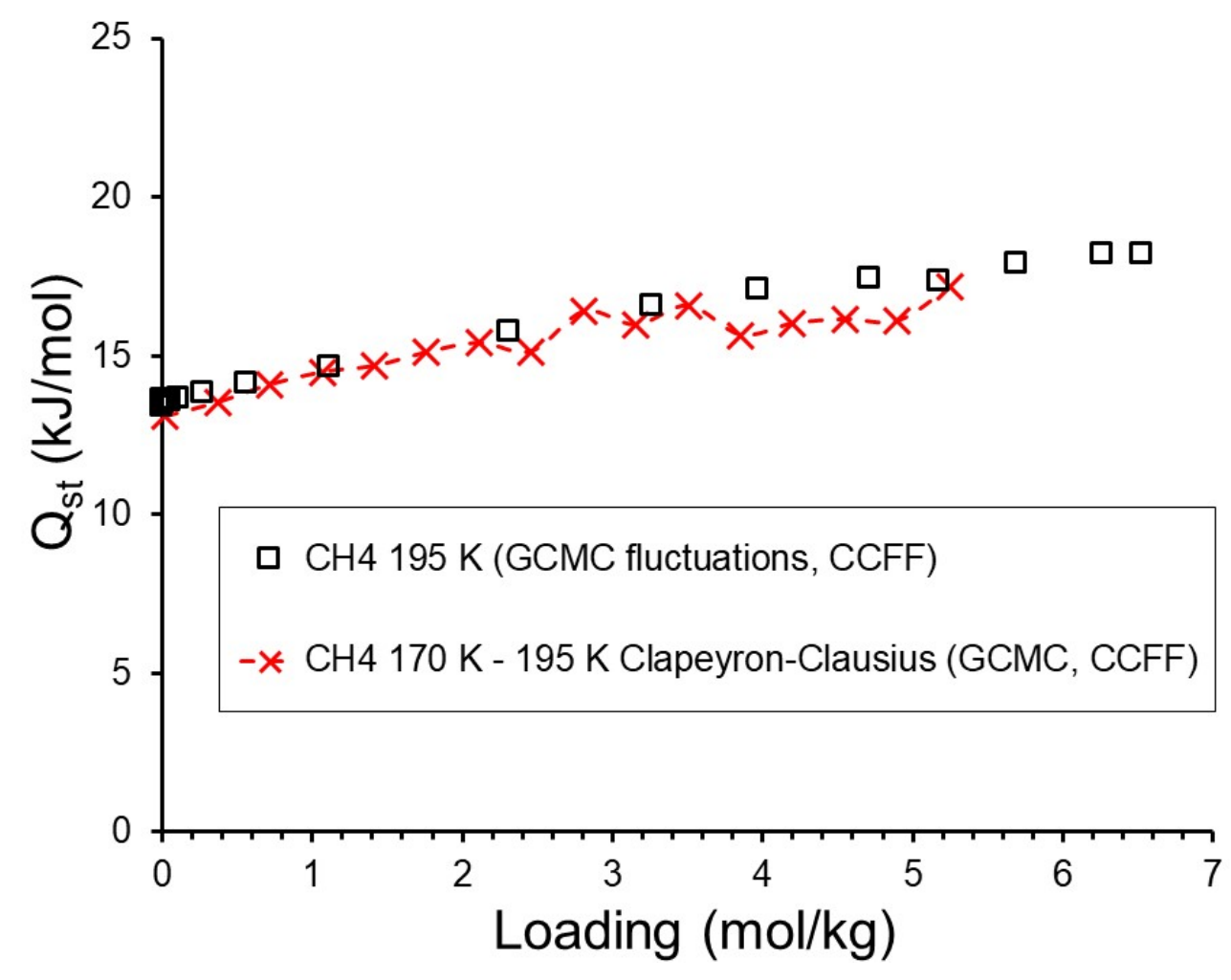

Figure S9. Comparison of the isosteric heats of adsorption of $\mathrm{CH}_{4}$ in ITQ-29 calculated from GCMC simulations with the CCFF force field using the fluctuations formula (squares), and Clausius-Clapeyron equation using isotherms at $170 \mathrm{~K}$ and $195 \mathrm{~K}$ (line, crosses).

\section{Comparison of the $\mathrm{CO}_{2}$ positioning relative to cations:}

For the cationic zeolites, the extra-framework cations will have the strongest interactions with the adsorbate molecules. The location of the $\mathrm{CO}_{2}$ molecules with respect to the cation positions in the framework can help us understand the change in the heats of adsorption. We have calculated the distance of each $\mathrm{CO}_{2}$ molecule present from snapshots in the Monte Carlo simulations and have set a distance parameter to decide whether a $\mathrm{CO}_{2}$ molecule is close to a sodium atom, in the cationic zeolites, or the center of an n-membered ring, in the siliceous zeolites. In both cases, the distance selected was $3.5 \AA$, as this is close to the sum of the van der Waals radii of oxygen or carbon (form $\mathrm{CO}_{2}$ ) and oxygen (from the zeolite) (3.14 $\AA$ for O-O and $3.22 \AA$ for C-O), with a little extra distance included for potential interactions. With this in mind, the distance between the oxygen atoms of $\mathrm{CO}_{2}$ and the sodium atoms or the carbon atom of $\mathrm{CO}_{2}$ and the center of the n-membered rings was calculated. $\mathrm{CO}_{2}$ molecules can be sitting in dual cation sites (both oxygen atoms are within $3.5 \AA$ of Na cations), single cation sites (only one oxygen atom is within $3.5 \AA$ of a Na cation), or a site with no cations (both oxygen atoms are greater than $3.5 \AA$ away from a Na cation). The percentage of the $\mathrm{CO}_{2}$ molecules sitting in each type of cation site in LTA-4A and Na-LTA with Si/Al = 2 are shown in Figure S10 and S12, respectively. The strengths of the interactions of $\mathrm{CO}_{2}$ in the different cation sites of LTA-4A were investigated by using molecular dynamics (MD) simulations. MD simulations were 
performed using the LAMMPS program ${ }^{29}$ using the same CCFF force field as in the GCMC simulations for $2 \times 10^{7}$ steps, with a timestep of 1 fs. The loading of $\mathrm{CO}_{2}$ molecules was held fixed at 1 molecule per $\alpha$ cage and the locations of the $\mathrm{CO}_{2}$ molecules and energies were tracked at each MD step. The interaction energy per $\mathrm{CO}_{2}$ molecule in different cation sites at $300 \mathrm{~K}$ is shown below in Figure S11. For the LTA-4A simulations, $\mathrm{CO}_{2}$ adsorption distributions at $600 \mathrm{~K}$ show a reduction in the percentage of $\mathrm{CO}_{2}$ molecules found in strongly interacting dual cation sites and an increase in the percentage of single cation and no cation occupations, compared to the adsorption distributions at $300 \mathrm{~K}$. The distributions for Na-LTA with $\mathrm{Si} / \mathrm{Al}=2$ show a similar trend to the distributions from LTA-4A, a reduction in the percentage of $\mathrm{CO}_{2}$ molecules found in strongly interacting dual cation sites and an increase in the number of single cation and no cation occupations at $600 \mathrm{~K}$, compared to adsorption at $303 \mathrm{~K}$.

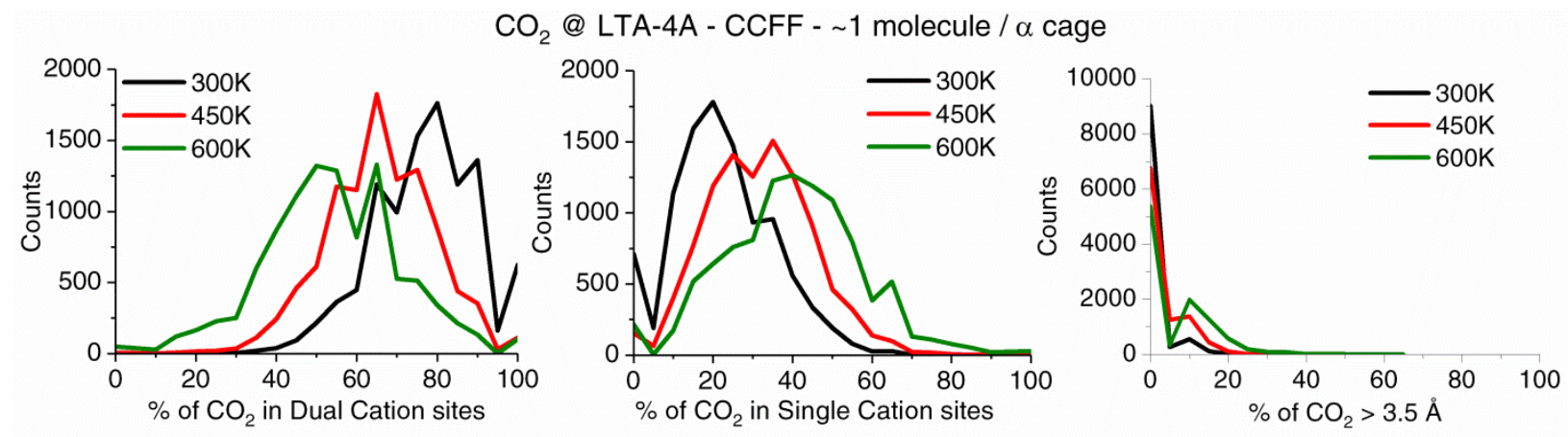

Figure S10: Comparison of the locations of $\mathrm{CO}_{2}$ molecules relative to the cation positions in the LTA-4A structure. For each temperature, the pressure at which an average loading of at least one molecule per $\alpha$-cage was selected. For 300,450 , and $600 \mathrm{~K}$, the pressures selected are $2 \times 10^{2}$, $1 \times 10^{5}$ and $1 \times 10^{6} \mathrm{~Pa}$, respectively. 


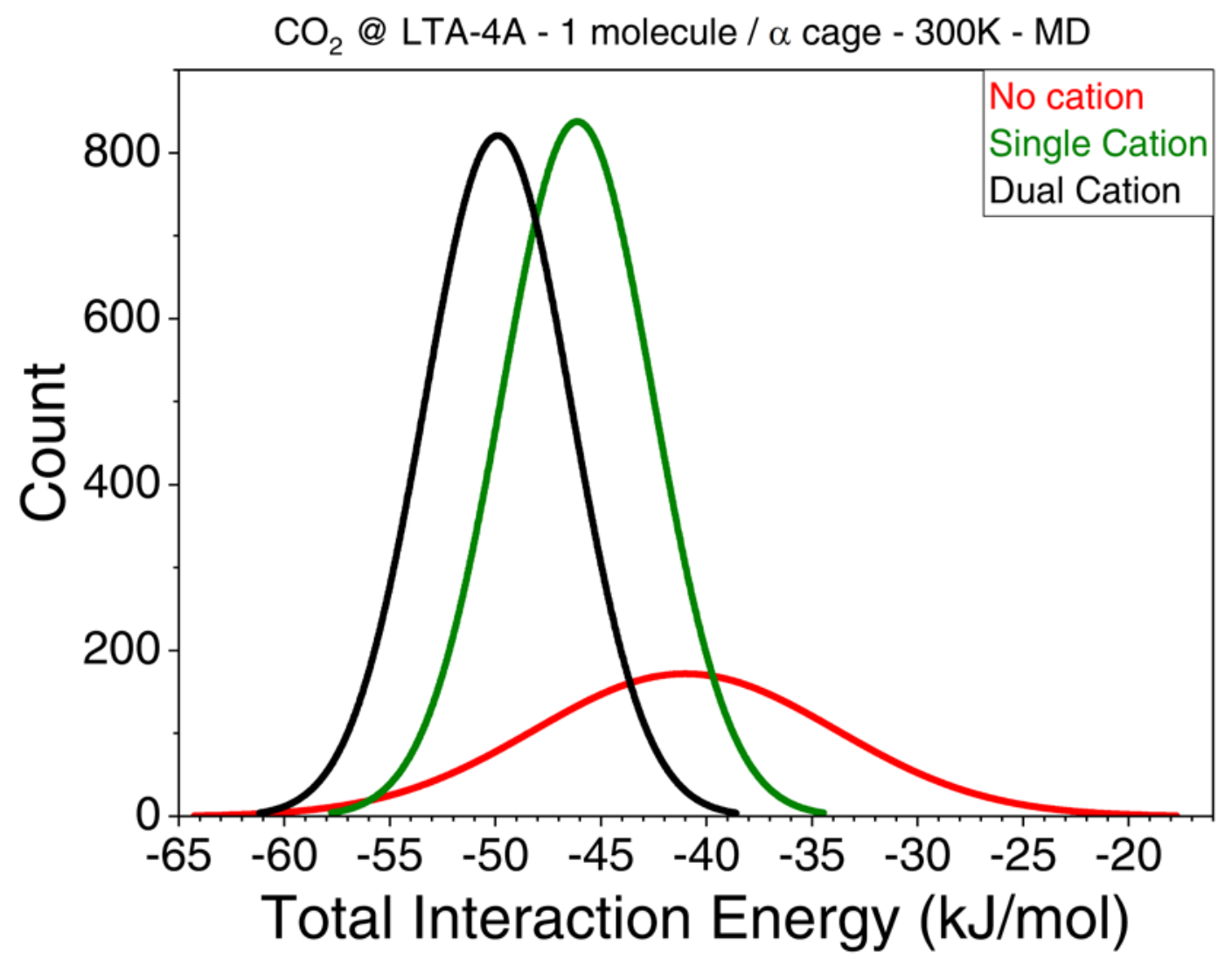

Figure S11: Comparison of the interaction energies of $\mathrm{CO}_{2}$ in different cation sites in the LTA4A structure from molecular dynamics simulations at $300 \mathrm{~K}$. The interaction energies were separated into $1 \mathrm{~kJ} / \mathrm{mol}$ bins before plotting. The average values for the interaction energies of $\mathrm{CO}_{2}$ in dual, single and no cation sites in LTA-4A at $300 \mathrm{~K}$ are $-50,-46$, and $-41 \mathrm{~kJ} / \mathrm{mol}$, respectively.

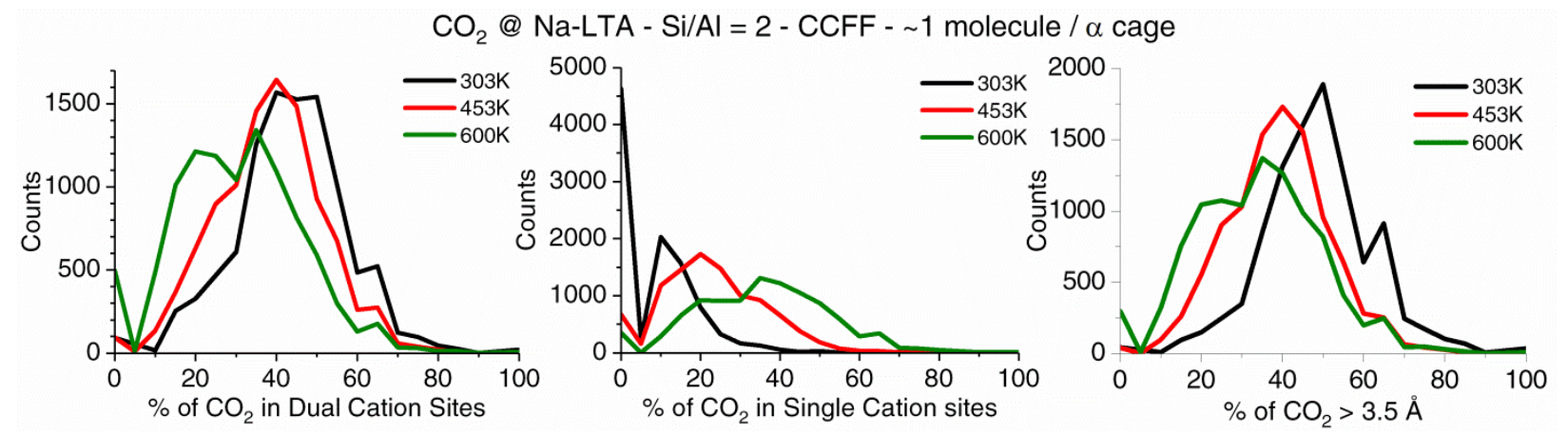

Figure S12: Comparison of the locations of $\mathrm{CO}_{2}$ molecules relative to the cation positions in the Na-LTA with Si/Al = 2 structure. For each temperature, the pressure at which an average loading of at least one molecule per $\alpha$-cage was selected. For 303, 453, and $600 \mathrm{~K}$, the pressures selected are $2 \times 10^{3}, 2 \times 10^{5}$ and $2 \times 10^{6} \mathrm{~Pa}$, respectively. 


\section{Comparison of the $\mathrm{CO}_{2}$ positioning relative to framework ring windows:}

For the siliceous zeolites, which are free of cations, there is another way to describe the positioning of $\mathrm{CO}_{2}$ molecules within the zeolite, namely the proximity to different ring window sizes in the framework. For the ITQ-29 and the siliceous-CHA frameworks, there are only 6, 8, and 4-member ring windows. The last 5\% of snapshots from GCMC simulations were analyzed and the distributions of $\mathrm{CO}_{2}$ molecules near different ring sizes are compared at each of the temperatures examined. The distributions of $\mathrm{CO}_{2}$ molecules in ITQ-29 and siliceous-CHA can be found below in Figures S13 and S14, respectively.

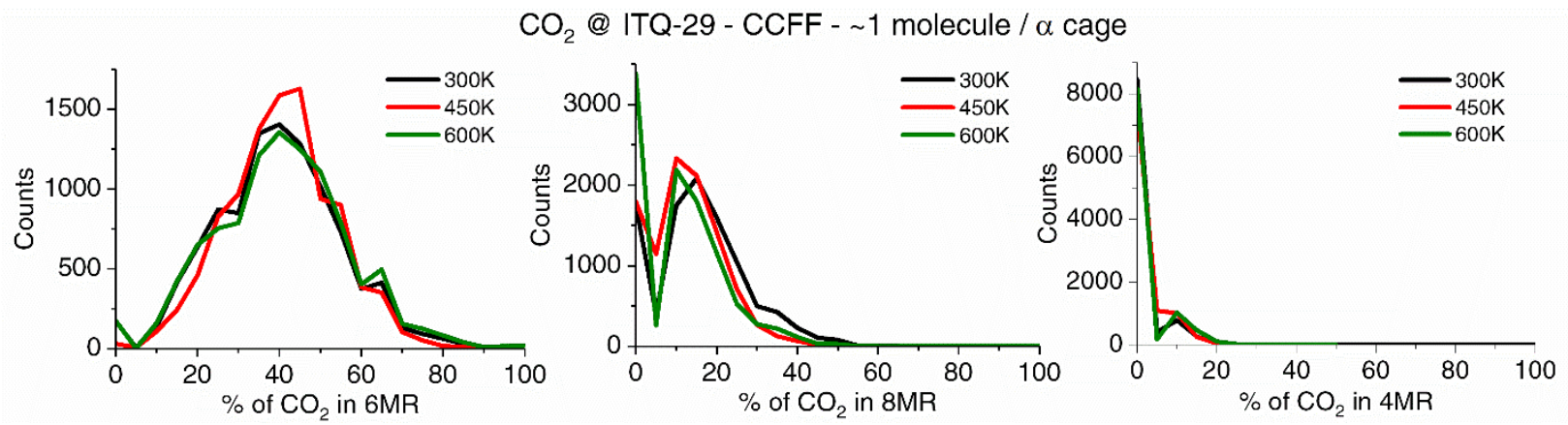

Figure S13: Comparison of the locations of $\mathrm{CO}_{2}$ molecules relative to the $6 \mathrm{MR}, 8 \mathrm{MR}$ and $4 \mathrm{MR}$ windows in the ITQ-29 structure. For each temperature, the pressure at which an average loading of at least one molecule per $\alpha$-cage was selected. For 300, 450, and $600 \mathrm{~K}$, the pressures selected are $1 \times 10^{5}, 2 \times 10^{6}$ and $5 \times 10^{6} \mathrm{~Pa}$, respectively.
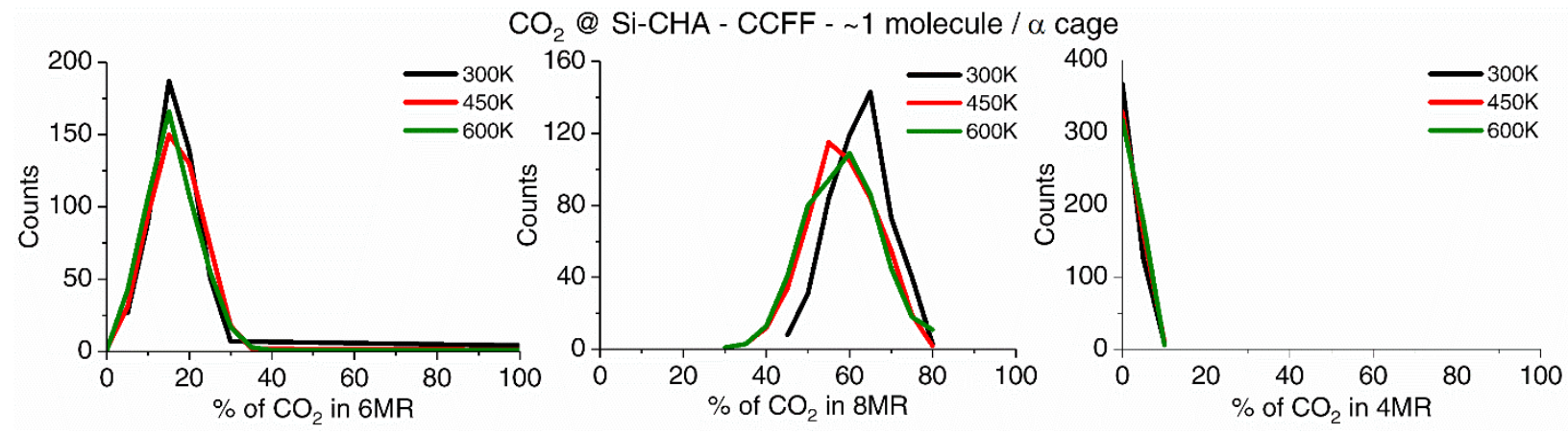

Figure S14: Comparison of the locations of $\mathrm{CO}_{2}$ molecules relative to the $6 \mathrm{MR}, 8 \mathrm{MR}$ and $4 \mathrm{MR}$ windows in the siliceous-CHA structure for the last 5\% of the GCMC simulations. For each temperature, the pressure at which an average loading of at least one molecule per unit cell was selected. For 300, 450, and $600 \mathrm{~K}$, the pressures selected are $1 \times 10^{5}, 2 \times 10^{6}$ and $1 \times 10^{7} \mathrm{~Pa}$, respectively. 
Table S5: Tabulated data for Figure 1 in the paper: Isotherms and heats of adsorption for $\mathrm{CO}_{2}$ in LTA-4A.

\begin{tabular}{|c|c|c|c|c|c|c|}
\hline \multirow[b]{2}{*}{$\frac{\text { Pressure }}{(\mathrm{kPa})}$} & \multicolumn{2}{|c|}{$300 \mathrm{~K}$} & \multicolumn{2}{|c|}{$450 \mathrm{~K}$} & \multicolumn{2}{|c|}{$600 \mathrm{~K}$} \\
\hline & $\begin{array}{c}\mathrm{Q}_{\mathrm{st}} \\
(\mathrm{kJ} / \mathrm{mol})\end{array}$ & 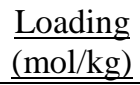 & $\begin{array}{c}\mathrm{Q}_{\mathrm{st}} \\
(\mathrm{kJ} / \mathrm{mol}) \\
\end{array}$ & $\begin{array}{l}\text { Loading } \\
\text { (mol/kg) }\end{array}$ & $\begin{array}{c}\underline{\mathrm{Q}}_{\mathrm{st}} \\
(\mathrm{kJ} / \mathrm{mol}) \\
\end{array}$ & 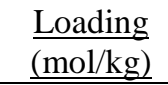 \\
\hline 0.001 & $47.3 \pm 2.04$ & 0.005 & $44.9 \pm 34.9$ & $1.540 \mathrm{E}-05$ & ---- & $0.000 \mathrm{E}+00$ \\
\hline 0.002 & $47.3 \pm 2.02$ & 0.009 & $44.0 \pm 32.7$ & 2.713E-05 & ---- & 7.333E-07 \\
\hline 0.005 & $47.8 \pm 1.96$ & 0.022 & $41.7 \pm 18.9$ & $5.206 \mathrm{E}-05$ & ---- & 4.400E-06 \\
\hline 0.01 & $48.1 \pm 1.78$ & 0.045 & $37.8 \pm 12.6$ & $1.071 \mathrm{E}-04$ & $32.5 \pm 41.1$ & $1.100 \mathrm{E}-05$ \\
\hline 0.02 & $47.6 \pm 1.17$ & 0.089 & $43.7 \pm 4.87$ & $2.295 \mathrm{E}-04$ & $40.4 \pm 53.5$ & 2.053E-05 \\
\hline 0.05 & $47.9 \pm 0.45$ & 0.215 & $43.7 \pm 7.14$ & 6.196E-04 & $40.3 \pm 43.4$ & 3.886E-05 \\
\hline 0.1 & $47.9 \pm 0.46$ & 0.433 & $43.8 \pm 2.64$ & 0.001 & $16.4 \pm 18.2$ & 8.506E-05 \\
\hline 0.2 & $48.3 \pm 1.26$ & 0.835 & $42.8 \pm 2.52$ & 0.002 & $34.1 \pm 10.3$ & 1.716E-04 \\
\hline 0.5 & $48.7 \pm 1.13$ & 1.683 & $42.5 \pm 2.04$ & 0.006 & $41.2 \pm 7.58$ & 4.583E-04 \\
\hline 1 & $48.9 \pm 1.04$ & 2.345 & $42.3 \pm 1.57$ & 0.011 & $40.4 \pm 9.64$ & 8.631E-04 \\
\hline 2 & $47.9 \pm 0.97$ & 2.962 & $42.4 \pm 2.47$ & 0.023 & $37.5 \pm 7.26$ & 0.002 \\
\hline 5 & $45.7 \pm 0.91$ & 3.400 & $43.1 \pm 1.79$ & 0.057 & $35.7 \pm 5.24$ & 0.004 \\
\hline 10 & $41.5 \pm 0.83$ & 3.643 & $43.1 \pm 1.08$ & 0.113 & $37.6 \pm 3.33$ & 0.008 \\
\hline 20 & $38.3 \pm 1.50$ & 3.933 & $42.8 \pm 1.07$ & 0.225 & $37.7 \pm 1.11$ & 0.017 \\
\hline 50 & $37.4 \pm 1.61$ & 4.485 & $42.9 \pm 0.92$ & 0.520 & $37.6 \pm 0.70$ & 0.042 \\
\hline 100 & $36.2 \pm 2.42$ & 4.769 & $42.9 \pm 1.02$ & 0.936 & $37.9 \pm 1.63$ & 0.083 \\
\hline 200 & $36.8 \pm 1.47$ & 5.155 & $43.7 \pm 0.83$ & 1.547 & $38.2 \pm 1.34$ & 0.162 \\
\hline 500 & $34.7 \pm 3.23$ & 5.658 & $43.7 \pm 0.47$ & 2.485 & $38.2 \pm 0.87$ & 0.380 \\
\hline 1,000 & $35.5 \pm 1.18$ & 5.966 & $42.7 \pm 0.68$ & 3.086 & $38.0 \pm 1.22$ & 0.694 \\
\hline 2,000 & $35.3 \pm 1.65$ & 6.308 & $40.8 \pm 1.06$ & 3.594 & $39.3 \pm 0.79$ & 1.183 \\
\hline 5,000 & $34.2 \pm 1.81$ & 6.561 & $38.6 \pm 1.97$ & 4.129 & $39.7 \pm 0.90$ & 2.041 \\
\hline 10,000 & $33.0 \pm 3.19$ & 6.709 & $37.4 \pm 1.44$ & 4.490 & $40.2 \pm 0.71$ & 2.715 \\
\hline
\end{tabular}

303K - Experiment

$453 \mathrm{~K}$ - Experiment

\begin{tabular}{|c|c|c|c|c|c|c|c|}
\hline \multicolumn{2}{|c|}{ Isotherm } & \multicolumn{2}{|c|}{$\underline{\text { Heats of adsorption }}$} & \multicolumn{2}{|c|}{ Isotherm } & \multicolumn{2}{|c|}{ Heats of adsorption } \\
\hline$\frac{\text { Pressure }}{\underline{(\mathrm{kPa})}}$ & $\begin{array}{l}\text { Loading } \\
\underline{(\mathrm{mol} / \mathrm{kg})}\end{array}$ & $\begin{array}{l}\text { Loading } \\
(\mathrm{mol} / \mathrm{kg})\end{array}$ & $\begin{array}{c}\underline{\mathrm{Q}_{\mathrm{st}}} \\
\underline{(\mathrm{kJ} / \mathrm{mol})}\end{array}$ & $\frac{\text { Pressure }}{\underline{(\mathrm{kPa})}}$ & $\begin{array}{l}\text { Loading } \\
(\mathrm{mol} / \mathrm{kg})\end{array}$ & $\frac{\text { Loading }}{(\mathrm{mol} / \mathrm{kg})}$ & $\begin{array}{c}\underline{\mathrm{Q}}_{\underline{\mathrm{st}}} \\
\underline{\mathrm{kJ} / \mathrm{mol})}\end{array}$ \\
\hline 0.066 & 0.598 & 0.600 & 47.750 & 0.0003 & 0.002 & 0.224 & 42.628 \\
\hline 0.125 & 0.852 & 0.700 & 47.564 & 0.0018 & 0.004 & 0.262 & 41.079 \\
\hline 0.263 & 1.313 & 0.800 & 47.453 & 0.0025 & 0.006 & 0.298 & 40.970 \\
\hline 0.526 & 1.821 & 0.900 & 47.292 & 0.0028 & 0.008 & 0.332 & 41.061 \\
\hline 0.800 & 2.116 & 1.000 & 47.193 & 0.0028 & 0.011 & 0.366 & 41.079 \\
\hline 1.062 & 2.303 & 1.100 & 47.192 & 0.0028 & 0.013 & 0.398 & 41.117 \\
\hline 1.344 & 2.442 & 1.200 & 47.569 & 0.0027 & 0.015 & 0.429 & 40.790 \\
\hline 1.605 & 2.549 & 1.300 & 47.975 & 0.0027 & 0.018 & 0.460 & 40.502 \\
\hline 1.897 & 2.639 & 1.400 & 47.743 & 0.0026 & 0.020 & 0.490 & 40.202 \\
\hline 2.167 & 2.712 & 1.500 & 47.450 & 0.0026 & 0.022 & 0.519 & 40.412 \\
\hline 2.420 & 2.764 & 1.600 & 47.354 & 0.0027 & 0.025 & 0.548 & 41.439 \\
\hline
\end{tabular}




\begin{tabular}{|c|c|c|c|c|c|c|c|}
\hline 2.684 & 2.815 & 1.700 & 47.445 & 0.0028 & 0.027 & 0.574 & 40.940 \\
\hline 5.342 & 3.116 & 1.800 & 47.569 & 0.0030 & 0.029 & 0.602 & 41.753 \\
\hline 8.069 & 3.275 & 1.900 & 47.257 & 0.0033 & 0.031 & 0.627 & 40.852 \\
\hline 10.853 & 3.397 & 2.000 & 46.909 & 0.0036 & 0.034 & 0.653 & 41.689 \\
\hline 16.131 & 3.552 & 2.100 & 46.779 & 0.0041 & 0.036 & 0.678 & 40.675 \\
\hline 21.555 & 3.666 & 2.200 & 46.534 & 0.0046 & 0.038 & 0.703 & 41.818 \\
\hline 26.886 & 3.760 & 2.300 & 46.276 & 0.0053 & 0.040 & 0.726 & 39.848 \\
\hline 32.276 & 3.838 & 2.400 & 45.720 & 0.0061 & 0.043 & 0.753 & 42.325 \\
\hline 37.233 & 3.903 & 2.500 & 45.222 & 0.0071 & 0.045 & 0.773 & 41.137 \\
\hline 42.654 & 3.960 & 2.600 & 44.931 & 0.0083 & 0.047 & 0.796 & 43.401 \\
\hline 47.952 & 4.016 & & & 0.0097 & 0.049 & 0.818 & 40.836 \\
\hline 53.406 & 4.057 & & & 0.0113 & 0.051 & 0.840 & 41.699 \\
\hline 58.663 & 4.102 & & & 0.0569 & 0.066 & 0.860 & 40.301 \\
\hline 64.065 & 4.146 & & & 0.1279 & 0.079 & 0.883 & 41.307 \\
\hline 69.420 & 4.178 & & & 0.2096 & 0.090 & & \\
\hline 74.737 & 4.212 & & & 0.3013 & 0.099 & & \\
\hline 80.151 & 4.245 & & & 0.4014 & 0.106 & & \\
\hline 85.461 & 4.272 & & & 0.5085 & 0.113 & & \\
\hline 90.818 & 4.302 & & & 0.6217 & 0.119 & & \\
\hline 96.145 & 4.325 & & & 0.7407 & 0.125 & & \\
\hline 101.516 & 4.348 & & & 0.8651 & 0.130 & & \\
\hline \multirow[t]{22}{*}{106.798} & 4.375 & & & 0.9917 & 0.135 & & \\
\hline & & & & 1.1049 & 0.141 & & \\
\hline & & & & 3.0496 & 0.184 & & \\
\hline & & & & 5.0121 & 0.224 & & \\
\hline & & & & 6.9831 & 0.262 & & \\
\hline & & & & 8.9630 & 0.298 & & \\
\hline & & & & 10.9506 & 0.332 & & \\
\hline & & & & 12.9425 & 0.366 & & \\
\hline & & & & 14.9351 & 0.398 & & \\
\hline & & & & 16.9366 & 0.429 & & \\
\hline & & & & 18.9361 & 0.460 & & \\
\hline & & & & 20.9396 & 0.490 & & \\
\hline & & & & 22.9424 & 0.519 & & \\
\hline & & & & 24.9520 & 0.548 & & \\
\hline & & & & 26.9728 & 0.574 & & \\
\hline & & & & 28.9790 & 0.602 & & \\
\hline & & & & 31.0067 & 0.627 & & \\
\hline & & & & 33.0249 & 0.653 & & \\
\hline & & & & 35.0507 & 0.678 & & \\
\hline & & & & 37.0792 & 0.703 & & \\
\hline & & & & 39.1158 & 0.726 & & \\
\hline & & & & 41.1228 & 0.753 & & \\
\hline
\end{tabular}




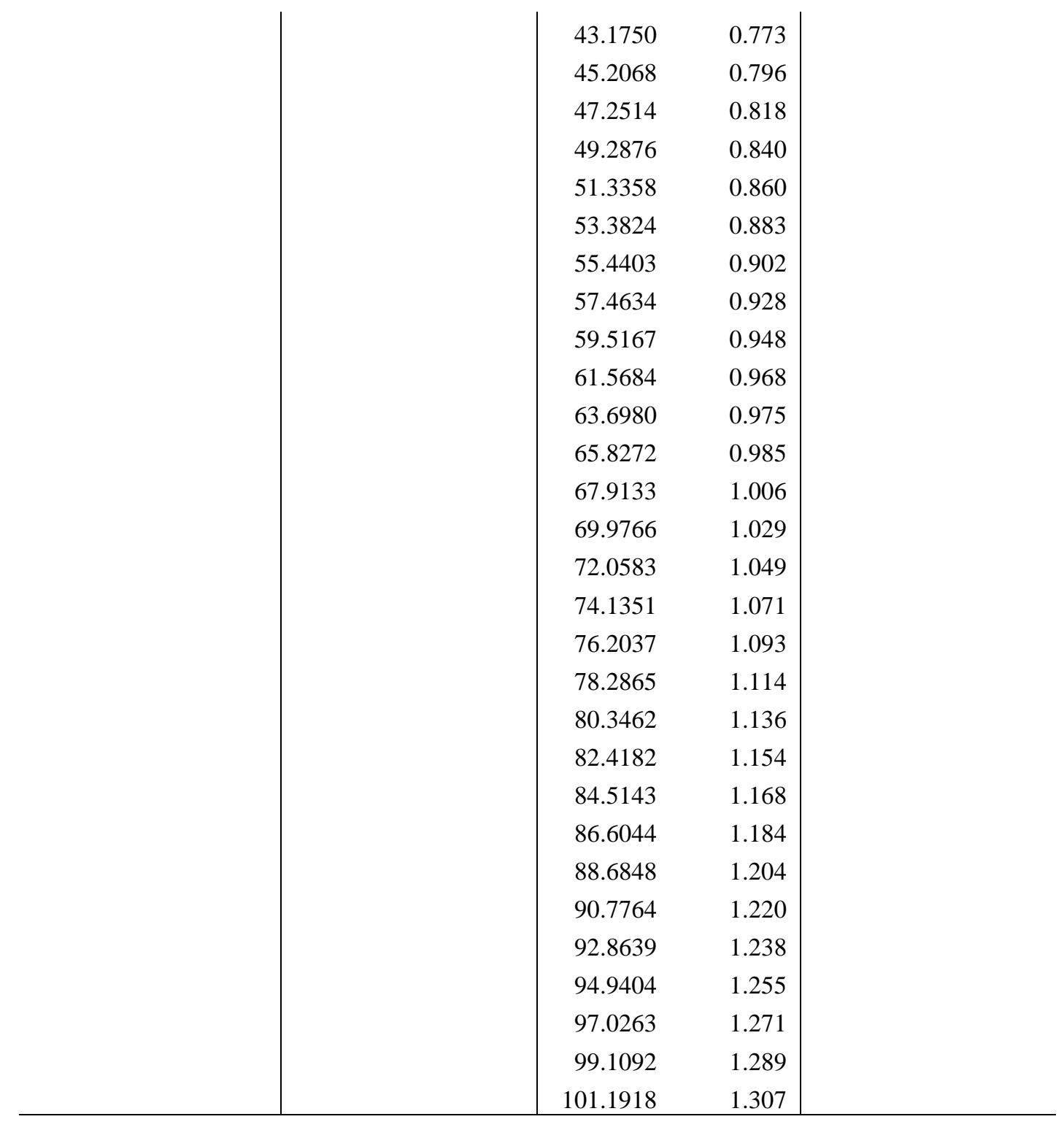


Table S6: Tabulated data for Figure 2 in the paper: Histograms of the interaction energy of $\mathrm{CO}_{2}$ in LTA-4A.

\begin{tabular}{|c|c|c|c|c|c|}
\hline $300 \mathrm{~K}$ & & $450 \mathrm{~K}$ & & $600 \mathrm{~K}$ & \\
\hline$\frac{\text { Interaction Energy / }}{\underline{\mathrm{CO}_{2}}} \frac{\text { molecule }}{(\mathrm{kJ} / \mathrm{mol})}$ & $\underline{\text { Counts }}$ & $\frac{\text { Interaction Energy / }}{\underline{\mathrm{CO}_{2}}} \frac{\text { molecule }}{(\mathrm{kJ} / \mathrm{mol})}$ & $\underline{\text { Counts }}$ & 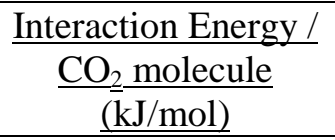 & $\underline{\text { Counts }}$ \\
\hline-55 & 1 & -52 & 2 & -42 & 372 \\
\hline-54 & 7 & -51 & 1 & -41 & 596 \\
\hline-53 & 29 & -50 & 9 & -40 & 786 \\
\hline-52 & 118 & -49 & 39 & -39 & 936 \\
\hline-51 & 453 & -48 & 95 & -38 & 1103 \\
\hline-50 & 965 & -47 & 212 & -37 & 1041 \\
\hline-49 & 1728 & -46 & 458 & -36 & 1028 \\
\hline-48 & 2140 & -45 & 875 & -35 & 971 \\
\hline-47 & 1899 & -44 & 1138 & -34 & 783 \\
\hline-46 & 1321 & -43 & 1417 & -33 & 609 \\
\hline-45 & 746 & -42 & 1585 & -32 & 430 \\
\hline-44 & 345 & -41 & 1366 & -31 & 293 \\
\hline-43 & 150 & -40 & 1081 & -30 & 188 \\
\hline-42 & 63 & -39 & 786 & -29 & 126 \\
\hline-41 & 25 & -38 & 456 & -28 & 75 \\
\hline-40 & 5 & -37 & 246 & -27 & 43 \\
\hline-39 & 1 & -36 & 119 & -26 & 21 \\
\hline-38 & 2 & -35 & 60 & -25 & 16 \\
\hline \multirow[t]{7}{*}{-34} & 1 & -34 & 33 & -24 & 3 \\
\hline & & -33 & 8 & -23 & 2 \\
\hline & & -32 & 9 & -22 & 2 \\
\hline & & -31 & 2 & -21 & 2 \\
\hline & & -30 & 1 & -16 & 1 \\
\hline & & -29 & 1 & -14 & 1 \\
\hline & & & & -8 & 1 \\
\hline
\end{tabular}


Table S7: Tabulated data for Figure 3 in the paper: Heats of adsorption and loadings of $\mathrm{CO}_{2}$ in LTA-4A from GCMC simulations and Clausius-Clapeyron analysis.

\begin{tabular}{|c|c|c|c|c|c|c|}
\hline & \multicolumn{2}{|c|}{$295 \mathrm{~K}$} & \multicolumn{2}{|c|}{$300 \mathrm{~K}$} & \multicolumn{2}{|c|}{$305 \mathrm{~K}$} \\
\hline$\frac{\text { Pressure }}{(\mathrm{kPa})}$ & $\begin{array}{c}\mathrm{Q}_{\mathrm{st}} \\
(\mathrm{kJ} / \mathrm{mol}) \\
\end{array}$ & $\begin{array}{l}\text { Loading } \\
\text { (mol/kg) }\end{array}$ & $\begin{array}{c}\underline{\mathrm{Q}}_{\mathrm{st}} \\
(\mathrm{kJ} / \mathrm{mol})\end{array}$ & $\begin{array}{l}\text { Loading } \\
\text { (mol/kg) }\end{array}$ & $\begin{array}{c}\underline{\mathrm{Q}}_{\mathrm{st}} \\
(\mathrm{kJ} / \mathrm{mol})\end{array}$ & $\begin{array}{l}\text { Loading } \\
\text { (mol/kg) }\end{array}$ \\
\hline 0.001 & $48.5 \pm 2.53$ & $0.007 \pm 0.001$ & $47.3 \pm 2.04$ & $0.005 \pm 0.001$ & $47.5 \pm 2.34$ & $0.004 \pm 4.2 \mathrm{E}-04$ \\
\hline 0.002 & $49.3 \pm 2.45$ & $0.014 \pm 0.002$ & $47.3 \pm 2.02$ & $0.009 \pm 0.001$ & $47.6 \pm 3.79$ & $0.008 \pm 3.9 \mathrm{E}-04$ \\
\hline 0.005 & $48.1 \pm 1.99$ & $0.037 \pm 0.002$ & $47.8 \pm 1.96$ & $0.022 \pm 0.001$ & $47.8 \pm 1.64$ & $0.020 \pm 0.001$ \\
\hline 0.01 & $49.2 \pm 1.27$ & $0.073 \pm 0.004$ & $48.1 \pm 1.78$ & $0.045 \pm 0.004$ & $48.8 \pm 0.71$ & $0.039 \pm 0.003$ \\
\hline 0.02 & $48.8 \pm 1.08$ & $0.146 \pm 0.010$ & $47.6 \pm 1.17$ & $0.089 \pm 0.005$ & $47.6 \pm 0.70$ & $0.080 \pm 0.005$ \\
\hline 0.05 & $49.3 \pm 0.65$ & $0.353 \pm 0.032$ & $47.9 \pm 0.45$ & $0.215 \pm 0.010$ & $48.2 \pm 0.72$ & $0.191 \pm 0.006$ \\
\hline 0.1 & $49.4 \pm 0.37$ & $0.693 \pm 0.038$ & $47.9 \pm 0.46$ & $0.433 \pm 0.022$ & $48.5 \pm 1.32$ & $0.365 \pm 0.019$ \\
\hline 0.2 & $49.4 \pm 0.50$ & $1.207 \pm 0.039$ & $48.3 \pm 1.26$ & $0.835 \pm 0.043$ & $48.7 \pm 0.52$ & $0.714 \pm 0.012$ \\
\hline 0.5 & $49.6 \pm 1.84$ & $2.163 \pm 0.097$ & $48.7 \pm 1.13$ & $1.683 \pm 0.043$ & $48.9 \pm 1.20$ & $1.472 \pm 0.068$ \\
\hline 1 & $49.8 \pm 0.56$ & $2.795 \pm 0.062$ & $48.9 \pm 1.04$ & $2.345 \pm 0.064$ & $49.2 \pm 1.06$ & $2.160 \pm 0.055$ \\
\hline 2 & $47.9 \pm 1.56$ & $3.185 \pm 0.056$ & $47.9 \pm 0.97$ & $2.962 \pm 0.063$ & $48.7 \pm 1.33$ & $2.781 \pm 0.020$ \\
\hline 5 & $43.2 \pm 3.03$ & $3.557 \pm 0.035$ & $45.7 \pm 0.91$ & $3.400 \pm 0.063$ & $46.6 \pm 1.97$ & $3.317 \pm 0.025$ \\
\hline 10 & $42.2 \pm 2.23$ & $3.854 \pm 0.089$ & $41.5 \pm 0.83$ & $3.643 \pm 0.062$ & $43.2 \pm 2.24$ & $3.601 \pm 0.043$ \\
\hline 20 & $38.0 \pm 1.13$ & $4.061 \pm 0.087$ & $38.3 \pm 1.50$ & $3.933 \pm 0.115$ & $39.7 \pm 1.35$ & $3.852 \pm 0.029$ \\
\hline 50 & $35.9 \pm 2.00$ & $4.464 \pm 0.064$ & $37.4 \pm 1.61$ & $4.485 \pm 0.053$ & $37.5 \pm 2.32$ & $4.237 \pm 0.078$ \\
\hline 100 & $35.7 \pm 1.44$ & $4.904 \pm 0.021$ & $36.2 \pm 2.42$ & $4.769 \pm 0.130$ & $35.2 \pm 1.44$ & $4.528 \pm 0.021$ \\
\hline 200 & $35.1 \pm 2.18$ & $5.220 \pm 0.095$ & $36.8 \pm 1.47$ & $5.155 \pm 0.091$ & $34.9 \pm 1.86$ & $4.859 \pm 0.034$ \\
\hline 500 & $34.8 \pm 1.02$ & $5.647 \pm 0.132$ & $34.7 \pm 3.23$ & $5.658 \pm 0.065$ & $34.5 \pm 1.80$ & $5.255 \pm 0.074$ \\
\hline 1,000 & $35.6 \pm 2.53$ & $6.069 \pm 0.143$ & $35.5 \pm 1.18$ & $5.966 \pm 0.095$ & $34.7 \pm 1.94$ & $5.587 \pm 0.064$ \\
\hline 2,000 & $35.0 \pm 1.02$ & $6.297 \pm 0.057$ & $35.3 \pm 1.65$ & $6.308 \pm 0.066$ & $34.1 \pm 2.44$ & $5.950 \pm 0.094$ \\
\hline 5,000 & $35.5 \pm 0.83$ & $6.641 \pm 0.113$ & $34.2 \pm 1.81$ & $6.561 \pm 0.079$ & $34.6 \pm 4.77$ & $6.259 \pm 0.158$ \\
\hline 10,000 & $33.8 \pm 3.82$ & $6.755 \pm 0.088$ & $33.0 \pm 3.19$ & $6.709 \pm 0.123$ & $34.6 \pm 1.43$ & $6.456 \pm 0.081$ \\
\hline
\end{tabular}

\begin{tabular}{c|c}
\hline \multicolumn{2}{c}{ Clausius-Clapeyron } \\
\hline $\begin{array}{c}\text { Loading } \\
\text { (mol/kg) }\end{array}$ & $\begin{array}{c}\mathrm{Q}_{\mathrm{st}} \\
(\mathrm{kJ} / \mathrm{mol})\end{array}$ \\
\hline 0.100 & 49.373 \\
0.589 & 49.335 \\
1.078 & 50.241 \\
1.567 & 49.180 \\
2.056 & 49.947 \\
2.544 & 50.218 \\
3.033 & 52.497 \\
3.522 & 49.176 \\
4.011 & 40.545 \\
4.500 & 41.372 \\
\hline
\end{tabular}


Table S8: Tabulated data for Figure 4 in the paper: Heats of adsorption at infinite dilution for $\mathrm{CO}_{2}$ in different cationic and siliceous zeolites.

\begin{tabular}{|c|c|c|c|c|c|c|}
\hline & LTA-4A & $\begin{array}{l}\text { Na-LTA } \\
\text { Si/Al }=2\end{array}$ & $\begin{array}{l}\text { Na-LTA } \\
\text { Si/Al = } 5\end{array}$ & Si-MFI & Si-CHA & ITQ-29 \\
\hline$\frac{\text { Temp. }}{(\mathrm{K})}$ & $\begin{array}{c}\mathrm{Q}_{\mathrm{st}}^{0} \\
(\mathrm{~kJ} / \mathrm{mol})\end{array}$ & $\begin{array}{c}\mathrm{Q}_{\mathrm{st}^{0}}{ }^{0} \\
(\mathrm{~kJ} / \mathrm{mol})\end{array}$ & $\begin{array}{c}\mathrm{Q}_{\mathrm{st}^{0}} \\
(\mathrm{~kJ} / \mathrm{mol})\end{array}$ & $\begin{array}{c}\mathrm{Q}_{\mathrm{st}^{0}}{ }^{0} \\
(\mathrm{~kJ} / \mathrm{mol})\end{array}$ & $\begin{array}{c}\mathrm{Q}_{\mathrm{st}^{0}} \\
(\mathrm{~kJ} / \mathrm{mol})\end{array}$ & $\begin{array}{c}\mathrm{Q}_{\mathrm{st}}{ }^{0} \\
(\mathrm{~kJ} / \mathrm{mol})\end{array}$ \\
\hline 300 & $.9 \pm 1$ & ---- & $.1 \pm 3.66$ & $6.5 \pm 0$ & $3.7 \pm 0$ & $20.6 \pm 0.07$ \\
\hline 303 & ---- & $46.8 \pm 1.20$ & ---- & ---- & $.7 \pm$ & ---- \\
\hline 330 & $.5 \pm 1.76$ & ---- & $44.6 \pm 3.48$ & $26.2 \pm 0.01$ & ---- & $19.5 \pm 0.01$ \\
\hline 333 & ---- & $45.8 \pm 0.39$ & ---- & ---- & $23.3 \pm 0.01$ & ---- \\
\hline 360 & $.7 \pm 2.82$ & ---- & $42.7 \pm 1.40$ & $25.9 \pm 0.01$ & ---- & $18.7 \pm 0.03$ \\
\hline 363 & ---- & ---- & ---- & ---- & $23.1 \pm 0.01$ & ---- \\
\hline 390 & $.5 \pm 1.31$ & ---- & $40.8 \pm 2.83$ & $25.7 \pm 0$ & ---- & $18.2 \pm 0.01$ \\
\hline 393 & ---- & $43.8 \pm 0.28$ & ---- & ---- & $22.9 \pm 0.01$ & ---- \\
\hline 420 & $.5 \pm 1.08$ & ---- & $37.6 \pm 1.80$ & $25.5 \pm 0.01$ & $22.8 \pm 0.01$ & $17.9 \pm 0.02$ \\
\hline 450 & $.9 \pm 1.12$ & ---- & $35.9 \pm 0.87$ & $25.4 \pm 0.01$ & $22.7 \pm 0.01$ & $17.7 \pm 0.01$ \\
\hline 45 & ---- & $41.2 \pm 0.88$ & ---- & ---- & ---- & ---- \\
\hline 4 & $.9 \pm 0$ & ---- & $34.4 \pm 1.89$ & $25.2 \pm 0.01$ & $22.6 \pm 0.01$ & $17.6 \pm 0.01$ \\
\hline 5 & ---- & $39.2 \pm 0.29$ & ---- & ---- & ---- & ---- \\
\hline 5 & $.8 \pm 0.81$ & ---- & $33.1 \pm 0.61$ & $25.2 \pm 0.02$ & $22.5 \pm 0.01$ & $17.6 \pm 0.01$ \\
\hline 5 & $.5 \pm$ & ---- & $31.7 \pm 0.40$ & $25.1 \pm 0.01$ & $22.5 \pm 0.01$ & $17.6 \pm 0.01$ \\
\hline & $37.7 \pm 0.64$ & ---- & $30.6 \pm 0.50$ & $25.1 \pm 0.02$ & $22.5 \pm 0.01$ & $17.7 \pm 0.01$ \\
\hline 600 & $36.8 \pm 0.65$ & $35.6 \pm 0.37$ & $29.7 \pm 0.35$ & $25.1 \pm 0.00$ & $22.6 \pm 0.01$ & $17.7 \pm 0.01$ \\
\hline
\end{tabular}

Experiment

\begin{tabular}{c|c|c|c|c|c|c}
195 & ---- & --- & --- & --- & --- & 27.2 \\
300 & ---- & ---- & --- & --- & --- & 20 \\
333 & 47.5 & ---- & --- & --- & --- & ---- \\
393 & 45 & ---- & --- & --- & --- & 15 \\
453 & 42.5 & ---- & --- & --- & --- & ---- \\
503 & 40 & ---- & ---- & ---- & --- & --- \\
\hline
\end{tabular}


Table S9: Tabulated data for Figure 5 in the paper: Heats of adsorption at infinite dilution for $\mathrm{CH}_{4}$ in different cationic and siliceous zeolites.

\begin{tabular}{|c|c|c|c|c|c|c|}
\hline & LTA-4A & $\begin{array}{l}\text { Na-LTA } \\
\text { Si/Al = } 2 \\
\end{array}$ & $\begin{array}{l}\text { Na-LTA } \\
\mathrm{Si} / \mathrm{Al}=5\end{array}$ & Si-MFI & Si-CHA & ITQ-29 \\
\hline$\frac{\text { Temp. }}{(\mathrm{K})}$ & $\begin{array}{c}\underline{\mathrm{Q}}_{\mathrm{st}}^{{ }^{0}} \\
(\mathrm{~kJ} / \mathrm{mol}) \\
\end{array}$ & $\begin{array}{c}{\underline{\mathrm{Q}_{\mathrm{st}}{ }^{0}}}_{(\mathrm{kJ} / \mathrm{mol})} \\
\end{array}$ & $\begin{array}{c}\underline{\mathrm{Q}}_{\mathrm{st}}^{{ }^{0}} \\
(\mathrm{~kJ} / \mathrm{mol}) \\
\end{array}$ & $\begin{array}{c}{\underline{\mathrm{Q}_{\mathrm{st}}}}^{{ }^{0}} \\
(\mathrm{~kJ} / \mathrm{mol}) \\
\end{array}$ & $\begin{array}{c}{\underline{\mathrm{Q}_{\mathrm{st}}}}^{{ }^{0}} \\
(\mathrm{~kJ} / \mathrm{mol}) \\
\end{array}$ & $\begin{array}{c}\underline{\mathrm{Q}}_{\mathrm{st}^{0}} \\
(\mathrm{~kJ} / \mathrm{mol}) \\
\end{array}$ \\
\hline 170 & ---- & ---- & ---- & ---- & ---- & $13.1 \pm 0.01$ \\
\hline 195 & ---- & ---- & ---- & ---- & ---- & $13.2 \pm 0.01$ \\
\hline 209 & ---- & ---- & ---- & ---- & $16.2 \pm 0.001$ & ---- \\
\hline 243 & ---- & ---- & ---- & ---- & $16.3 \pm 0.002$ & ---- \\
\hline 273 & ---- & ---- & ---- & ---- & $16.4 \pm 0.002$ & ---- \\
\hline 300 & $18.0 \pm 0.01$ & $16.4 \pm 0.03$ & $15.1 \pm 0.02$ & $19.3 \pm 0.004$ & $16.6 \pm 0.002$ & $13.6 \pm 0.002$ \\
\hline 303 & ---- & ---- & ---- & ---- & $16.6 \pm 0.001$ & ---- \\
\hline 333 & ---- & ---- & ---- & ---- & $16.7 \pm 0.002$ & ---- \\
\hline 363 & ---- & ---- & ---- & ---- & $16.9 \pm 0.002$ & ---- \\
\hline 393 & ---- & ---- & ---- & ---- & $17.0 \pm 0.002$ & ---- \\
\hline 450 & $17.8 \pm 0.02$ & $16.4 \pm 0.01$ & $15.2 \pm 0.02$ & $19.8 \pm 0.004$ & $17.3 \pm 0.002$ & $14.5 \pm 0.003$ \\
\hline 600 & $18.3 \pm 0.02$ & $17.0 \pm 0.02$ & $15.9 \pm 0.03$ & $20.4 \pm 0.01$ & $18.2 \pm 0.003$ & $15.4 \pm 0.01$ \\
\hline
\end{tabular}

Table S10: Tabulated data for Figure 6 in paper: Heats of adsorption at infinite dilution for $\mathrm{N}_{2}$ in different cationic and siliceous zeolites.

\begin{tabular}{|c|c|c|c|c|c|c|}
\hline & LTA-4A & $\begin{array}{l}\text { Na-LTA } \\
\mathrm{Si} / \mathrm{Al}=2\end{array}$ & $\begin{array}{l}\text { Na-LTA } \\
\mathrm{Si} / \mathrm{Al}=5\end{array}$ & Si-MFI & Si-CHA & ITQ-29 \\
\hline$\frac{\text { Temp. }}{(\mathrm{K})}$ & 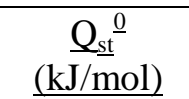 & $\begin{array}{c}\mathrm{Q}_{\mathrm{Qts}^{0}}{ }^{0} \\
(\mathrm{~kJ} / \mathrm{mol})\end{array}$ & $\begin{array}{c}\mathrm{Q}_{\mathrm{Qts}^{0}}{ }^{0} \\
(\mathrm{~kJ} / \mathrm{mol})\end{array}$ & $\begin{array}{c}\mathrm{Q}_{\mathrm{Qst}{ }^{0}} \\
(\mathrm{~kJ} / \mathrm{mol})\end{array}$ & 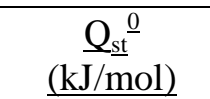 & 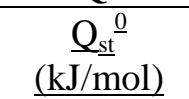 \\
\hline 300 & $17.1 \pm 0.07$ & $15.8 \pm 0.11$ & $15.2 \pm 0.04$ & $16.8 \pm 0.00$ & $14.8 \pm 0.003$ & $12.1 \pm 0.00$ \\
\hline 450 & $15.1 \pm 0.05$ & $14.4 \pm 0.03$ & $13.8 \pm 0.03$ & $17.2 \pm 0.00$ & $15.4 \pm 0.003$ & $12.8 \pm 0.00$ \\
\hline 600 & $14.7 \pm 0.05$ & $14.3 \pm 0.02$ & $14.0 \pm 0.03$ & $17.8 \pm 0.01$ & $16.2 \pm 0.003$ & $13.7 \pm 0.00$ \\
\hline
\end{tabular}

Table S11: Tabulated data for Figure 7 in paper: $\mathrm{CO}_{2}$ positions in Na-LTA with $\mathrm{Si} / \mathrm{Al}=5$.

\begin{tabular}{|c|c|c|c|c|c|c|c|c|c|c|c|}
\hline \multicolumn{6}{|c|}{$300 \mathrm{~K}$} & \multicolumn{6}{|c|}{$450 \mathrm{~K}$} \\
\hline$\frac{\frac{\% \text { of } \mathrm{CO}_{2}}{\text { molecules }}}{\frac{\text { in dual }}{\underline{\text { cation }}}}$ & $\underline{\text { Counts }}$ & $\frac{\frac{\% \text { of } \mathrm{CO}_{2}}{\text { molecules }}}{\frac{\text { in single }}{\frac{\text { cation }}{\text { sites }}}}$ & $\underline{\text { Counts }}$ & $\frac{\frac{\% \text { of } \mathrm{CO}_{2}}{\text { molecules }}}{\frac{\text { with O-Na }}{\underline{\text { distances }}}}$ & $\underline{\text { Counts }}$ & $\frac{\frac{\% \text { of } \mathrm{CO}_{2}}{\text { molecules }}}{\frac{\text { in dual }}{\underline{\text { cation }}}}$ & $\underline{\text { Counts }}$ & $\frac{\frac{\% \text { of } \mathrm{CO}_{2}}{\text { molecules }}}{\frac{\text { in single }}{\underline{\text { cation }}}}$ & $\underline{\text { Counts }}$ & $\frac{\frac{\% \text { of } \mathrm{CO}_{2}}{\text { molecules }}}{\frac{\text { with O-Na }}{\text { distances }}}$ & $\underline{\text { Counts }}$ \\
\hline 0 & 3 & 0 & 203 & 0 & 2246 & 0 & 640 & 0 & 157 & 0 & 1247 \\
\hline 5 & 0 & 5 & 5 & 5 & 361 & 5 & 12 & 5 & 0 & 5 & 16 \\
\hline 10 & 4 & 10 & 470 & 10 & 2775 & 10 & 539 & 10 & 63 & 10 & 772 \\
\hline 15 & 11 & 15 & 589 & 15 & 1868 & 15 & 1219 & 15 & 280 & 15 & 1537 \\
\hline 20 & 54 & 20 & 1093 & 20 & 1458 & 20 & 1329 & 20 & 367 & 20 & 1374 \\
\hline 25 & 113 & 25 & 1230 & 25 & 749 & 25 & 1234 & 25 & 448 & 25 & 1111 \\
\hline 30 & 203 & 30 & 1081 & 30 & 298 & 30 & 990 & 30 & 511 & 30 & 895 \\
\hline 35 & 539 & 35 & 1537 & 35 & 174 & 35 & 1222 & 35 & 874 & 35 & 1029 \\
\hline
\end{tabular}




\begin{tabular}{|c|c|c|c|c|c|c|c|c|c|c|c|}
\hline 40 & 863 & 40 & 1368 & 40 & 56 & 40 & 980 & 40 & 1082 & 40 & 809 \\
\hline 45 & 1287 & 45 & 1064 & 45 & 12 & 45 & 663 & 45 & 1177 & 45 & 471 \\
\hline 50 & 1337 & 50 & 588 & 50 & 2 & 50 & 587 & 50 & 1368 & 50 & 399 \\
\hline 55 & 1519 & 55 & 397 & 55 & 1 & 55 & 210 & 55 & 1008 & 55 & 137 \\
\hline 60 & 1130 & 60 & 187 & 60 & 0 & 60 & 117 & 60 & 588 & 60 & 72 \\
\hline 65 & 1307 & 65 & 129 & 65 & 0 & 65 & 146 & 65 & 957 & 65 & 80 \\
\hline 70 & 526 & 70 & 32 & 70 & 0 & 70 & 23 & 70 & 326 & 70 & 11 \\
\hline 75 & 454 & 75 & 20 & 75 & 0 & 75 & 35 & 75 & 295 & 75 & 17 \\
\hline 80 & 371 & 80 & 4 & 80 & 0 & 80 & 24 & 80 & 215 & 80 & 15 \\
\hline 85 & 122 & 85 & 1 & 85 & 0 & 85 & 10 & 85 & 160 & 85 & 4 \\
\hline 90 & 114 & 90 & 2 & 90 & 0 & 90 & 1 & 90 & 51 & 90 & 1 \\
\hline 95 & 0 & 95 & 0 & 95 & 0 & 95 & 0 & 95 & 0 & 95 & 0 \\
\hline 100 & 43 & 100 & 0 & 100 & 0 & 100 & 19 & 100 & 73 & 100 & 3 \\
\hline \multicolumn{12}{|c|}{$600 \mathrm{~K}$} \\
\hline$\frac{\frac{\% \text { of } \mathrm{CO}_{2}}{\text { molecules }}}{\frac{\text { in dual }}{\text { cation }}}$ & $\underline{\text { Counts }}$ & $\frac{\frac{\% \text { of } \mathrm{CO}_{2}}{\text { molecules }}}{\frac{\text { in single }}{\underline{\text { cation }}}}$ & $\underline{\text { Counts }}$ & $\begin{array}{c}\frac{\text { \% of } \mathrm{CO}_{2}}{\text { molecules }} \\
\frac{\text { with O-Na }}{\text { distances }} \\
\geq 3.5 \AA \\
\end{array}$ & $\underline{\text { Counts }}$ & & & & & & \\
\hline 0 & 1832 & 0 & 58 & 0 & 226 & & & & & & \\
\hline 5 & 242 & 5 & 0 & 5 & 5 & & & & & & \\
\hline 10 & 1978 & 10 & 70 & 10 & 266 & & & & & & \\
\hline 15 & 1874 & 15 & 210 & 15 & 563 & & & & & & \\
\hline 20 & 1610 & 20 & 325 & 20 & 790 & & & & & & \\
\hline 25 & 994 & 25 & 478 & 25 & 1019 & & & & & & \\
\hline 30 & 553 & 30 & 524 & 30 & 953 & & & & & & \\
\hline 35 & 443 & 35 & 901 & 35 & 1356 & & & & & & \\
\hline 40 & 222 & 40 & 1106 & 40 & 1353 & & & & & & \\
\hline 45 & 115 & 45 & 1255 & 45 & 1128 & & & & & & \\
\hline 50 & 100 & 50 & 1274 & 50 & 895 & & & & & & \\
\hline 55 & 15 & 55 & 1118 & 55 & 625 & & & & & & \\
\hline 60 & 9 & 60 & 686 & 60 & 289 & & & & & & \\
\hline 65 & 9 & 65 & 948 & 65 & 303 & & & & & & \\
\hline 70 & 1 & 70 & 381 & 70 & 88 & & & & & & \\
\hline 75 & 2 & 75 & 282 & 75 & 72 & & & & & & \\
\hline 80 & 0 & 80 & 180 & 80 & 34 & & & & & & \\
\hline 85 & 0 & 85 & 96 & 85 & 16 & & & & & & \\
\hline 90 & 0 & 90 & 69 & 90 & 8 & & & & & & \\
\hline 95 & 0 & 95 & 0 & 95 & 0 & & & & & & \\
\hline 100 & 1 & 100 & 39 & 100 & 11 & & & & & & \\
\hline
\end{tabular}


Table S12: Tabulated data for Figure 8 in paper: $\mathrm{CO}_{2}$ positions in Si-MFI.

\begin{tabular}{|c|c|c|c|c|c|c|c|c|c|c|c|}
\hline \multicolumn{4}{|c|}{$300 \mathrm{~K}$} & \multicolumn{4}{|c|}{$450 \mathrm{~K}$} & \multicolumn{4}{|c|}{$600 \mathrm{~K}$} \\
\hline$\frac{\frac{\% \text { of } \mathrm{CO}_{2}}{\text { molecules }}}{\frac{\text { in } 6 \mathrm{MR}}{\underline{\text { sites }}}}$ & Counts & $\frac{\frac{\% \text { of } \mathrm{CO}_{2}}{\text { molecules }}}{\frac{\text { in } 10 \mathrm{MR}}{\underline{\text { sites }}}}$ & $\underline{\text { Counts }}$ & $\frac{\frac{\% \text { of } \mathrm{CO}_{2}}{\text { molecules }}}{\frac{\text { in } 6 \mathrm{MR}}{\underline{\text { sites }}}}$ & $\underline{\text { Counts }}$ & $\frac{\frac{\% \text { of } \mathrm{CO}_{2}}{\text { molecules }}}{\frac{\underline{\text { in } 10 \mathrm{MR}}}{\underline{\text { sites }}}}$ & $\underline{\text { Counts }}$ & $\frac{\frac{\% \text { of } \mathrm{CO}_{2}}{\text { molecules }}}{\frac{\text { in } 6 \mathrm{MR}}{\underline{\text { sites }}}}$ & $\underline{\text { Counts }}$ & $\frac{\frac{\% \text { of } \mathrm{CO}_{2}}{\text { molecules }}}{\frac{\text { in } 10 \mathrm{MR}}{\underline{\text { sites }}}}$ & $\underline{\text { Counts }}$ \\
\hline 0 & 9566 & 0 & 701 & 0 & 9266 & 0 & 387 & 0 & 9233 & 0 & 493 \\
\hline 5 & 56 & 5 & 29 & 5 & 243 & 5 & 65 & 5 & 141 & 5 & 60 \\
\hline 10 & 242 & 10 & 546 & 10 & 381 & 10 & 704 & 10 & 455 & 10 & 734 \\
\hline 15 & 112 & 15 & 1184 & 15 & 97 & 15 & 1053 & 15 & 153 & 15 & 1140 \\
\hline 20 & 18 & 20 & 1309 & 20 & 10 & 20 & 1433 & 20 & 16 & 20 & 1352 \\
\hline 25 & 1 & 25 & 1262 & 25 & 2 & 25 & 1536 & 25 & 2 & 25 & 1361 \\
\hline 30 & 5 & 30 & 904 & 30 & 0 & 30 & 1176 & 30 & 0 & 30 & 1083 \\
\hline 35 & 0 & 35 & 1205 & 35 & 0 & 35 & 1236 & 35 & 0 & 35 & 1251 \\
\hline 40 & 0 & 40 & 947 & 40 & 1 & 40 & 950 & 40 & 0 & 40 & 944 \\
\hline 45 & 0 & 45 & 734 & 45 & 0 & 45 & 674 & 45 & 0 & 45 & 662 \\
\hline 50 & 0 & 50 & 557 & 50 & 0 & 50 & 403 & 50 & 0 & 50 & 475 \\
\hline 55 & 0 & 55 & 237 & 55 & 0 & 55 & 205 & 55 & 0 & 55 & 207 \\
\hline 60 & 0 & 60 & 147 & 60 & 0 & 60 & 65 & 60 & 0 & 60 & 97 \\
\hline 65 & 0 & 65 & 146 & 65 & 0 & 65 & 80 & 65 & 0 & 65 & 95 \\
\hline 70 & 0 & 70 & 35 & 70 & 0 & 70 & 11 & 70 & 0 & 70 & 14 \\
\hline 75 & 0 & 75 & 23 & 75 & 0 & 75 & 8 & 75 & 0 & 75 & 15 \\
\hline 80 & 0 & 80 & 11 & 80 & 0 & 80 & 10 & 80 & 0 & 80 & 8 \\
\hline 85 & 0 & 85 & 10 & 85 & 0 & 85 & 2 & 85 & 0 & 85 & 5 \\
\hline 90 & 0 & 90 & 1 & 90 & 0 & 90 & 0 & 90 & 0 & 90 & 0 \\
\hline 95 & 0 & 95 & 0 & 95 & 0 & 95 & 0 & 95 & 0 & 95 & 0 \\
\hline 100 & 0 & 100 & 12 & 100 & 0 & 100 & 2 & 100 & 0 & 100 & 4 \\
\hline
\end{tabular}


Table S13: Tabulated data for Figure S1: Comparison of literature force fields with CCFF used in this study and experimental data obtained by calorimetric experiments during this study. The $\sigma$ value in the table refers to the $\sigma$ for the oxygen atoms in the zeolite in each force field.

\begin{tabular}{|c|c|c|c|c|c|c|c|c|c|c|c|}
\hline \multirow[b]{2}{*}{$\frac{\text { Pressure }}{(\mathrm{kPa})}$} & \multicolumn{11}{|c|}{ Loading (mol/kg) } \\
\hline & $\begin{array}{c}\sigma= \\
3.101\end{array}$ & $\begin{array}{c}\sigma= \\
3\end{array}$ & $\begin{array}{c}\sigma= \\
3.04\end{array}$ & $\begin{array}{l}\sigma= \\
3.6\end{array}$ & $\begin{array}{c}\sigma= \\
2.789\end{array}$ & $\begin{array}{c}\sigma= \\
3.001\end{array}$ & $\begin{array}{c}\sigma= \\
2.806\end{array}$ & $\begin{array}{c}\sigma= \\
3.011\end{array}$ & $\begin{array}{c}\sigma= \\
3.5532\end{array}$ & $\begin{array}{c}\sigma= \\
3.34\end{array}$ & $\begin{array}{c}\sigma= \\
3.265\end{array}$ \\
\hline 0.001 & 0.002 & 3.47E-06 & 4.126 & 0.018 & 0.002 & 0.001 & 0.002 & 0.001 & 0.003 & 0.001 & 0.002 \\
\hline 0.002 & 0.003 & $2.60 \mathrm{E}-06$ & 4.989 & 0.037 & 0.004 & 0.002 & 0.003 & 0.002 & 0.006 & 0.001 & 0.005 \\
\hline 0.005 & 0.008 & 6.07E-06 & 5.582 & 0.093 & 0.010 & 0.005 & 0.008 & 0.006 & 0.015 & 0.003 & 0.012 \\
\hline 0.01 & 0.016 & 2.17E-05 & 5.895 & 0.192 & 0.019 & 0.011 & 0.015 & 0.012 & 0.030 & 0.006 & 0.024 \\
\hline 0.02 & 0.031 & 5.46E-05 & 6.054 & 0.402 & 0.038 & 0.021 & 0.030 & 0.023 & 0.057 & 0.011 & 0.050 \\
\hline 0.05 & 0.078 & $1.27 \mathrm{E}-04$ & 6.157 & 1.049 & 0.097 & 0.055 & 0.073 & 0.060 & 0.139 & 0.029 & 0.126 \\
\hline 0.1 & 0.153 & 2.61E-04 & 6.212 & 1.828 & 0.184 & 0.115 & 0.145 & 0.119 & 0.283 & 0.055 & 0.245 \\
\hline 0.2 & 0.299 & 0.001 & 6.216 & 2.617 & 0.345 & 0.253 & 0.276 & 0.241 & 0.525 & 0.113 & 0.481 \\
\hline 0.5 & 0.776 & 0.001 & 6.278 & 3.487 & 0.767 & 0.881 & 0.641 & 0.670 & 1.336 & 0.298 & 1.410 \\
\hline 1 & 1.997 & 0.003 & 6.239 & 3.864 & 1.446 & 2.535 & 1.234 & 2.255 & 4.157 & 0.776 & 4.935 \\
\hline 2 & 5.411 & 0.005 & 6.240 & 4.033 & 3.581 & 4.104 & 3.211 & 5.915 & 5.785 & 4.965 & 5.900 \\
\hline 5 & 6.249 & 0.013 & 6.270 & 4.121 & 6.060 & 4.947 & 6.028 & 6.648 & 6.352 & 6.135 & 6.358 \\
\hline 10 & 6.555 & 0.027 & 6.473 & 4.140 & 6.572 & 5.479 & 6.567 & 6.936 & 6.616 & 6.455 & 6.551 \\
\hline 20 & 6.758 & 0.055 & 6.551 & 4.149 & 6.891 & 5.997 & 6.889 & 7.172 & 6.805 & 6.657 & 6.709 \\
\hline 50 & 6.989 & 0.147 & 6.571 & 4.155 & 7.192 & 6.423 & 7.179 & 7.400 & 7.021 & 6.911 & 6.922 \\
\hline 100 & 7.192 & 0.346 & 6.503 & 4.158 & 7.345 & 6.803 & 7.379 & 7.486 & 7.113 & 7.025 & 6.973 \\
\hline 200 & 7.287 & 0.975 & 6.431 & 4.160 & 7.481 & 6.950 & 7.483 & 7.546 & 7.283 & 7.103 & 7.121 \\
\hline 500 & 7.309 & 0.963 & 6.436 & 4.160 & 7.493 & 6.886 & 7.474 & 7.574 & 7.312 & 7.155 & 7.082 \\
\hline 1,000 & 7.268 & 1.001 & 6.444 & 4.160 & 7.466 & 7.002 & 7.484 & 7.562 & 7.248 & 7.127 & 7.177 \\
\hline 2,000 & 7.318 & 1.058 & 6.510 & 4.160 & 7.495 & 6.991 & 7.482 & 7.581 & 7.284 & 7.140 & 7.178 \\
\hline 5,000 & 7.319 & 1.250 & 6.536 & 4.160 & 7.473 & 7.025 & 7.498 & 7.579 & 7.293 & 7.165 & 7.149 \\
\hline 10,000 & 7.340 & 1.684 & 6.738 & 4.159 & 7.496 & 7.008 & 7.508 & 7.578 & 7.270 & 7.210 & 7.179 \\
\hline \multicolumn{12}{|c|}{ Experiment } \\
\hline $\begin{array}{c}\text { Pressure } \\
(\mathrm{kPa})\end{array}$ & $\begin{array}{l}\text { Loading } \\
\text { (mol/kg) }\end{array}$ & & $\begin{array}{c}\text { Pressure } \\
(\mathrm{kPa})\end{array}$ & $\begin{array}{l}\begin{array}{l}\text { Loading } \\
(\mathrm{mol} / \mathrm{kg})\end{array} \\
\end{array}$ & & & & & & & \\
\hline 0.02 & 0.047 & & 0.01 & 0.022 & & & & & & & \\
\hline 0.14 & 0.267 & & 0.02 & 0.044 & & & & & & & \\
\hline 0.41 & 0.634 & & 0.05 & 0.115 & & & & & & & \\
\hline 0.62 & 1.012 & & 0.09 & 0.188 & & & & & & & \\
\hline 0.79 & 1.400 & & 0.14 & 0.260 & & & & & & & \\
\hline 0.91 & 1.795 & & 0.29 & 0.474 & & & & & & & \\
\hline 1.01 & 2.193 & & 0.41 & 0.639 & & & & & & & \\
\hline 1.09 & 2.592 & & 0.52 & 0.809 & & & & & & & \\
\hline 1.46 & 4.175 & & 0.62 & 0.984 & & & & & & & \\
\hline 2.83 & 5.522 & & 0.70 & 1.162 & & & & & & & \\
\hline 7.74 & 6.188 & & 0.78 & 1.342 & & & & & & & \\
\hline 14.66 & 6.472 & & 0.84 & 1.524 & & & & & & & \\
\hline 26.11 & 6.694 & & 0.89 & 1.708 & & & & & & & \\
\hline
\end{tabular}




\begin{tabular}{cccc}
38.01 & 6.829 & 0.94 & 1.894 \\
50.07 & 6.930 & 0.97 & 2.080 \\
62.24 & 7.008 & 1.01 & 2.266 \\
74.49 & 7.070 & 1.04 & 2.452 \\
86.77 & 7.127 & 1.11 & 2.826 \\
96.80 & 7.161 & 1.18 & 3.198 \\
101.26 & 7.197 & 1.25 & 3.567 \\
& & 1.34 & 3.931 \\
& & 1.45 & 4.288 \\
& & 1.60 & 4.634 \\
& & 1.83 & 4.964 \\
& & 2.21 & 5.268 \\
& & 2.79 & 5.535 \\
& & 3.64 & 5.756 \\
& & 4.75 & 5.933 \\
& & 6.08 & 6.072 \\
& & 7.57 & 6.181 \\
& & 9.17 & 6.270 \\
& & 10.86 & 6.344 \\
& & 22.00 & 6.606 \\
& & 33.77 & 6.744 \\
\hline
\end{tabular}


Table S14: Tabulated for Figure S2: Difference between literature force fields and CCFF used in this study. The $\sigma$ value in the table refers to the $\sigma$ for the oxygen atoms in the zeolite in each force field.

\begin{tabular}{|c|c|c|c|c|c|c|c|c|c|c|c|}
\hline \multirow{2}{*}{$\frac{\text { Pressure }}{(\mathrm{kPa})}$} & \multicolumn{11}{|c|}{ Difference between loading from literature force fields and CCFF (mol/kg) } \\
\hline & $\begin{array}{c}\sigma= \\
3.101\end{array}$ & $\begin{array}{c}\sigma= \\
3\end{array}$ & $\begin{array}{c}\sigma= \\
3.04\end{array}$ & $\begin{array}{l}\sigma= \\
3.6\end{array}$ & $\begin{array}{c}\sigma= \\
2.789\end{array}$ & $\begin{array}{c}\sigma= \\
3.001\end{array}$ & $\begin{array}{c}\sigma= \\
2.806\end{array}$ & $\begin{array}{c}\sigma= \\
3.011\end{array}$ & $\begin{array}{c}\sigma= \\
3.5532\end{array}$ & $\begin{array}{c}\sigma= \\
3.34\end{array}$ & $\begin{array}{c}\sigma= \\
3.265\end{array}$ \\
\hline 0.001 & 0.000 & -0.002 & 4.124 & 0.017 & $4.80 \mathrm{E}-04$ & $-4.50 \mathrm{E}-04$ & $-4.00 \mathrm{E}-05$ & $-4.00 \mathrm{E}-04$ & 0.001 & $-9.85 E-04$ & $9.20 \mathrm{E}-04$ \\
\hline 0.002 & 0.000 & -0.003 & 4.986 & 0.034 & $9.70 \mathrm{E}-04$ & $-8.70 \mathrm{E}-04$ & $7.00 \mathrm{E}-05$ & $-7.60 \mathrm{E}-04$ & 0.003 & -0.002 & 0.002 \\
\hline 0.005 & 0.000 & -0.008 & 5.575 & 0.086 & 0.002 & -0.002 & $2.80 \mathrm{E}-04$ & -0.002 & 0.007 & -0.005 & 0.005 \\
\hline 0.01 & 0.000 & -0.016 & 5.879 & 0.176 & 0.003 & -0.005 & $-9.80 \mathrm{E}-04$ & -0.004 & 0.014 & -0.010 & 0.008 \\
\hline 0.02 & 0.000 & -0.030 & 6.023 & 0.371 & 0.008 & -0.009 & $-3.20 \mathrm{E}-04$ & -0.007 & 0.026 & -0.019 & 0.019 \\
\hline 0.05 & 0.000 & -0.078 & 6.079 & 0.972 & 0.019 & -0.022 & -0.005 & -0.018 & 0.061 & -0.049 & 0.048 \\
\hline 0.1 & 0.000 & -0.153 & 6.059 & 1.674 & 0.031 & -0.038 & -0.008 & -0.035 & 0.129 & -0.098 & 0.092 \\
\hline 0.2 & 0.000 & -0.299 & 5.917 & 2.318 & 0.046 & -0.046 & -0.023 & -0.058 & 0.226 & -0.187 & 0.182 \\
\hline 0.5 & 0.000 & -0.775 & 5.502 & 2.711 & -0.010 & 0.105 & -0.135 & -0.106 & 0.560 & -0.478 & 0.634 \\
\hline 1 & 0.000 & -1.995 & 4.242 & 1.867 & -0.552 & 0.538 & -0.763 & 0.257 & 2.160 & -1.221 & 2.938 \\
\hline 2 & 0.000 & -5.406 & 0.829 & -1.379 & -1.830 & -1.307 & -2.200 & 0.504 & 0.374 & -0.446 & 0.489 \\
\hline 5 & 0.000 & -6.236 & 0.020 & -2.129 & -0.189 & -1.302 & -0.222 & 0.398 & 0.102 & -0.114 & 0.108 \\
\hline 10 & 0.000 & -6.528 & -0.082 & -2.415 & 0.017 & -1.076 & 0.011 & 0.381 & 0.061 & -0.100 & -0.004 \\
\hline 20 & 0.000 & -6.704 & -0.207 & -2.610 & 0.132 & -0.762 & 0.130 & 0.414 & 0.047 & -0.101 & -0.049 \\
\hline 50 & 0.000 & -6.842 & -0.418 & -2.834 & 0.203 & -0.566 & 0.190 & 0.411 & 0.032 & -0.078 & -0.067 \\
\hline 100 & 0.000 & -6.846 & -0.689 & -3.034 & 0.153 & -0.389 & 0.187 & 0.294 & -0.079 & -0.167 & -0.219 \\
\hline 200 & 0.000 & -6.312 & -0.857 & -3.128 & 0.194 & -0.337 & 0.196 & 0.259 & -0.005 & -0.184 & -0.166 \\
\hline 500 & 0.000 & -6.346 & -0.873 & -3.149 & 0.184 & -0.423 & 0.166 & 0.266 & 0.003 & -0.153 & -0.227 \\
\hline 1,000 & 0.000 & -6.267 & -0.824 & -3.108 & 0.198 & -0.266 & 0.216 & 0.294 & -0.021 & -0.141 & -0.091 \\
\hline 2,000 & 0.000 & -6.260 & -0.807 & -3.158 & 0.177 & -0.327 & 0.164 & 0.263 & -0.034 & -0.178 & -0.140 \\
\hline 5,000 & 0.000 & -6.070 & -0.783 & -3.159 & 0.154 & -0.294 & 0.179 & 0.260 & -0.026 & -0.154 & -0.171 \\
\hline 10,000 & 0.000 & -5.656 & -0.602 & -3.181 & 0.156 & -0.332 & 0.167 & 0.237 & -0.070 & -0.130 & -0.161 \\
\hline
\end{tabular}


Table S15: Comparison of simulated (CCFF) and experimental adsorption isotherms and heats of adsorption of $\mathrm{CH}_{4}$ in (a and b) LTA-4A, (c and d) Na-LTA with Si/Al = 2, and (e and f) NaLTA with $\mathrm{Si} / \mathrm{Al}=5$. The experimental data are from Harper et al., ${ }^{21} \mathrm{Li}$ et al., ${ }^{22}$ Ahmed et al., ${ }^{23}$ Eagan et al., ${ }^{24}$ Jensen et al., ${ }^{25}$ and Palomino et al. ${ }^{26}$

\begin{tabular}{|c|c|c|c|c|c|c|c|}
\hline \multicolumn{8}{|c|}{$\mathrm{CH}_{4}$ in LTA-4A } \\
\hline \multicolumn{2}{|c|}{$\begin{array}{c}\text { CCFF } \\
(303 \mathrm{~K})\end{array}$} & \multicolumn{2}{|c|}{$\begin{array}{c}\text { Exp. Harper } \\
\text { (303 K) }\end{array}$} & \multicolumn{2}{|c|}{$\begin{array}{l}\text { Exp. Li } \\
(301 \mathrm{~K})\end{array}$} & \multicolumn{2}{|c|}{$\begin{array}{l}\text { Exp. Ahmed } \\
\text { (301 K) }\end{array}$} \\
\hline $\begin{array}{c}\begin{array}{c}\text { Pressure } \\
(\mathrm{kPa})\end{array} \\
\end{array}$ & $\begin{array}{l}\text { Loading } \\
\text { (mol/kg) }\end{array}$ & $\begin{array}{c}\text { Pressure } \\
(\mathrm{kPa})\end{array}$ & $\begin{array}{l}\text { Loading } \\
\text { (mol/kg) }\end{array}$ & $\begin{array}{c}\text { Pressure } \\
(\mathrm{kPa})\end{array}$ & $\begin{array}{l}\text { Loading } \\
\text { (mol/kg) }\end{array}$ & $\begin{array}{c}\text { Pressure } \\
(\mathrm{kPa})\end{array}$ & $\begin{array}{l}\text { Loading } \\
\text { (mol/kg) }\end{array}$ \\
\hline 0.001 & $1.10 \mathrm{E}-05$ & 24.938 & 0.175 & 7.229 & 0.092 & 33.290 & 0.314 \\
\hline 0.005 & 2.49E-05 & 50.055 & 0.347 & 15.663 & 0.164 & 59.119 & 0.483 \\
\hline 0.01 & 7.63E-05 & 73.992 & 0.484 & 26.305 & 0.261 & 92.983 & 0.632 \\
\hline 0.05 & $3.11 \mathrm{E}-04$ & 98.775 & 0.657 & 38.956 & 0.381 & 123.404 & 0.726 \\
\hline 0.1 & 0.001 & & & 57.831 & 0.483 & 154.972 & 0.801 \\
\hline 0.5 & 0.003 & & & 88.353 & 0.656 & 188.263 & 0.845 \\
\hline 1 & 0.007 & & & & & 211.221 & 0.861 \\
\hline 5 & 0.033 & & & & & & \\
\hline 10 & 0.065 & & & & & & \\
\hline 20 & 0.129 & & & & & & \\
\hline 40 & 0.253 & & & & & & \\
\hline 60 & 0.371 & & & & & & \\
\hline 80 & 0.485 & & & & & & \\
\hline 100 & 0.594 & & & & & & \\
\hline 200 & 1.061 & & & & & & \\
\hline 300 & 1.418 & & & & & & \\
\hline 400 & 1.706 & & & & & & \\
\hline 500 & 1.929 & & & & & & \\
\hline 800 & 2.399 & & & & & & \\
\hline 1000 & 2.605 & & & & & & \\
\hline
\end{tabular}

\begin{tabular}{|c|c|c|c|c|c|c|c|}
\hline \multicolumn{8}{|c|}{$\mathrm{CH}_{4}$ in LTA-4A } \\
\hline \multicolumn{2}{|c|}{$\begin{array}{c}\text { CCFF } \\
(303 \mathrm{~K})\end{array}$} & \multicolumn{2}{|c|}{$\begin{array}{c}\text { Exp. Harper } \\
(303 \mathrm{~K})\end{array}$} & \multicolumn{2}{|c|}{$\begin{array}{c}\text { Exp. Eagan } \\
(253-273 \mathrm{~K})\end{array}$} & \multicolumn{2}{|c|}{$\begin{array}{c}\text { Exp. Jensen } \\
(248-302 \mathrm{~K})\end{array}$} \\
\hline $\begin{array}{l}\text { Loading } \\
\text { (mol/kg) }\end{array}$ & $\begin{array}{c}\mathrm{Q}_{\mathrm{st}} \\
(\mathrm{kJ} / \mathrm{mol})\end{array}$ & $\begin{array}{l}\text { Loading } \\
\text { (mol/kg) }\end{array}$ & $\begin{array}{c}\mathrm{Q}_{\mathrm{st}} \\
(\mathrm{kJ} / \mathrm{mol})\end{array}$ & $\begin{array}{l}\text { Loading } \\
\text { (mol/kg) }\end{array}$ & $\begin{array}{c}\mathrm{Q}_{\mathrm{st}} \\
(\mathrm{kJ} / \mathrm{mol})\end{array}$ & $\begin{array}{l}\text { Loading } \\
\text { (mol/kg) }\end{array}$ & $\begin{array}{c}\mathrm{Q}_{\mathrm{st}} \\
(\mathrm{kJ} / \mathrm{mol})\end{array}$ \\
\hline 0.003 & $18.206 \pm 2.413$ & 0.223 & 16.736 & 0.201 & 20.200 & 0.066 & 17.570 \\
\hline 0.033 & $18.417 \pm 0.509$ & 0.446 & 16.318 & 0.452 & 20.200 & 0.182 & 18.318 \\
\hline 0.065 & $18.491 \pm 0.205$ & 1.339 & 14.853 & 0.648 & 19.850 & 0.284 & 18.505 \\
\hline 0.129 & $18.655 \pm 0.481$ & 2.232 & 14.016 & 0.884 & 20.200 & 0.393 & 19.065 \\
\hline 0.253 & $18.769 \pm 0.187$ & & & 1.094 & 19.499 & 0.503 & 19.252 \\
\hline 0.371 & $18.783 \pm 0.254$ & & & 1.332 & 19.266 & & \\
\hline 0.485 & $19.042 \pm 0.101$ & & & 1.555 & 19.032 & & \\
\hline 0.594 & $19.111 \pm 0.218$ & & & 1.779 & 19.032 & & \\
\hline 1.061 & $19.661 \pm 0.116$ & & & 2.002 & 18.565 & & \\
\hline 1.418 & $20.076 \pm 0.227$ & & & 2.225 & 18.565 & & \\
\hline 1.706 & $20.303 \pm 0.407$ & & & & & & \\
\hline 1.929 & $20.619 \pm 0.221$ & & & & & & \\
\hline 2.399 & $21.066 \pm 0.203$ & & & & & & \\
\hline 2.605 & $21.248 \pm 0.201$ & & & & & & \\
\hline
\end{tabular}




\begin{tabular}{|c|c|c|c|c|c|c|c|}
\hline \multicolumn{8}{|c|}{$\mathrm{CH}_{4}$ in Na-LTA $(\mathrm{Si} / \mathrm{Al}=2)$} \\
\hline \multicolumn{2}{|c|}{$\begin{array}{c}\text { CCFF } \\
(303 \mathrm{~K})\end{array}$} & \multicolumn{2}{|c|}{$\begin{array}{l}\text { Exp. Palomino } \\
(303 \mathrm{~K})\end{array}$} & \multicolumn{2}{|c|}{$\begin{array}{c}\text { CCFF } \\
(303 \mathrm{~K})\end{array}$} & \multicolumn{2}{|c|}{$\begin{array}{c}\text { Exp. Palomino } \\
(273-303 \mathrm{~K})\end{array}$} \\
\hline $\begin{array}{l}\text { Pressure } \\
(\mathrm{kPa})\end{array}$ & $\begin{array}{l}\text { Loading } \\
\text { (mol/kg) }\end{array}$ & $\begin{array}{l}\text { Pressure } \\
(\mathrm{kPa})\end{array}$ & $\begin{array}{l}\text { Loading } \\
\text { (mol/kg) }\end{array}$ & $\begin{array}{l}\text { Loading } \\
\text { (mol/kg) }\end{array}$ & $\begin{array}{c}\mathrm{Q}_{\mathrm{st}} \\
(\mathrm{kJ} / \mathrm{mol})\end{array}$ & $\begin{array}{l}\text { Loading } \\
\text { (mol/kg) }\end{array}$ & $\begin{array}{c}\mathrm{Q}_{\mathrm{st}} \\
(\mathrm{kJ} / \mathrm{mol})\end{array}$ \\
\hline 0.001 & 4.64E-06 & 2.626 & 0.033 & 0.002 & $17.238 \pm 1.848$ & 0.002 & 15.252 \\
\hline 0.005 & 2.71E-05 & 5.033 & 0.044 & 0.023 & $17.228 \pm 0.486$ & 0.017 & 15.957 \\
\hline 0.01 & 4.79E-05 & 7.221 & 0.054 & 0.046 & $17.327 \pm 0.503$ & 0.031 & 16.459 \\
\hline 0.05 & 2.12E-04 & 9.190 & 0.064 & 0.091 & $17.248 \pm 0.359$ & 0.046 & 16.861 \\
\hline 0.1 & 4.50E-04 & 10.722 & 0.071 & 0.180 & $17.286 \pm 0.136$ & 0.064 & 16.959 \\
\hline 0.5 & 0.002 & 12.254 & 0.078 & 0.265 & $17.203 \pm 0.245$ & 0.086 & 17.157 \\
\hline 1 & 0.005 & 14.442 & 0.089 & 0.349 & $17.459 \pm 0.130$ & 0.104 & 17.457 \\
\hline 5 & 0.023 & 16.193 & 0.097 & 0.428 & $17.365 \pm 0.086$ & 0.127 & 17.756 \\
\hline 10 & 0.046 & 17.505 & 0.103 & 0.793 & $17.776 \pm 0.362$ & 0.149 & 17.955 \\
\hline 20 & 0.091 & 18.818 & 0.110 & 1.099 & $18.072 \pm 0.183$ & 0.171 & 18.153 \\
\hline 40 & 0.180 & 20.350 & 0.117 & 1.357 & $18.314 \pm 0.238$ & 0.192 & 18.251 \\
\hline 60 & 0.265 & 22.538 & 0.127 & 1.574 & $18.475 \pm 0.157$ & 0.209 & 18.349 \\
\hline 80 & 0.349 & 25.383 & 0.141 & & & 0.225 & 18.548 \\
\hline 100 & 0.428 & 28.009 & 0.153 & & & 0.245 & 18.747 \\
\hline 200 & 0.793 & 30.635 & 0.166 & & & 0.263 & 18.845 \\
\hline 300 & 1.099 & 33.479 & 0.179 & & & 0.285 & 19.043 \\
\hline 400 & 1.357 & 36.105 & 0.192 & & & 0.303 & 19.242 \\
\hline \multirow[t]{10}{*}{500} & 1.574 & 38.512 & 0.203 & & & 0.323 & 19.340 \\
\hline & & 41.138 & 0.216 & & & 0.339 & 19.539 \\
\hline & & 44.639 & 0.232 & & & 0.359 & 19.839 \\
\hline & & 46.827 & 0.243 & & & 0.376 & 19.937 \\
\hline & & 53.173 & 0.273 & & & 0.394 & 20.035 \\
\hline & & 60.394 & 0.307 & & & 0.412 & 20.335 \\
\hline & & 66.740 & 0.337 & & & 0.431 & 20.433 \\
\hline & & 98.468 & 0.488 & & & 0.449 & 20.530 \\
\hline & & 100.438 & 0.497 & & & 0.466 & 20.629 \\
\hline & & & & & & 0.481 & 20.626 \\
\hline \multicolumn{8}{|c|}{$\mathrm{CH}_{4}$ in Na-LTA $(\mathrm{Si} / \mathrm{Al}=5)$} \\
\hline \multicolumn{2}{|c|}{$\begin{array}{c}\text { CCFF } \\
(303 \mathrm{~K})\end{array}$} & \multicolumn{2}{|c|}{$\begin{array}{c}\text { Exp. Palomino } \\
(303 \mathrm{~K})\end{array}$} & \multicolumn{2}{|c|}{$\begin{array}{c}\text { CCFF } \\
(303 \mathrm{~K})\end{array}$} & \multicolumn{2}{|c|}{$\begin{array}{c}\text { Exp. Palomino } \\
(273-303 \mathrm{~K})\end{array}$} \\
\hline $\begin{array}{c}\text { Pressure } \\
(\mathrm{kPa})\end{array}$ & $\begin{array}{l}\text { Loading } \\
\text { (mol/kg) }\end{array}$ & $\begin{array}{c}\text { Pressure } \\
(\mathrm{kPa})\end{array}$ & $\begin{array}{l}\text { Loading } \\
\text { (mol/kg) }\end{array}$ & $\begin{array}{l}\text { Loading } \\
\text { (mol/kg) }\end{array}$ & $\begin{array}{c}\mathrm{Q}_{\mathrm{st}} \\
(\mathrm{kJ} / \mathrm{mol})\end{array}$ & $\begin{array}{l}\text { Loading } \\
\text { (mol } / \mathrm{kg})\end{array}$ & $\begin{array}{c}\mathrm{Q}_{\mathrm{st}} \\
(\mathrm{kJ} / \mathrm{mol})\end{array}$ \\
\hline 0.001 & $4.90 \mathrm{E}-06$ & 2.626 & 0.009 & $3.31 \mathrm{E}-04$ & $15.178 \pm 2.664$ & 0.010 & 16.867 \\
\hline 0.005 & $1.63 \mathrm{E}-05$ & 5.033 & 0.017 & 0.002 & $15.952 \pm 2.161$ & 0.029 & 16.965 \\
\hline 0.01 & $2.29 E-05$ & 7.221 & 0.024 & 0.003 & $15.721 \pm 1.007$ & 0.052 & 16.961 \\
\hline 0.05 & $1.63 \mathrm{E}-04$ & 9.190 & 0.031 & 0.016 & $15.776 \pm 0.076$ & 0.072 & 16.857 \\
\hline 0.1 & 3.31E-04 & 10.722 & 0.036 & 0.032 & $15.701 \pm 0.255$ & 0.092 & 16.954 \\
\hline 0.5 & 0.002 & 12.254 & 0.041 & 0.064 & $15.591 \pm 0.284$ & 0.110 & 16.951 \\
\hline 1 & 0.003 & 14.442 & 0.048 & 0.127 & $15.600 \pm 0.192$ & 0.133 & 16.745 \\
\hline 5 & 0.016 & 16.193 & 0.054 & 0.189 & $15.800 \pm 0.108$ & 0.152 & 16.641 \\
\hline 10 & 0.032 & 17.505 & 0.059 & 0.249 & $15.838 \pm 0.111$ & 0.172 & 16.638 \\
\hline 20 & 0.064 & 18.818 & 0.063 & 0.306 & $15.869 \pm 0.216$ & 0.195 & 16.634 \\
\hline 40 & 0.127 & 19.915 & 0.067 & 0.582 & $16.053 \pm 0.215$ & 0.212 & 16.631 \\
\hline 60 & 0.189 & 21.228 & 0.071 & 0.832 & $16.292 \pm 0.123$ & 0.231 & 16.729 \\
\hline 80 & 0.249 & 22.760 & 0.076 & 1.053 & $16.500 \pm 0.126$ & 0.253 & 16.624 \\
\hline
\end{tabular}




\begin{tabular}{|c|c|c|c|c|c|c|c|}
\hline 100 & 0.306 & 25.386 & 0.085 & \multirow[t]{17}{*}{1.251} & \multirow[t]{17}{*}{$16.629 \pm 0.151$} & 0.269 & 16.722 \\
\hline 200 & 0.582 & 28.012 & 0.094 & & & 0.288 & 16.719 \\
\hline 300 & 0.832 & 30.857 & 0.103 & & & 0.306 & 16.716 \\
\hline 400 & 1.053 & 33.265 & 0.111 & & & 0.323 & 16.713 \\
\hline \multirow[t]{13}{*}{500} & 1.251 & 36.110 & 0.121 & & & 0.345 & 16.710 \\
\hline & & 38.736 & 0.130 & & & 0.364 & 16.605 \\
\hline & & 41.581 & 0.139 & & & 0.386 & 16.703 \\
\hline & & 43.988 & 0.147 & & & 0.408 & 16.901 \\
\hline & & 46.834 & 0.157 & & & 0.426 & 16.797 \\
\hline & & 53.399 & 0.179 & & & 0.450 & 16.692 \\
\hline & & 59.964 & 0.200 & & & & \\
\hline & & 66.748 & 0.223 & & & & \\
\hline & & 73.313 & 0.245 & & & & \\
\hline & & 80.098 & 0.268 & & & & \\
\hline & & 86.663 & 0.290 & & & & \\
\hline & & 93.447 & 0.312 & & & & \\
\hline & & 100.231 & 0.335 & & & & \\
\hline
\end{tabular}


Table S16: Tabulated data for Figure S5: Comparison of GCMC simulations using the ITQ-29 crystal structure, and an average unit cell structure obtained from MD simulations at the temperature with experimental data from calorimetric experiments obtained during this study.

\begin{tabular}{|c|c|c|c|c|c|c|}
\hline & $\begin{array}{l}195 \text { K - Crystal } \\
\text { Structure }\end{array}$ & $\begin{array}{c}195 \text { K - Avg. MD } \\
\text { Structure }\end{array}$ & \multicolumn{2}{|c|}{195 K - Exp. 1} & \multicolumn{2}{|c|}{195 K - Exp. 2} \\
\hline$\frac{\text { Pressure }}{(\mathrm{kPa})}$ & $\begin{array}{l}\text { Loading } \\
\text { (mol/kg) }\end{array}$ & $\begin{array}{l}\text { Loading } \\
\text { (mol/kg) }\end{array}$ & $\frac{\text { Pressure }}{(\mathrm{kPa})}$ & $\begin{array}{l}\text { Loading } \\
\text { (mol/kg) }\end{array}$ & $\frac{\text { Pressure }}{(\mathrm{kPa})}$ & $\begin{array}{l}\text { Loading } \\
\text { (mol/kg) }\end{array}$ \\
\hline 0.001 & 0.001 & 0.001 & 0.02 & 0.047 & 0.01 & 0.022 \\
\hline 0.002 & 0.002 & 0.003 & 0.14 & 0.267 & 0.02 & 0.044 \\
\hline 0.005 & 0.005 & 0.007 & 0.41 & 0.634 & 0.05 & 0.115 \\
\hline 0.01 & 0.009 & 0.014 & 0.62 & 1.012 & 0.09 & 0.188 \\
\hline 0.02 & 0.019 & 0.029 & 0.79 & 1.400 & 0.14 & 0.260 \\
\hline 0.05 & 0.047 & 0.070 & 0.91 & 1.795 & 0.29 & 0.474 \\
\hline 0.1 & 0.094 & 0.137 & 1.01 & 2.193 & 0.41 & 0.639 \\
\hline 0.2 & 0.191 & 0.269 & 1.09 & 2.592 & 0.52 & 0.809 \\
\hline 0.5 & 0.507 & 0.661 & 1.46 & 4.175 & 0.62 & 0.984 \\
\hline 1 & 1.256 & 1.584 & 2.83 & 5.522 & 0.70 & 1.162 \\
\hline 2 & 5.111 & 5.183 & 7.74 & 6.188 & 0.78 & 1.342 \\
\hline 5 & 6.127 & 6.233 & 14.66 & 6.472 & 0.84 & 1.524 \\
\hline 10 & 6.419 & 6.558 & 26.11 & 6.694 & 0.89 & 1.708 \\
\hline 20 & 6.634 & 6.798 & 38.01 & 6.829 & 0.94 & 1.894 \\
\hline 50 & 6.867 & 7.056 & 50.07 & 6.930 & 0.97 & 2.080 \\
\hline 100 & 7.023 & 7.216 & 62.24 & 7.008 & 1.01 & 2.266 \\
\hline 200 & 7.100 & 7.315 & 74.49 & 7.070 & 1.04 & 2.452 \\
\hline 500 & 7.115 & 7.333 & 86.77 & 7.127 & 1.11 & 2.826 \\
\hline 1,000 & 7.101 & 7.347 & 96.80 & 7.161 & 1.18 & 3.198 \\
\hline 2,000 & 7.106 & 7.354 & 101.26 & 7.197 & 1.25 & 3.567 \\
\hline 5,000 & 7.162 & 7.357 & & & 1.34 & 3.931 \\
\hline 10,000 & 7.147 & 7.365 & & & 1.45 & 4.288 \\
\hline & & & & & 1.60 & 4.634 \\
\hline & & & & & 1.83 & 4.964 \\
\hline & & & & & 2.21 & 5.268 \\
\hline & & & & & 2.79 & 5.535 \\
\hline & & & & & 3.64 & 5.756 \\
\hline & & & & & 4.75 & 5.933 \\
\hline & & & & & 6.08 & 6.072 \\
\hline & & & & & 7.57 & 6.181 \\
\hline & & & & & 9.17 & 6.270 \\
\hline & & & & & 10.86 & 6.344 \\
\hline & & & & & 22.00 & 6.606 \\
\hline & & & & & 33.77 & 6.744 \\
\hline
\end{tabular}


Table S17: Tabulated data for Figure S6: Heats of adsorption and loadings of $\mathrm{CO}_{2}$ in LTA-4A from GCMC simulations and Clausius-Clapeyron analysis.

\begin{tabular}{|c|c|c|c|c|c|c|}
\hline & \multicolumn{2}{|r|}{$440 \mathrm{~K}$} & \multicolumn{2}{|r|}{$450 \mathrm{~K}$} & \multicolumn{2}{|r|}{$460 \mathrm{~K}$} \\
\hline$\frac{\text { Pressure }}{(\mathrm{kPa})}$ & $\begin{array}{c}\mathrm{Q}_{\mathrm{st}} \\
(\mathrm{kJ} / \mathrm{mol}) \\
\end{array}$ & $\begin{array}{l}\text { Loading } \\
\text { (mol/kg) }\end{array}$ & $\begin{array}{c}\mathrm{Q}_{\mathrm{st}} \\
(\mathrm{kJ} / \mathrm{mol}) \\
\end{array}$ & $\begin{array}{l}\text { Loading } \\
\text { (mol } / \mathrm{kg}) \\
\end{array}$ & $\begin{array}{c}\mathrm{Q}_{\mathrm{st}} \\
(\mathrm{kJ} / \mathrm{mol})\end{array}$ & $\begin{array}{l}\text { Loading } \\
\text { (mol/kg) }\end{array}$ \\
\hline 0.001 & $29.4 \pm 25.8$ & $1.10 \mathrm{E}-05 \pm 1.14 \mathrm{E}-05$ & $44.9 \pm 34.9$ & $1.54 \mathrm{E}-05 \pm 1.50 \mathrm{E}-05$ & $38.7 \pm 54.8$ & $1.03 \mathrm{E}-05 \pm 8.55 \mathrm{E}-06$ \\
\hline 0.002 & $37.2 \pm 19.7$ & $2.35 \mathrm{E}-05 \pm 1.89 \mathrm{E}-05$ & $44.0 \pm 32.7$ & $2.71 \mathrm{E}-05 \pm 1.89 \mathrm{E}-05$ & $54.2 \pm 86.9$ & $1.25 \mathrm{E}-05 \pm 1.28 \mathrm{E}-05$ \\
\hline 0.005 & $47.7 \pm 17.6$ & $8.07 \mathrm{E}-05 \pm 2.45 \mathrm{E}-05$ & $41.7 \pm 18.9$ & $5.21 \mathrm{E}-05 \pm 2.76 \mathrm{E}-05$ & $36.4 \pm 34.1$ & $4.62 \mathrm{E}-05 \pm 1.95 \mathrm{E}-05$ \\
\hline 0.01 & $41.3 \pm 18.4$ & $1.36 \mathrm{E}-04 \pm 3.86 \mathrm{E}-05$ & $37.8 \pm 12.6$ & $1.07 \mathrm{E}-04 \pm 5.21 \mathrm{E}-05$ & $42.8 \pm 9.80$ & $1.10 \mathrm{E}-04 \pm 3.31 \mathrm{E}-05$ \\
\hline 0.02 & $44.0 \pm 6.39$ & $2.95 \mathrm{E}-04 \pm 8.34 \mathrm{E}-05$ & $43.7 \pm 4.87$ & $2.30 \mathrm{E}-04 \pm 2.57 \mathrm{E}-05$ & $46.3 \pm 9.57$ & $1.66 \mathrm{E}-04 \pm 3.49 \mathrm{E}-05$ \\
\hline 0.05 & $43.2 \pm 4.36$ & $0.001 \pm 5.31 \mathrm{E}-05$ & $43.7 \pm 7.14$ & $0.001 \pm 6.08 \mathrm{E}-05$ & $38.2 \pm 4.20$ & $4.56 \mathrm{E}-04 \pm 1.04 \mathrm{E}-04$ \\
\hline 0.1 & $42.1 \pm 4.65$ & $0.002 \pm 1.66 \mathrm{E}-04$ & $43.8 \pm 2.64$ & $0.001 \pm 8.30 \mathrm{E}-05$ & $42.6 \pm 5.59$ & $0.001 \pm 1.22 \mathrm{E}-04$ \\
\hline 0.2 & $42.9 \pm 4.26$ & $0.003 \pm 1.57 \mathrm{E}-04$ & $42.8 \pm 2.52$ & $0.002 \pm 2.16 \mathrm{E}-04$ & $41.6 \pm 5.62$ & $0.002 \pm 1.55 \mathrm{E}-04$ \\
\hline 0.5 & $43.2 \pm 2.77$ & $0.008 \pm 2.80 \mathrm{E}-04$ & $42.5 \pm 2.04$ & $0.006 \pm 3.24 \mathrm{E}-04$ & $42.0 \pm 2.87$ & $0.005 \pm 2.17 \mathrm{E}-04$ \\
\hline 1 & $43.4 \pm 1.02$ & $0.015 \pm 0.001$ & $42.3 \pm 1.57$ & $0.011 \pm 3.10 \mathrm{E}-04$ & $43.0 \pm 1.70$ & $0.009 \pm 3.07 \mathrm{E}-04$ \\
\hline 2 & $43.1 \pm 0.69$ & $0.031 \pm 0.001$ & $42.4 \pm 2.47$ & $0.023 \pm 6.13 \mathrm{E}-04$ & $42.8 \pm 1.82$ & $0.018 \pm 0.001$ \\
\hline 5 & $43.0 \pm 1.96$ & $0.076 \pm 0.002$ & $43.1 \pm 1.79$ & $0.057 \pm 2.72 \mathrm{E}-04$ & $42.1 \pm 1.32$ & $0.046 \pm 0.002$ \\
\hline 10 & $43.5 \pm 1.17$ & $0.150 \pm 0.004$ & $43.1 \pm 1.08$ & $0.113 \pm 0.003$ & $42.1 \pm 1.13$ & $0.090 \pm 0.003$ \\
\hline 20 & $43.2 \pm 0.56$ & $0.285 \pm 0.009$ & $42.8 \pm 1.07$ & $0.225 \pm 0.007$ & $42.7 \pm 1.03$ & $0.179 \pm 0.007$ \\
\hline 50 & $43.9 \pm 0.69$ & $0.660 \pm 0.012$ & $42.9 \pm 0.92$ & $0.520 \pm 0.006$ & $42.8 \pm 0.79$ & $0.426 \pm 0.012$ \\
\hline 100 & $43.9 \pm 0.26$ & $1.171 \pm 0.018$ & $42.9 \pm 1.02$ & $0.936 \pm 0.021$ & $42.7 \pm 1.41$ & $0.766 \pm 0.021$ \\
\hline 200 & $44.1 \pm 1.24$ & $1.846 \pm 0.027$ & $43.7 \pm 0.83$ & $1.547 \pm 0.020$ & $43.3 \pm 0.71$ & $1.330 \pm 0.031$ \\
\hline 500 & $43.9 \pm 1.24$ & $2.754 \pm 0.025$ & $43.7 \pm 0.47$ & $2.485 \pm 0.024$ & $44.0 \pm 0.84$ & $2.257 \pm 0.024$ \\
\hline 1,000 & $42.3 \pm 2.17$ & $3.289 \pm 0.013$ & $42.7 \pm 0.68$ & $3.086 \pm 0.017$ & $43.7 \pm 1.10$ & $2.912 \pm 0.024$ \\
\hline 2,000 & $40.4 \pm 1.39$ & $3.754 \pm 0.013$ & $40.8 \pm 1.06$ & $3.594 \pm 0.023$ & $41.8 \pm 1.24$ & $3.444 \pm 0.018$ \\
\hline 5,000 & $38.4 \pm 1.33$ & $4.282 \pm 0.019$ & $38.6 \pm 1.97$ & $4.129 \pm 0.029$ & $39.0 \pm 0.40$ & $4.022 \pm 0.015$ \\
\hline 10,000 & $37.5 \pm 1.45$ & $4.637 \pm 0.032$ & $37.4 \pm 1.44$ & $4.490 \pm 0.040$ & $38.0 \pm 1.59$ & $4.382 \pm 0.023$ \\
\hline
\end{tabular}

\begin{tabular}{c|c}
\hline \multicolumn{2}{|c|}{ Clausius-Clapeyron } \\
\hline $\begin{array}{c}\text { Loading } \\
(\mathrm{mol} / \mathrm{kg})\end{array}$ & $\begin{array}{c}\mathbf{Q}_{\text {st }} \\
(\mathrm{kJ} / \mathrm{mol})\end{array}$ \\
\hline 0.100 & 44.536 \\
0.324 & 44.349 \\
0.547 & 44.318 \\
0.771 & 44.122 \\
0.995 & 44.007 \\
1.218 & 43.543 \\
1.442 & 44.307 \\
1.666 & 44.457 \\
1.889 & 43.695 \\
2.113 & 42.557 \\
2.337 & 41.321 \\
2.561 & 41.393 \\
2.784 & 42.342 \\
3.008 & 40.925 \\
3.232 & 40.481
\end{tabular}




\begin{tabular}{l|l}
3.455 & 40.138 \\
3.679 & 40.432 \\
3.903 & 41.068 \\
4.126 & 38.644 \\
4.350 & 41.493 \\
\hline
\end{tabular}


Table S18: Tabulated data for Figure S7: Heats of adsorption and loadings of $\mathrm{CO}_{2}$ in LTA-4A from GCMC simulations and Clausius-Clapeyron analysis.

\begin{tabular}{|c|c|c|c|c|c|c|}
\hline & \multicolumn{2}{|r|}{$570 \mathrm{~K}$} & \multicolumn{2}{|r|}{$600 \mathrm{~K}$} & \multicolumn{2}{|r|}{$630 \mathrm{~K}$} \\
\hline$\frac{\text { Pressure }}{(\mathrm{kPa})}$ & $\begin{array}{c}\begin{array}{c}\mathrm{Q}_{\mathrm{st}} \\
(\mathrm{kJ} / \mathrm{mol})\end{array} \\
\end{array}$ & Loading (mol $/ \mathrm{kg}$ ) & $\underline{\mathrm{Q}_{\mathrm{st}}}(\mathrm{kJ} / \mathrm{mol})$ & Loading (mol $/ \mathrm{kg}$ ) & $\underline{\mathrm{Q}_{\mathrm{st}}(\mathrm{kJ} / \mathrm{mol})}$ & Loading (mol $/ \mathrm{kg}$ ) \\
\hline 0.001 & ---- & $7.33 \mathrm{E}-07 \pm 2.93 \mathrm{E}-06$ & ---- & ---- & ---- & ---- \\
\hline 0.002 & ---- & $2.93 \mathrm{E}-06 \pm 5.49 \mathrm{E}-06$ & ---- & 7.33E-07 $\pm 2.93 \mathrm{E}-06$ & ---- & $1.47 \mathrm{E}-06 \pm 5.87 \mathrm{E}-06$ \\
\hline 0.005 & ---- & 7.33E-06 $\pm 9.28 \mathrm{E}-06$ & --- & $4.40 \mathrm{E}-06 \pm 5.49 \mathrm{E}-06$ & ---- & $1.47 \mathrm{E}-06 \pm 3.59 \mathrm{E}-06$ \\
\hline 0.01 & $19.0 \pm 47.6$ & $1.61 \mathrm{E}-05 \pm 2.20 \mathrm{E}-05$ & $32.5 \pm 41.1$ & $1.10 \mathrm{E}-06 \pm 1.14 \mathrm{E}-06$ & ---- & $5.13 \mathrm{E}-06 \pm 7.48 \mathrm{E}-06$ \\
\hline 0.02 & $43.2 \pm 35.0$ & $3.37 \mathrm{E}-05 \pm 1.42 \mathrm{E}-05$ & $40.4 \pm 53.5$ & $2.05 \mathrm{E}-05 \pm 7.48 \mathrm{E}-06$ & ---- & $1.39 \mathrm{E}-05 \pm 1.88 \mathrm{E}-05$ \\
\hline 0.05 & $35.2 \pm 12.1$ & $5.28 \mathrm{E}-05 \pm 3.92 \mathrm{E}-05$ & $40.3 \pm 43.4$ & $3.89 \mathrm{E}-05 \pm 2.39 \mathrm{E}-05$ & $20.2 \pm 44.3$ & $3.15 \mathrm{E}-05 \pm 1.10 \mathrm{E}-05$ \\
\hline 0.1 & $37.2 \pm 5.25$ & $1.14 \mathrm{E}-04 \pm 1.82 \mathrm{E}-05$ & $16.4 \pm 18.2$ & $8.51 \mathrm{E}-05 \pm 1.57 \mathrm{E}-05$ & $30.4 \pm 34.1$ & $6.75 \mathrm{E}-05 \pm 1.77 \mathrm{E}-05$ \\
\hline 0.2 & $38.1 \pm 11.9$ & $2.70 \mathrm{E}-04 \pm 4.63 \mathrm{E}-05$ & $34.1 \pm 10.3$ & $1.72 \mathrm{E}-04 \pm 1.99 \mathrm{E}-05$ & $49.2 \pm 20.5$ & $1.15 \mathrm{E}-04 \pm 3.33 \mathrm{E}-05$ \\
\hline 0.5 & $42.4 \pm 4.28$ & $0.001 \pm 9.98 \mathrm{E}-05$ & $41.2 \pm 7.58$ & $4.58 \mathrm{E}-04 \pm 6.85 \mathrm{E}-05$ & $34.3 \pm 6.56$ & $2.87 \mathrm{E}-04 \pm 6.45 \mathrm{E}-05$ \\
\hline 1 & $38.6 \pm 3.93$ & $0.001 \pm 8.51 \mathrm{E}-05$ & $40.4 \pm 9.64$ & $8.63 \mathrm{E}-04 \pm 2.30 \mathrm{E}-05$ & $37.7 \pm 7.33$ & $0.001 \pm 7.56 \mathrm{E}-05$ \\
\hline 2 & $38.5 \pm 3.62$ & $0.002 \pm 7.00 \mathrm{E}-05$ & $37.5 \pm 7.26$ & $0.002 \pm 1.91 \mathrm{E}-04$ & $36.3 \pm 4.96$ & $0.001 \pm 9.49 \mathrm{E}-05$ \\
\hline 5 & $38.5 \pm 1.29$ & $0.006 \pm 3.34 \mathrm{E}-04$ & $35.7 \pm 5.24$ & $0.004 \pm 3.01 \mathrm{E}-04$ & $36.2 \pm 5.26$ & $0.003 \pm 1.10 \mathrm{E}-04$ \\
\hline 10 & $38.7 \pm 0.63$ & $0.012 \pm 4.52 \mathrm{E}-04$ & $37.6 \pm 3.33$ & $0.008 \pm 2.79 \mathrm{E}-04$ & $37.6 \pm 3.74$ & $0.006 \pm 3.85 \mathrm{E}-04$ \\
\hline 20 & $38.4 \pm 1.85$ & $0.024 \pm 0.001$ & $37.7 \pm 1.11$ & $0.017 \pm 4.58 \mathrm{E}-04$ & $36.7 \pm 2.44$ & $0.012 \pm 3.01 \mathrm{E}-04$ \\
\hline 50 & $38.3 \pm 1.30$ & $0.061 \pm 0.001$ & $37.6 \pm 0.70$ & $0.042 \pm 3.87 \mathrm{E}-04$ & $36.4 \pm 1.47$ & $0.029 \pm 0.001$ \\
\hline 100 & $38.8 \pm 0.48$ & $0.120 \pm 0.004$ & $37.9 \pm 1.63$ & $0.083 \pm 0.002$ & $37.3 \pm 1.37$ & $0.058 \pm 0.001$ \\
\hline 200 & $38.7 \pm 1.01$ & $0.232 \pm 0.002$ & $38.2 \pm 1.34$ & $0.162 \pm 0.003$ & $37.0 \pm 1.49$ & $0.115 \pm 0.002$ \\
\hline 500 & $39.3 \pm 0.73$ & $0.538 \pm 0.009$ & $38.2 \pm 0.87$ & $0.38 \pm 0.006$ & $36.9 \pm 0.59$ & $0.277 \pm 0.004$ \\
\hline 1,000 & $39.4 \pm 0.40$ & $0.946 \pm 0.009$ & $38.0 \pm 1.22$ & $0.694 \pm 0.014$ & $37.5 \pm 0.73$ & $0.516 \pm 0.011$ \\
\hline 2,000 & $40.1 \pm 0.55$ & $1.548 \pm 0.021$ & $39.3 \pm 0.79$ & $1.183 \pm 0.025$ & $37.9 \pm 0.85$ & $0.912 \pm 0.010$ \\
\hline 5,000 & $40.8 \pm 0.81$ & $2.449 \pm 0.016$ & $39.7 \pm 0.90$ & $2.041 \pm 0.021$ & $38.9 \pm 1.02$ & $1.681 \pm 0.006$ \\
\hline 10,000 & $40.7 \pm 0.74$ & $3.083 \pm 0.032$ & $40.2 \pm 0.71$ & $2.715 \pm 0.015$ & $39.3 \pm 1.36$ & $2.362 \pm 0.018$ \\
\hline
\end{tabular}

Clausius-Clapeyron

\begin{tabular}{c|c}
\hline $\begin{array}{c}\text { Loading } \\
(\mathrm{mol} / \mathrm{kg})\end{array}$ & $\begin{array}{c}\mathrm{Q}_{\mathrm{st}} \\
(\mathrm{kJ} / \mathrm{mol})\end{array}$ \\
\hline 0.100 & 36.502 \\
0.344 & 36.461 \\
0.589 & 36.905 \\
0.833 & 36.692 \\
1.078 & 37.470 \\
1.322 & 38.495 \\
1.567 & 38.691 \\
1.811 & 38.553 \\
2.056 & 38.986 \\
2.300 & 38.878 \\
\hline
\end{tabular}


Table S19: Tabulated data for Figure S8: Heats of adsorption and loadings of $\mathrm{CO}_{2}$ in ITQ-29 from GCMC simulations and Clausius-Clapeyron analysis.

\begin{tabular}{|c|c|c|c|c|c|c|}
\hline \multirow[b]{2}{*}{$\frac{\text { Pressure }}{(\mathrm{kPa})}$} & \multicolumn{2}{|c|}{$190 \mathrm{~K}$} & \multicolumn{2}{|c|}{$195 \mathrm{~K}$} & \multicolumn{2}{|c|}{$200 \mathrm{~K}$} \\
\hline & $\begin{array}{c}\underline{\mathrm{Q}}_{\mathrm{st}} \\
(\mathrm{kJ} / \mathrm{mol}) \\
\end{array}$ & $\begin{array}{l}\text { Loading } \\
\text { (mol } / \mathrm{kg}) \\
\end{array}$ & $\begin{array}{c}\mathrm{Q}_{\mathrm{st}} \\
(\mathrm{kJ} / \mathrm{mol}) \\
\end{array}$ & $\begin{array}{l}\text { Loading } \\
\text { (mol } / \mathrm{kg})\end{array}$ & $\begin{array}{c}\underline{\mathrm{Q}}_{\mathrm{st}} \\
(\mathrm{kJ} / \mathrm{mol}) \\
\end{array}$ & $\begin{array}{l}\text { Loading } \\
\text { (mol } / \mathrm{kg})\end{array}$ \\
\hline 0.001 & $27.8 \pm 0.21$ & $\begin{array}{c}0.002 \pm 1.29 \mathrm{E}- \\
04 \\
0.005 \pm 4.22 \mathrm{E}-\end{array}$ & $27.4 \pm 0.44$ & $0.002 \pm 1.66 \mathrm{E}-04$ & $27.5 \pm 0.28$ & $0.001 \pm 9.38 \mathrm{E}-05$ \\
\hline 0.002 & $27.7 \pm 0.25$ & 04 & $27.5 \pm 0.22$ & $0.003 \pm 4.14 \mathrm{E}-04$ & $27.2 \pm 0.39$ & $0.002 \pm 1.85 \mathrm{E}-04$ \\
\hline 0.005 & $27.8 \pm 0.21$ & $0.012 \pm 0.001$ & $27.4 \pm 0.17$ & $0.008 \pm 0.001$ & $27.0 \pm 0.29$ & $0.005 \pm 4.35 \mathrm{E}-04$ \\
\hline 0.01 & $27.7 \pm 0.36$ & $0.024 \pm 0.003$ & $27.6 \pm 0.19$ & $0.016 \pm 0.002$ & $27.3 \pm 0.21$ & $0.010 \pm 0.001$ \\
\hline 0.02 & $27.6 \pm 0.14$ & $0.048 \pm 0.003$ & $27.4 \pm 0.14$ & $0.031 \pm 0.003$ & $27.3 \pm 0.34$ & $0.021 \pm 0.002$ \\
\hline 0.05 & $27.4 \pm 0.40$ & $0.121 \pm 0.014$ & $27.4 \pm 0.34$ & $0.078 \pm 0.006$ & $27.1 \pm 0.21$ & $0.049 \pm 0.003$ \\
\hline 0.1 & $27.1 \pm 0.18$ & $0.221 \pm 0.024$ & $27.1 \pm 0.25$ & $0.153 \pm 0.009$ & $27.0 \pm 0.12$ & $0.101 \pm 0.009$ \\
\hline 0.2 & $26.7 \pm 0.38$ & $0.463 \pm 0.036$ & $26.7 \pm 0.45$ & $0.299 \pm 0.014$ & $26.6 \pm 0.20$ & $0.192 \pm 0.007$ \\
\hline 0.5 & $25.4 \pm 0.72$ & $1.223 \pm 0.125$ & $25.8 \pm 0.21$ & $0.776 \pm 0.065$ & $26.0 \pm 0.43$ & $0.497 \pm 0.031$ \\
\hline 1 & $28.3 \pm 0.35$ & $4.890 \pm 0.060$ & $25.8 \pm 0.27$ & $1.997 \pm 0.168$ & $25.1 \pm 0.10$ & $1.057 \pm 0.061$ \\
\hline 2 & $31.0 \pm 0.70$ & $6.008 \pm 0.051$ & $29.3 \pm 0.52$ & $5.411 \pm 0.066$ & $27.2 \pm 0.31$ & $3.962 \pm 0.089$ \\
\hline 5 & $31.5 \pm 0.65$ & $6.474 \pm 0.032$ & $31.2 \pm 1.03$ & $6.249 \pm 0.045$ & $30.8 \pm 0.64$ & $5.954 \pm 0.047$ \\
\hline 10 & $31.4 \pm 2.16$ & $6.718 \pm 0.038$ & $31.0 \pm 1.25$ & $6.555 \pm 0.030$ & $31.3 \pm 1.21$ & $6.360 \pm 0.055$ \\
\hline 20 & $31.4 \pm 1.62$ & $6.908 \pm 0.060$ & $31.6 \pm 1.06$ & $6.758 \pm 0.052$ & $31.1 \pm 0.51$ & $6.625 \pm 0.032$ \\
\hline 50 & $31.0 \pm 1.10$ & $7.107 \pm 0.093$ & $30.6 \pm 2.50$ & $6.989 \pm 0.072$ & $31.0 \pm 2.59$ & $6.887 \pm 0.074$ \\
\hline 100 & $30.7 \pm 2.43$ & $7.262 \pm 0.017$ & $30.8 \pm 1.39$ & $7.192 \pm 0.056$ & $31.1 \pm 1.80$ & $7.037 \pm 0.106$ \\
\hline 200 & $30.4 \pm 2.31$ & $7.283 \pm 0.041$ & $29.3 \pm 1.55$ & $7.287 \pm 0.098$ & $30.0 \pm 1.78$ & $7.231 \pm 0.135$ \\
\hline 500 & $29.7 \pm 3.97$ & $7.325 \pm 0.029$ & $30.2 \pm 2.41$ & $7.309 \pm 0.063$ & $30.1 \pm 4.24$ & $7.249 \pm 0.084$ \\
\hline 1,000 & $30.5 \pm 1.97$ & $7.357 \pm 0.093$ & $29.2 \pm 2.54$ & $7.268 \pm 0.125$ & $30.5 \pm 4.63$ & $7.253 \pm 0.115$ \\
\hline 2,000 & $30.0 \pm 3.07$ & $7.350 \pm 0.079$ & $29.4 \pm 3.16$ & $7.318 \pm 0.047$ & $30.7 \pm 1.62$ & $7.238 \pm 0.076$ \\
\hline 5,000 & $30.1 \pm 3.09$ & $7.371 \pm 0.096$ & $29.5 \pm 2.36$ & $7.319 \pm 0.091$ & $29.5 \pm 4.03$ & $7.206 \pm 0.159$ \\
\hline 10,000 & $29.5 \pm 5.39$ & $7.355 \pm 0.103$ & $30.2 \pm 2.71$ & $7.340 \pm 0.062$ & $29.1 \pm 1.90$ & $7.284 \pm 0.035$ \\
\hline
\end{tabular}

Clausius-Clapeyron

\begin{tabular}{c|c}
\hline $\begin{array}{c}\text { Loading } \\
(\mathrm{mol} / \mathrm{kg})\end{array}$ & $\begin{array}{c}\underline{\mathrm{Q}}_{\mathrm{st}} \\
(\mathrm{kJ} / \mathrm{mol})\end{array}$ \\
0.002 & 27.390 \\
0.004 & 27.008 \\
0.007 & 26.709 \\
0.012 & 26.437 \\
0.021 & 26.853 \\
0.035 & 27.423 \\
0.060 & 26.882 \\
0.102 & 27.116 \\
0.174 & 26.592 \\
0.296 & 26.718 \\
0.504 & 26.400 \\
0.860 & 25.196
\end{tabular}




\begin{tabular}{l|l}
0.774 & 25.503 \\
1.111 & 25.318 \\
1.447 & 25.323 \\
1.784 & 25.655 \\
2.121 & 25.778 \\
2.458 & 25.859 \\
2.795 & 26.074 \\
3.132 & 26.403 \\
3.468 & 26.829 \\
3.805 & 27.331 \\
4.142 & 27.878 \\
4.479 & 28.429 \\
4.816 & 28.955 \\
5.153 & 29.424 \\
5.489 & 29.501 \\
\hline
\end{tabular}


Table S20: Tabulated data for Figure S9: Heats of adsorption of $\mathrm{CH}_{4}$ in ITQ-29 at $195 \mathrm{~K}$ calculated by different methods (GCMC fluctuation formula, Clausius-Clapeyron equation).

\begin{tabular}{cc|cc}
\hline \multicolumn{2}{c|}{ GCMC Fluctuations } & \multicolumn{2}{c}{ Clausius-Clapeyron } \\
\hline $\begin{array}{c}\text { Loading } \\
(\mathrm{mol} / \mathrm{kg})\end{array}$ & $\begin{array}{c}\mathrm{Q}_{\text {st }} \\
(\mathrm{kJ} / \mathrm{mol})\end{array}$ & $\begin{array}{c}\text { Loading } \\
(\mathrm{mol} / \mathrm{kg})\end{array}$ & $\begin{array}{c}\mathrm{Q}_{\text {st }} \\
(\mathrm{kJ} / \mathrm{mol})\end{array}$ \\
\hline $5.37 \mathrm{E}-05$ & 13.4 & 0.022 & 13.1 \\
$9.88 \mathrm{E}-05$ & 13.5 & 0.370 & 13.5 \\
$2.70 \mathrm{E}-04$ & 13.6 & 0.719 & 14.1 \\
0.001 & 13.5 & 1.067 & 14.5 \\
0.001 & 13.6 & 1.415 & 14.7 \\
0.003 & 13.5 & 1.764 & 15.1 \\
0.005 & 13.5 & 2.112 & 15.4 \\
0.011 & 13.5 & 2.460 & 15.1 \\
0.027 & 13.6 & 2.808 & 16.4 \\
0.053 & 13.6 & 3.157 & 16.0 \\
0.108 & 13.7 & 3.505 & 16.6 \\
0.273 & 13.8 & 3.853 & 15.6 \\
0.558 & 14.1 & 4.202 & 16.0 \\
1.114 & 14.7 & 4.550 & 16.1 \\
2.310 & 15.7 & 4.898 & 16.1 \\
3.265 & 16.6 & 5.246 & 17.2 \\
3.970 & 17.1 & & \\
4.710 & 17.4 & & \\
5.174 & 17.4 & & \\
5.693 & 17.9 & & \\
6.260 & 18.2 & & \\
6.530 & 18.2 & & \\
\hline
\end{tabular}


Table S21: Tabulated data for Figure S10: $\mathrm{CO}_{2}$ positions in LTA-4A.

\begin{tabular}{|c|c|c|c|c|c|c|c|c|c|c|c|}
\hline \multicolumn{6}{|c|}{$300 \mathrm{~K}$} & \multicolumn{6}{|c|}{$450 \mathrm{~K}$} \\
\hline$\frac{\frac{\% \text { of } \mathrm{CO}_{2}}{\text { molecules }}}{\frac{\text { in dual }}{\underline{\text { cation }}}}$ & $\underline{\text { Counts }}$ & $\frac{\frac{\% \text { of } \mathrm{CO}_{2}}{\text { molecules }}}{\frac{\text { in single }}{\underline{\text { cation }}}}$ & $\underline{\text { Counts }}$ & $\begin{array}{l}\frac{\frac{\% \text { of } \mathrm{CO}_{2}}{2}}{\frac{\text { molecules }}{\text { with } \mathrm{O}-}} \\
\frac{\mathrm{Na}}{\text { distances }} \\
\underline{>3.5 \AA} \\
\end{array}$ & $\underline{\text { Counts }}$ & $\frac{\frac{\% \text { of } \mathrm{CO}_{2}}{\text { molecules }}}{\frac{\text { in dual }}{\underline{\text { cation }}}}$ & $\underline{\text { Counts }}$ & $\frac{\frac{\% \text { of } \mathrm{CO}_{2}}{\text { molecules }}}{\frac{\text { in single }}{\underline{\text { cation }}}}$ & $\underline{\text { Counts }}$ & $\begin{array}{l}\frac{\frac{\% \text { of } \mathrm{CO}_{2}}{2}}{\frac{\text { molecules }}{\text { with } \mathrm{O}-}} \\
\frac{\mathrm{Na}}{\mathrm{distances}} \\
\underline{3.5 \AA} \\
\end{array}$ & $\underline{\text { Counts }}$ \\
\hline 0 & 1 & 0 & 710 & 0 & 9023 & 0 & 6 & 0 & 153 & 0 & 6761 \\
\hline 5 & 0 & 5 & 191 & 5 & 268 & 5 & 0 & 5 & 64 & 5 & 1259 \\
\hline 10 & 0 & 10 & 1137 & 10 & 562 & 10 & 1 & 10 & 400 & 10 & 1388 \\
\hline 15 & 0 & 15 & 1594 & 15 & 125 & 15 & 6 & 15 & 769 & 15 & 446 \\
\hline 20 & 1 & 20 & 1781 & 20 & 18 & 20 & 14 & 20 & 1190 & 20 & 111 \\
\hline 25 & 5 & 25 & 1473 & 25 & 1 & 25 & 21 & 25 & 1409 & 25 & 26 \\
\hline 30 & 4 & 30 & 933 & 30 & 2 & 30 & 37 & 30 & 1254 & 30 & 8 \\
\hline 35 & 20 & 35 & 955 & 35 & 1 & 35 & 113 & 35 & 1508 & 35 & 0 \\
\hline 40 & 38 & 40 & 558 & 40 & 0 & 40 & 244 & 40 & 1268 & 40 & 1 \\
\hline 45 & 95 & 45 & 338 & 45 & 0 & 45 & 460 & 45 & 912 & 45 & 0 \\
\hline 50 & 217 & 50 & 189 & 50 & 0 & 50 & 613 & 50 & 464 & 50 & 0 \\
\hline 55 & 364 & 55 & 80 & 55 & 0 & 55 & 1175 & 55 & 323 & 55 & 0 \\
\hline 60 & 447 & 60 & 26 & 60 & 0 & 60 & 1152 & 60 & 137 & 60 & 0 \\
\hline 65 & 1191 & 65 & 29 & 65 & 0 & 65 & 1825 & 65 & 98 & 65 & 0 \\
\hline 70 & 994 & 70 & 2 & 70 & 0 & 70 & 1224 & 70 & 22 & 70 & 0 \\
\hline 75 & 1528 & 75 & 3 & 75 & 0 & 75 & 1293 & 75 & 16 & 75 & 0 \\
\hline 80 & 1761 & 80 & 0 & 80 & 0 & 80 & 879 & 80 & 7 & 80 & 0 \\
\hline 85 & 1189 & 85 & 0 & 85 & 0 & 85 & 440 & 85 & 2 & 85 & 0 \\
\hline 90 & 1360 & 90 & 0 & 90 & 0 & 90 & 354 & 90 & 0 & 90 & 0 \\
\hline 95 & 161 & 95 & 0 & 95 & 0 & 95 & 31 & 95 & 0 & 95 & 0 \\
\hline 100 & 624 & 100 & 1 & 100 & 0 & 100 & 112 & 100 & 4 & 100 & 0 \\
\hline
\end{tabular}

$600 \mathrm{~K}$

\begin{tabular}{|c|c|c|c|c|c|}
\hline$\frac{\frac{\% \text { of } \mathrm{CO}_{2}}{\text { molecules }}}{\frac{\text { in dual }}{\underline{\text { cation }}}}$ & $\underline{\text { Counts }}$ & $\frac{\frac{\% \text { of } \mathrm{CO}_{2}}{\text { molecules }}}{\frac{\text { in single }}{\underline{\text { cation }}}}$ & $\underline{\text { Counts }}$ & $\begin{array}{l}\frac{\frac{\% \text { of } \mathrm{CO}_{2}}{\text { molecules }}}{\frac{\text { with O- }}{\mathrm{Na}}} \\
\frac{\text { distances }}{>3.5 \AA} \\
\end{array}$ & Counts \\
\hline 0 & 48 & 0 & 213 & 0 & 5372 \\
\hline 5 & 0 & 5 & 4 & 5 & 348 \\
\hline 10 & 28 & 10 & 171 & 10 & 1990 \\
\hline 15 & 120 & 15 & 518 & 15 & 1286 \\
\hline 20 & 163 & 20 & 642 & 20 & 583 \\
\hline 25 & 227 & 25 & 759 & 25 & 193 \\
\hline 30 & 252 & 30 & 810 & 30 & 94 \\
\hline 35 & 601 & 35 & 1226 & 35 & 85 \\
\hline
\end{tabular}




\begin{tabular}{rrrrrr}
40 & 867 & 40 & 1267 & 40 & 25 \\
45 & 1108 & 45 & 1189 & 45 & 12 \\
50 & 1321 & 50 & 1091 & 50 & 10 \\
55 & 1288 & 55 & 798 & 55 & 1 \\
60 & 818 & 60 & 383 & 60 & 0 \\
65 & 1329 & 65 & 516 & 65 & 1 \\
70 & 527 & 70 & 129 & 70 & 0 \\
75 & 514 & 75 & 108 & 75 & 0 \\
80 & 340 & 80 & 77 & 80 & 0 \\
85 & 215 & 85 & 51 & 85 & 0 \\
90 & 133 & 90 & 21 & 90 & 0 \\
95 & 1 & 95 & 0 & 95 & 0 \\
100 & 100 & 100 & 27 & 100 & 0 \\
\hline & & & & &
\end{tabular}


Table S22: Tabulated data for Figure S11: Interaction energies of $\mathrm{CO}_{2}$ in different sites in LTA4A.

\begin{tabular}{|c|c|c|c|c|c|}
\hline \multicolumn{2}{|c|}{ No Cation } & \multicolumn{2}{|c|}{ Single Cation } & \multicolumn{2}{|c|}{ Dual Cation } \\
\hline$\frac{\text { Interaction Energy }}{\frac{/ \mathrm{CO}_{2} \text { molecule }}{(\mathrm{kJ} / \mathrm{mol})}}$ & Counts & $\frac{\frac{\text { Interaction Energy }}{/ \mathrm{CO}_{2} \text { molecule }}}{(\mathrm{kJ} / \mathrm{mol})}$ & Counts & $\frac{\text { Interaction Energy }}{\frac{/ \mathrm{CO}_{2} \text { molecule }}{(\mathrm{kJ} / \mathrm{mol})}}$ & Counts \\
\hline-63 & 0 & -63 & 1 & -63 & 0 \\
\hline-61 & 2 & -61 & 0 & -61 & 10 \\
\hline-59 & 1 & -59 & 3 & -59 & 27 \\
\hline-57 & 11 & -57 & 12 & -57 & 76 \\
\hline-55 & 9 & -55 & 31 & -55 & 214 \\
\hline-53 & 34 & -53 & 104 & -53 & 529 \\
\hline-51 & 57 & -51 & 258 & -51 & 821 \\
\hline-49 & 71 & -49 & 585 & -49 & 758 \\
\hline-47 & 135 & -47 & 838 & -47 & 448 \\
\hline-45 & 147 & -45 & 766 & -45 & 231 \\
\hline-43 & 172 & -43 & 439 & -43 & 101 \\
\hline-41 & 142 & -41 & 240 & -41 & 43 \\
\hline-39 & 125 & -39 & 103 & -39 & 19 \\
\hline-37 & 95 & -37 & 33 & -37 & 6 \\
\hline-35 & 89 & -35 & 18 & -35 & 2 \\
\hline-33 & 63 & -33 & 6 & -33 & 1 \\
\hline-31 & 45 & -31 & 1 & & \\
\hline-29 & 36 & -29 & 0 & & \\
\hline-27 & 25 & -27 & 2 & & \\
\hline-25 & 13 & -25 & 2 & & \\
\hline-23 & 14 & & & & \\
\hline-21 & 4 & & & & \\
\hline-19 & 2 & & & & \\
\hline-17 & 4 & & & & \\
\hline-15 & 1 & & & & \\
\hline-13 & 0 & & & & \\
\hline-11 & 1 & & & & \\
\hline
\end{tabular}


Table S23: Tabulated data for Figure S12: $\mathrm{CO}_{2}$ positions in Na-LTA Si/Al = 2 .

\begin{tabular}{|c|c|c|c|c|c|c|c|c|c|c|c|}
\hline \multicolumn{6}{|c|}{$303 \mathrm{~K}$} & \multicolumn{6}{|c|}{$453 \mathrm{~K}$} \\
\hline$\frac{\frac{\% \text { of } \mathrm{CO}_{2}}{\text { molecules }}}{\frac{\text { in dual }}{\underline{\text { cation }}}}$ & $\underline{\text { Counts }}$ & $\frac{\frac{\% \text { of } \mathrm{CO}_{2}}{\text { molecules }}}{\frac{\text { in single }}{\underline{\text { sation }}}}$ & $\underline{\text { Counts }}$ & $\begin{array}{l}\frac{\frac{\% \text { of } \mathrm{CO}_{2}}{\text { molecules }}}{\frac{\text { with } \mathrm{O}-}{\mathrm{Na}}} \\
\frac{\text { distances }}{\geq 3.5 \AA} \\
\end{array}$ & $\underline{\text { Counts }}$ & $\frac{\frac{\% \text { of } \mathrm{CO}_{2}}{\text { molecules }}}{\frac{\underline{\text { in dual }}}{\underline{\text { cation }}}}$ & $\underline{\text { Counts }}$ & $\frac{\frac{\% \text { of } \mathrm{CO}_{2}}{\text { molecules }}}{\frac{\text { in single }}{\underline{\text { cation }}}}$ & $\underline{\text { Counts }}$ & $\begin{array}{l}\frac{\frac{\% \text { of } \mathrm{CO}_{2}}{\text { molecules }}}{\frac{\text { with } \mathrm{O}-}{\mathrm{Na}}} \\
\frac{\text { distances }}{\geq 3.5 \AA} \\
\end{array}$ & $\underline{\text { Counts }}$ \\
\hline 0 & 92 & 0 & 4629 & 0 & 43 & 0 & 95 & 0 & 672 & 0 & 41 \\
\hline 5 & 0 & 5 & 231 & 5 & 0 & 5 & 10 & 5 & 160 & 5 & 3 \\
\hline 10 & 16 & 10 & 2032 & 10 & 9 & 10 & 137 & 10 & 1183 & 10 & 97 \\
\hline 15 & 255 & 15 & 1579 & 15 & 95 & 15 & 367 & 15 & 1455 & 15 & 260 \\
\hline 20 & 327 & 20 & 795 & 20 & 149 & 20 & 630 & 20 & 1730 & 20 & 553 \\
\hline 25 & 468 & 25 & 330 & 25 & 249 & 25 & 897 & 25 & 1481 & 25 & 904 \\
\hline 30 & 610 & 30 & 167 & 30 & 350 & 30 & 1011 & 30 & 1009 & 30 & 1030 \\
\hline 35 & 1257 & 35 & 126 & 35 & 851 & 35 & 1455 & 35 & 927 & 35 & 1536 \\
\hline 40 & 1570 & 40 & 59 & 40 & 1313 & 40 & 1644 & 40 & 659 & 40 & 1731 \\
\hline 45 & 1526 & 45 & 17 & 45 & 1601 & 45 & 1485 & 45 & 376 & 45 & 1557 \\
\hline 50 & 1543 & 50 & 29 & 50 & 1887 & 50 & 927 & 50 & 183 & 50 & 954 \\
\hline 55 & 1012 & 55 & 2 & 55 & 1263 & 55 & 676 & 55 & 78 & 55 & 645 \\
\hline 60 & 486 & 60 & 0 & 60 & 641 & 60 & 261 & 60 & 37 & 60 & 282 \\
\hline 65 & 523 & 65 & 4 & 65 & 913 & 65 & 274 & 65 & 27 & 65 & 252 \\
\hline 70 & 124 & 70 & 0 & 70 & 246 & 70 & 59 & 70 & 12 & 70 & 64 \\
\hline 75 & 98 & 75 & 0 & 75 & 173 & 75 & 39 & 75 & 4 & 75 & 43 \\
\hline 80 & 45 & 80 & 0 & 80 & 104 & 80 & 20 & 80 & 5 & 80 & 29 \\
\hline 85 & 25 & 85 & 0 & 85 & 69 & 85 & 7 & 85 & 1 & 85 & 10 \\
\hline 90 & 2 & 90 & 0 & 90 & 8 & 90 & 2 & 90 & 0 & 90 & 1 \\
\hline 95 & 0 & 95 & 0 & 95 & 0 & 95 & 1 & 95 & 0 & 95 & 0 \\
\hline 100 & 21 & 100 & 0 & 100 & 36 & 100 & 3 & 100 & 1 & 100 & 8 \\
\hline
\end{tabular}

$600 \mathrm{~K}$

\begin{tabular}{|c|c|c|c|c|c|}
\hline$\frac{\frac{\% \text { of } \mathrm{CO}_{2}}{\text { molecules }}}{\frac{\text { in dual }}{\underline{\text { cation }}}}$ & $\underline{\text { Counts }}$ & $\frac{\frac{\% \text { of } \mathrm{CO}_{2}}{\text { molecules }}}{\frac{\text { in single }}{\underline{\text { cation }}}}$ & $\underline{\text { Counts }}$ & $\begin{array}{l}\frac{\frac{\% \text { of } \mathrm{CO}_{2}}{\text { molecules }}}{\frac{\text { with O- }}{\mathrm{Na}}} \\
\frac{\text { distances }}{>3.5 \AA}\end{array}$ & Counts \\
\hline 0 & 497 & 0 & 355 & 0 & 297 \\
\hline 5 & 13 & 5 & 5 & 5 & 9 \\
\hline 10 & 490 & 10 & 287 & 10 & 321 \\
\hline 15 & 1012 & 15 & 652 & 15 & 755 \\
\hline 20 & 1214 & 20 & 923 & 20 & 1046 \\
\hline 25 & 1187 & 25 & 910 & 25 & 1074 \\
\hline 30 & 1042 & 30 & 917 & 30 & 1040 \\
\hline 35 & 1343 & 35 & 1315 & 35 & 1370 \\
\hline
\end{tabular}




\begin{tabular}{rrrrrr}
40 & 1093 & 40 & 1221 & 40 & 1265 \\
45 & 813 & 45 & 1053 & 45 & 988 \\
50 & 590 & 50 & 870 & 50 & 819 \\
55 & 298 & 55 & 590 & 55 & 412 \\
60 & 129 & 60 & 286 & 60 & 198 \\
65 & 177 & 65 & 341 & 65 & 248 \\
70 & 35 & 70 & 89 & 70 & 47 \\
75 & 30 & 75 & 74 & 75 & 50 \\
80 & 14 & 80 & 50 & 80 & 32 \\
85 & 13 & 85 & 32 & 85 & 16 \\
90 & 2 & 90 & 11 & 90 & 3 \\
95 & 0 & 95 & 0 & 95 & 0 \\
100 & 8 & 100 & 19 & 100 & 10 \\
\hline
\end{tabular}


Table S24: Tabulated data for Figure S13: $\mathrm{CO}_{2}$ positions in ITQ-29.

\begin{tabular}{|c|c|c|c|c|c|c|c|c|c|c|c|}
\hline \multicolumn{6}{|c|}{$300 \mathrm{~K}$} & \multicolumn{6}{|c|}{$450 \mathrm{~K}$} \\
\hline$\frac{\frac{\% \text { of } \mathrm{CO}_{2}}{\text { molecules }}}{\underline{\text { in } 6 \mathrm{MR}}}$ & $\underline{\text { Counts }}$ & $\frac{\frac{\% \text { of } \mathrm{CO}_{2}}{\text { molecules }}}{\underline{\text { in 8MR }}}$ & $\underline{\text { Counts }}$ & $\frac{\frac{\% \text { of } \mathrm{CO}_{2}}{\text { molecules }}}{\underline{\text { in 4MR }}}$ & $\underline{\text { Counts }}$ & $\frac{\frac{\% \text { of } \mathrm{CO}_{2}}{\text { molecules }}}{\underline{\text { in } 6 \mathrm{MR}}}$ & $\underline{\text { Counts }}$ & $\frac{\frac{\% \text { of } \mathrm{CO}_{2}}{\text { molecules }}}{\underline{\text { in 8MR }}}$ & $\underline{\text { Counts }}$ & $\frac{\frac{\% \text { of } \mathrm{CO}_{2}}{\text { molecules }}}{\underline{\text { in 4MR }}}$ & $\underline{\text { Counts }}$ \\
\hline 0 & 172 & 0 & 1753 & 0 & 8458 & 0 & 31 & 0 & 1793 & 0 & 7568 \\
\hline 5 & 6 & 5 & 397 & 5 & 409 & 5 & 7 & 5 & 1148 & 5 & 1097 \\
\hline 10 & 136 & 10 & 1751 & 10 & 775 & 10 & 109 & 10 & 2330 & 10 & 1011 \\
\hline 15 & 417 & 15 & 2084 & 15 & 272 & 15 & 245 & 15 & 2114 & 15 & 250 \\
\hline 20 & 635 & 20 & 1590 & 20 & 61 & 20 & 460 & 20 & 1412 & 20 & 52 \\
\hline 25 & 872 & 25 & 1051 & 25 & 14 & 25 & 827 & 25 & 715 & 25 & 15 \\
\hline 30 & 848 & 30 & 499 & 30 & 6 & 30 & 967 & 30 & 267 & 30 & 6 \\
\hline 35 & 1346 & 35 & 423 & 35 & 2 & 35 & 1375 & 35 & 128 & 35 & 0 \\
\hline 40 & 1405 & 40 & 227 & 40 & 0 & 40 & 1586 & 40 & 67 & 40 & 1 \\
\hline 45 & 1283 & 45 & 109 & 45 & 0 & 45 & 1627 & 45 & 18 & 45 & 0 \\
\hline 50 & 1015 & 50 & 82 & 50 & 2 & 50 & 937 & 50 & 5 & 50 & 0 \\
\hline 55 & 734 & 55 & 11 & 55 & 0 & 55 & 901 & 55 & 2 & 55 & 0 \\
\hline 60 & 375 & 60 & 10 & 60 & 0 & 60 & 383 & 60 & 0 & 60 & 0 \\
\hline 65 & 412 & 65 & 5 & 65 & 0 & 65 & 351 & 65 & 1 & 65 & 0 \\
\hline 70 & 130 & 70 & 0 & 70 & 0 & 70 & 105 & 70 & 0 & 70 & 0 \\
\hline 75 & 92 & 75 & 1 & 75 & 0 & 75 & 52 & 75 & 0 & 75 & 0 \\
\hline 80 & 63 & 80 & 1 & 80 & 0 & 80 & 17 & 80 & 0 & 80 & 0 \\
\hline 85 & 30 & 85 & 0 & 85 & 0 & 85 & 10 & 85 & 0 & 85 & 0 \\
\hline 90 & 8 & 90 & 0 & 90 & 0 & 90 & 10 & 90 & 0 & 90 & 0 \\
\hline 95 & 0 & 95 & 0 & 95 & 0 & 95 & 0 & 95 & 0 & 95 & 0 \\
\hline 100 & 21 & 100 & 6 & 100 & 1 & 100 & 0 & 100 & 0 & 100 & 0 \\
\hline \multicolumn{6}{|c|}{$600 \mathrm{~K}$} & & & & & & \\
\hline $\begin{array}{l}\frac{\% \text { of } \mathrm{CO}_{2}}{\text { molecules }} \\
\text { in } 6 \mathrm{MR}\end{array}$ & $\underline{\text { Counts }}$ & $\frac{\frac{\% \text { of } \mathrm{CO}_{2}}{\text { molecules }}}{\underline{\text { in } 8 \mathrm{MR}}}$ & $\underline{\text { Counts }}$ & $\frac{\frac{\% \text { of } \mathrm{CO}_{2}}{\text { molecules }}}{\underline{\text { in } 4 \mathrm{MR}}}$ & $\underline{\text { Counts }}$ & & & & & & \\
\hline 0 & 173 & 0 & 3378 & 0 & 8169 & & & & & & \\
\hline 5 & 2 & 5 & 263 & 5 & 172 & & & & & & \\
\hline 10 & 161 & 10 & 2188 & 10 & 1029 & & & & & & \\
\hline 15 & 427 & 15 & 1799 & 15 & 468 & & & & & & \\
\hline 20 & 650 & 20 & 1154 & 20 & 111 & & & & & & \\
\hline 25 & 754 & 25 & 531 & 25 & 27 & & & & & & \\
\hline 30 & 787 & 30 & 273 & 30 & 5 & & & & & & \\
\hline 35 & 1211 & 35 & 222 & 35 & 15 & & & & & & \\
\hline 40 & 1354 & 40 & 117 & 40 & 3 & & & & & & \\
\hline 45 & 1248 & 45 & 35 & 45 & 0 & & & & & & \\
\hline 50 & 1107 & 50 & 28 & 50 & 1 & & & & & & \\
\hline 55 & 790 & 55 & 4 & 55 & 0 & & & & & & \\
\hline 60 & 403 & 60 & 4 & 60 & 0 & & & & & & \\
\hline
\end{tabular}




\begin{tabular}{rrrrrr}
65 & 495 & 65 & 3 & 65 & 0 \\
70 & 157 & 70 & 0 & 70 & 0 \\
75 & 126 & 75 & 0 & 75 & 0 \\
80 & 84 & 80 & 0 & 80 & 0 \\
85 & 41 & 85 & 0 & 85 & 0 \\
90 & 9 & 90 & 0 & 90 & 0 \\
95 & 0 & 95 & 0 & 95 & 0 \\
100 & 21 & 100 & 1 & 100 & 0 \\
\hline
\end{tabular}


Table S25: Tabulated data for Figure S14: $\mathrm{CO}_{2}$ positions in Si-CHA.

\begin{tabular}{|c|c|c|c|c|c|c|c|c|c|c|c|}
\hline \multicolumn{6}{|c|}{$300 \mathrm{~K}$} & \multicolumn{6}{|c|}{$450 \mathrm{~K}$} \\
\hline$\frac{\frac{\% \text { of } \mathrm{CO}_{2}}{\text { molecules }}}{\underline{\text { in } 6 \mathrm{MR}}}$ & $\underline{\text { Counts }}$ & $\frac{\frac{\% \text { of } \mathrm{CO}_{2}}{\text { molecules }}}{\underline{\text { in 8MR }}}$ & $\underline{\text { Counts }}$ & $\frac{\frac{\% \text { of } \mathrm{CO}_{2}}{\text { molecules }}}{\underline{\text { in 4MR }}}$ & $\underline{\text { Counts }}$ & $\frac{\frac{\% \text { of } \mathrm{CO}_{2}}{\text { molecules }}}{\underline{\text { in } 6 \mathrm{MR}}}$ & $\underline{\text { Counts }}$ & $\frac{\frac{\% \text { of } \mathrm{CO}_{2}}{\text { molecules }}}{\underline{\text { in 8MR }}}$ & $\underline{\text { Counts }}$ & $\frac{\frac{\% \text { of } \mathrm{CO}_{2}}{\text { molecules }}}{\underline{\text { in } 4 \mathrm{MR}}}$ & $\underline{\text { Counts }}$ \\
\hline 0 & 0 & 0 & 0 & 0 & 367 & 0 & 2 & 0 & 0 & 0 & 328 \\
\hline 5 & 27 & 5 & 0 & 5 & 126 & 5 & 31 & 5 & 0 & 5 & 163 \\
\hline 10 & 90 & 10 & 0 & 10 & 8 & 10 & 95 & 10 & 0 & 10 & 10 \\
\hline 15 & 187 & 15 & 0 & 15 & 0 & 15 & 150 & 15 & 0 & 15 & 0 \\
\hline 20 & 139 & 20 & 0 & 20 & 0 & 20 & 130 & 20 & 0 & 20 & 0 \\
\hline 25 & 51 & 25 & 0 & 25 & 0 & 25 & 73 & 25 & 0 & 25 & 0 \\
\hline 30 & 7 & 30 & 0 & 30 & 0 & 30 & 18 & 30 & 0 & 30 & 0 \\
\hline 35 & 0 & 35 & 0 & 35 & 0 & 35 & 2 & 35 & 3 & 35 & 0 \\
\hline 40 & 0 & 40 & 0 & 40 & 0 & 40 & 0 & 40 & 12 & 40 & 0 \\
\hline 45 & 0 & 45 & 8 & 45 & 0 & 45 & 0 & 45 & 34 & 45 & 0 \\
\hline 50 & 0 & 50 & 31 & 50 & 0 & 50 & 0 & 50 & 72 & 50 & 0 \\
\hline 55 & 0 & 55 & 84 & 55 & 0 & 55 & 0 & 55 & 115 & 55 & 0 \\
\hline 60 & 0 & 60 & 119 & 60 & 0 & 60 & 0 & 60 & 105 & 60 & 0 \\
\hline 65 & 0 & 65 & 143 & 65 & 0 & 65 & 0 & 65 & 84 & 65 & 0 \\
\hline 70 & 0 & 70 & 73 & 70 & 0 & 70 & 0 & 70 & 55 & 70 & 0 \\
\hline 75 & 0 & 75 & 40 & 75 & 0 & 75 & 0 & 75 & 19 & 75 & 0 \\
\hline 80 & 0 & 80 & 3 & 80 & 0 & 80 & 0 & 80 & 2 & 80 & 0 \\
\hline 85 & 0 & 85 & 0 & 85 & 0 & 85 & 0 & 85 & 0 & 85 & 0 \\
\hline 90 & 0 & 90 & 0 & 90 & 0 & 90 & 0 & 90 & 0 & 90 & 0 \\
\hline 95 & 0 & 95 & 0 & 95 & 0 & 95 & 0 & 95 & 0 & 95 & 0 \\
\hline 100 & 0 & 100 & 0 & 100 & 0 & 100 & 0 & 100 & 0 & 100 & 0 \\
\hline
\end{tabular}

\begin{tabular}{|c|c|c|c|c|c|}
\hline & \multirow[b]{2}{*}{$\underline{\text { Counts }}$} \\
\hline$\frac{\frac{\% \text { of } \mathrm{CO}_{2}}{\text { molecules }}}{\underline{\text { in } 6 \mathrm{MR}}}$ & $\underline{\text { Counts }}$ & $\frac{\frac{\% \text { of } \mathrm{CO}_{2}}{\text { molecules }}}{\text { in 8MR }}$ & $\underline{\text { Counts }}$ & $\frac{\frac{\% \text { of } \mathrm{CO}_{2}}{\text { molecules }}}{\text { in } 4 \mathrm{MR}}$ & \\
\hline 0 & 1 & 0 & 0 & 0 & 317 \\
\hline 5 & 43 & 5 & 0 & 5 & 178 \\
\hline 10 & 107 & 10 & 0 & 10 & 6 \\
\hline 15 & 166 & 15 & 0 & 15 & 0 \\
\hline 20 & 108 & 20 & 0 & 20 & 0 \\
\hline 25 & 55 & 25 & 0 & 25 & 0 \\
\hline 30 & 17 & 30 & 1 & 30 & 0 \\
\hline 35 & 3 & 35 & 3 & 35 & 0 \\
\hline 40 & 1 & 40 & 13 & 40 & 0 \\
\hline 45 & 0 & 45 & 41 & 45 & 0 \\
\hline 50 & 0 & 50 & 80 & 50 & 0 \\
\hline 55 & 0 & 55 & 94 & 55 & 0 \\
\hline 60 & 0 & 60 & 109 & 60 & 0 \\
\hline
\end{tabular}




\begin{tabular}{rrrrrr}
65 & 0 & 65 & 86 & 65 & 0 \\
70 & 0 & 70 & 45 & 70 & 0 \\
75 & 0 & 75 & 18 & 75 & 0 \\
80 & 0 & 80 & 11 & 80 & 0 \\
85 & 0 & 85 & 0 & 85 & 0 \\
90 & 0 & 90 & 0 & 90 & 0 \\
95 & 0 & 95 & 0 & 95 & 0 \\
100 & 0 & 100 & 0 & 100 & 0 \\
\hline
\end{tabular}




\section{References:}

1. Fang, H.; Kamakoti, P.; Ravikovitch, P. I.; Aronson, M.; Paur, C.; Sholl, D. S. "First Principles Derived, Transferable Force Fields for $\mathrm{CO}_{2}$ Adsorption in Na-Exchanged Cationic Zeolites." Phys. Chem. Chem. Phys. 2013, 15 (31), 12882-12894.

2. Akten, E. D.; Siriwardane, R.; Sholl, D. S. "Monte Carlo Simulation of Single- and BinaryComponent Adsorption of $\mathrm{CO}_{2}, \mathrm{~N}_{2}$, and $\mathrm{H}_{2}$ in Zeolite Na-4A." Energy Fuels 2003, 17 (4), 977983.

3. Jaramillo, E.; Chandross, M. "Adsorption of Small Molecules in LTA Zeolites. 1. $\mathrm{NH}_{3}, \mathrm{CO}_{2}$, and $\mathrm{H}_{2} \mathrm{O}$ in Zeolite 4A." J. Phys. Chem. B 2004, 108 (52), 20155-20159.

4. Maurin, G.; Llewellyn, P. L.; Bell, R. G. "Adsorption Mechanism of Carbon Dioxide in Faujasites: Grand Canonical Monte Carlo Simulations and Microcalorimetry Measurements." J. Phys. Chem. B 2005, 109 (33), 16084-16091.

5. García-Pérez, E.; Parra, J. B.; Ania, C. O.; García-Sánchez, A.; van Baten, J. M.; Krishna, R.; Dubbeldam, D.; Calero, S. "A Computational Study of $\mathrm{CO}_{2}, \mathrm{~N}_{2}$, and $\mathrm{CH}_{4}$ Adsorption in Zeolites." Adsorption 2007, 13 (5-6), 469-476.

6. García-Sánchez, A.; Ania, C. O.; Parra, J. B.; Dubbeldam, D.; Vlugt, T. J. H.; Krishna, R.; Calero, S. "Transferable Force Field for Carbon Dioxide Adsorption in Zeolites." J. Phys. Chem. C 2009, 113 (20), 8814-8820.

7. Pham, T. D.; Xiong, R.; Sandler, S. I.; Lobo, R. F. "Experimental and Computational Studies on the Adsorption of $\mathrm{CO}_{2}$ and $\mathrm{N}_{2}$ on Pure Silica Zeolites." Microporous Mesoporous Mater. 2014, 185 (1 February 2014), 157-166.

8. Vujić, B.; Lyubartsev, A. P. "Transferable Force-Field for Modelling of $\mathrm{CO}_{2}, \mathrm{~N}_{2}, \mathrm{O}_{2}$ and $\mathrm{Ar}$ in All Silica and $\mathrm{Na}^{+}$Exchanged Zeolites." Modell. Simul. Mater. Sci. Eng. 2016, 24, 045002(1-26).

9. Cygan, R. T.; Liang, J.-J.; Kalinichev, A. G. "Molecular Models of Hydroxide, Oxyhydroxide, and Clay Phases and the Development of a General Force Field." J. Phys. Chem. B 2004, 108 (4), 1255-1266.

10. Bai, P.; Tsapatsis, M.; Siepmann, J. I. "TraPPE-zeo: Transferable Potentials for Phase Equilibria Force Field for All-Silica Zeolites." J. Phys. Chem. C 2013, 117 (46), 24375-24387. 11. Talu, O.; Myers, A. L. "Reference Potentials for Adsorption of Helium, Argon, Methane, and Krypton in High-Silica Zeolites." Colloids Surf., A 2001, 187-188 (31 August 2001), 83-93. 12. Harris, J. G.; Yung, K. H. "Carbon Dioxide's Liquid-Vapor Coexistence Curve and Critical Properties As Predicted by a Simple Molecular Model." J. Phys. Chem. 1995, 99 (31), 1202112024.

13. Potoff, J. J.; Siepmann, J. I. "Vapor-Liquid Equilibria of Mixtures Containing Alkanes, Carbon Dioxide, and Nitrogen." AIChE J. 2001, 47 (7), 1676-1682.

14. Fang, H.; Awati, R. V.; Boulfelfel, S. E.; Ravikovitch, P. I.; Sholl, D. S. "First-PrinciplesDerived Force Fields for CH4 Adsorption and Diffusion in Siliceous Zeolites." J. Phys. Chem. C 2018, 122 (24), 12880-12891.

15. Bludský, O.; Rubeš, M.; Soldán, P.; Nachtigall, P. "Invesitgation of the Benzene-Dimer Potential Energy Surface: DFT/CCSD(T) Correction Scheme." J. Chem. Phys. 2008, 128 (11), 114102.

16. Otero Areán, C.; Turnes Palomino, G.; Llop Carayol, M. R.; Pulido, A.; Rubeš, M.; Bludský, O.; Nachtigall, P. "Hydrogen adsorption on the zeolite Ca-A: DFT and FT-IR investigation." Chem. Phys. Lett. 2009, 477 (1-3), 139-143.

17. Martin, M. G.; Siepmann, J. I. "Transferable Potentials for Phase Equilibria. 1. United-Atom Description of $n$-Alkanes." J. Phys. Chem. B 1998, 102 (14), 2569-2577. 
18. Manz, T. A.; Sholl, D. S. "Improved Atoms-in-Molecule Charge Partitioning Functional for Simultaneously Reproducing the Electrostatic Potential and Chemical States in Periodic and Nonperiodic Materials." J. Chem. Theory Comput. 2012, 8 (8), 2844-2867.

19. Manz, T. A.; Sholl, D. S. "Methods for Computing Accurate Atomic Spin Moments for Collinear and Noncollinear Magnetism in Periodic and Nonperiodic Materials." J. Chem. Theory Comput. 2011, 7 (12), 4146.

20. Manz, T. A.; Sholl, D. S. "Chemically Meaningful Atomic Charges that Reproduce the Electrostatic Potential in Periodic and Nonperiodic Materials." J. Chem. Theory Comput. 2010, 6 (8), 2455-2468.

21. Harper, R. J.; Stifel, G. R.; Anderson, R. B. "Adsorption of gases on 4A synthetic zeolite." Can. J. Chem. 1969, 47 (24), 4661-4670.

22. Li, Y.; Yi, H.; Tang, X.; Li, F.; Yuan, Q. "Adsorption separation of $\mathrm{CO}_{2} / \mathrm{CH}_{4}$ gas mixture on the commercial zeolites at atmospheric pressure." Chem. Eng. J (Amsterdam, Neth.) 2013, 229, 50-56.

23. Ahmed, M. J.; Theydan, S. K. "Equilibrium isotherms studies for light hydrocarbons adsorption on 4A molecular sieve zeolite." J. Pet. Sci. Eng. 2013, 108, 316-320.

24. Eagan, J. D.; Anderson, R. B. "Kinetics and Equilibrium of Adsorption on 4A Zeolite." J. Colloid Interface Sci. 1975, 50 (3), 419-433.

25. Jensen, N. K.; Rufford, T. E.; Watson, G.; Zhang, D. K.; Chan, K. I.; May, E. F. "Screening Zeolites for Gas Separation Applications Involving Methane, Nitrogen, and Carbon Dioxide." J. Chem. Eng. Data 2012, 57 (1), 106-113.

26. Palomino, M.; Corma, A.; Rey, F.; Valencia, S. "New Insights on $\mathrm{CO}_{2}-$ Methane Separation Using LTA Zeolites with Different Si/Al Ratios and a First Comparison with MOFs." Langmuir 2010, 26 (3), 1910-1917.

27. Pluth, J. J.; Smith, J. V. "Accurate Redetermination of Crystal Structure of Dehydrated Zeolite A. Absence of Near Zero Coordination of Sodium. Refinement of Si,Al-Ordered Superstructure." J. Am. Chem. Soc. 1980, 102 (14), 4704-4708.

28. Vlugt, T. J. H.; García-Pérez, E.; Dubbeldam, D.; Ban, S.; Calero, S. "Computing the Heat of Adsorption using Molecular Simulations: The Effect of Strong Coulombic Interactions." J. Chem. Theory Comput. 2008, 4, 1107-1118.

29. Plimpton, S. "Fast Parallel Algorithms for Short-Range Molecular Dynamics." J. Comput. Phys. 1995, 117 (1), 1-19.

30. Awati, R. "Development of Accurate Computational Methods for Simulations of Adsorption and Diffusion in Zeolites." Ph.D. Thesis, Georgia Institute of Technology, May 2016. 31. Corma, A.; Rey, F.; Rius, J.; Sabater, M. J.; Valencia, S. "Supramolecular Self-Assembled Molecules as Organic Directing Agent for Synthesis of Zeolites." Nature 2004, 431, 287-290. 